\title{
Computational Design of Staged Pressurized Oxy-Coal Combustion
}

Gideon Ozioma Udochukwu

West Virginia University, gou0001@mix.wvu.edu

Follow this and additional works at: https://researchrepository.wvu.edu/etd

Part of the Heat Transfer, Combustion Commons

\section{Recommended Citation}

Udochukwu, Gideon Ozioma, "Computational Design of Staged Pressurized Oxy-Coal Combustion" (2019). Graduate Theses, Dissertations, and Problem Reports. 4028.

https://researchrepository.wvu.edu/etd/4028

This Thesis is protected by copyright and/or related rights. It has been brought to you by the The Research Repository @ WVU with permission from the rights-holder(s). You are free to use this Thesis in any way that is permitted by the copyright and related rights legislation that applies to your use. For other uses you must obtain permission from the rights-holder(s) directly, unless additional rights are indicated by a Creative Commons license in the record and/ or on the work itself. This Thesis has been accepted for inclusion in WVU Graduate Theses, Dissertations, and Problem Reports collection by an authorized administrator of The Research Repository @ WVU. For more information, please contact researchrepository@mail.wvu.edu. 


\title{
Computational Design of Staged Pressurized Oxy-Coal Combustion Gideon Udochukwu
}

\author{
Thesis submitted to the \\ Benjamin M. Statler College of Engineering and Mineral Resources \\ at West Virginia University
}

in partial fulfillment of the requirements for the degree of

\author{
Master of Sciences \\ in \\ Mechanical Engineering \\ V'yacheslav Akkerman, Ph.D., Chair \\ Patrick Browning, Ph.D. \\ Wade Huebsch, Ph.D. \\ Terence Musho, Ph.D.
}

Department of Mechanical and Aerospace Engineering

Morgantown, West Virginia

2019

Keywords: Staged pressurized oxy-coal combustion (SPOC); Reacting flows; Computational fluid dynamics (CFD), Reynolds-averaged Navier-Stokes (RANS) equations; Reynolds number (Re); Large-eddy simulation (LES), Vortex shedding 


\section{Abstract \\ Computational Design of Staged Pressurized Oxy-Coal Combustion \\ Gideon Udochukwu}

Staged pressurized oxy-coal combustion (SPOC) is nowadays a promising technology to be used for low-cost, low-emission, high-efficiency power generation. The objective of this thesis is to compliment the experiments ongoing at the Washington University, St. Louis (WUSTL) by means of numerical simulations, thereby providing better understanding of the fluid flow, turbulence, combustion characteristics, particle dynamics and heat transfer. Carbon dioxide $\left(\mathrm{CO}_{2}\right)$ is injected alongside the coal, for its carriage. A small amount of methane $\left(\mathrm{CH}_{4}\right)$ is also injected alongside the coal to maintain a steady flame. The simulations are performed for a 3D geometry with the following energy source distribution: out of $100 \mathrm{~kW}$ in a lab-scale reactor, $10 \mathrm{~kW}$ originates from $\mathrm{CH}_{4}$ and $90 \mathrm{~kW}$ comes from coal combustion. Steady and unsteady Reynolds-averaged NavierStokes (RANS) simulations are performed resulting in an asymmetric flame shape. Two causes of the flame asymmetry are hypothesized: (i) influence of coal injection and (ii) onset of a shearlayer instability due to the density variation of different gases and velocity differences of various streams in a shear layer, where mixing occurs. An impact of coal on flame symmetry is shown. In addition, a benchmark at which the further increase of coal would result in flame asymmetry has been found. The present simulations also demonstrated an occurrence of vortex shedding when the flow passes over a disk (bluff body) in a reactor, used to stabilize the flame, constituting a potential reason for periodic flame oscillations observed. An aerodynamic investigation of a flow past this bluff body is conducted for various Reynolds numbers (Re), with the bluff body height determining the characteristic length scale. Consequently, various regimes of flow are identified as Re increases. Particularly, an onset of the vortex shedding is noticed when $\operatorname{Re}>3000$. Spectral analysis is further conducted to identify the frequencies at which the flame oscillations occur, which is aimed at guiding an eventual re-design of this bluff body. It is shown that coal injection is the major contributor to the flame oscillations, as hypothesized. A non-uniform coal distribution in the burner region is found, which, in turn, creates a non-steady coal feed and ultimately results in the flame oscillations. It is subsequently demonstrated that an increase in the coal carrier $\left(\mathrm{CO}_{2}\right)$ concentration provides a better feeding of coal (continuous coal injection into the burner region), ultimately resulting in a more symmetric shape of the flame front. 


\section{ACKNOWLEDGEMENTS}

I would like to thank everyone who has contributed, directly or indirectly, to my activities at West Virginia University, in general, and to completing this thesis, in particular. Specifically, my heart felt gratitude goes to Dr. Akkerman, my research advisor, who has entrusted the responsibility to work on a research field as interesting as this one. Furthermore, my heart felt gratitude goes to Ozioma Ozor, who has remained a permanent source of encouragement during this journey.

Special thanks goes to my parents, Mr. and Mrs. Promise Udochukwu for all their efforts especially in upbringing. They have consistently strived to see that I grow up to become a professional who is morally upright and responsible when adjudged by any standard, culture and society I find myself.

I also want to thank Dr. Terence Musho and the WVU IT department for constant help in debugging issues associated with the High Performance Computing (HPC) systems, specifically, the Spruce Knob cluster. 
Dedicated to

Ozioma Ozor 


\section{Table of Content}

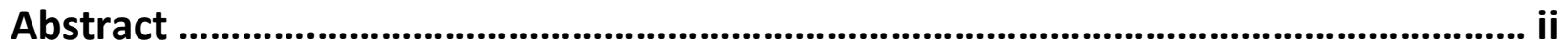

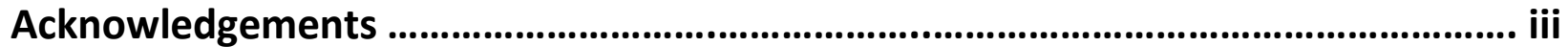

Table of Content

List of Figures ............................................................................................................................ vi

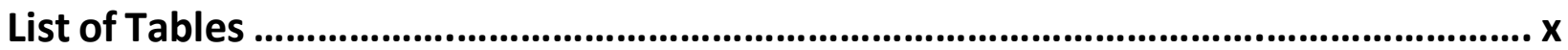

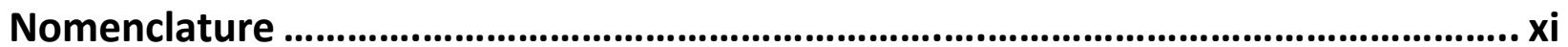

Chapter 1 - Introduction .................................................................................................... 1

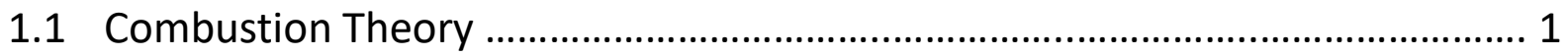

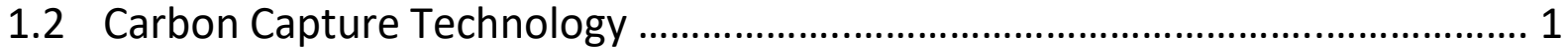

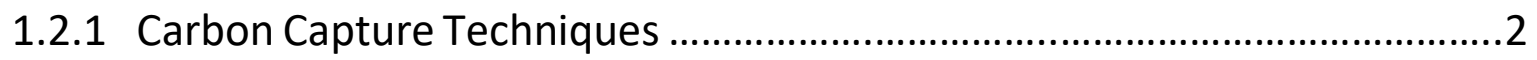

1.2.1.1 Pre-combustion capture .............................................................. 2

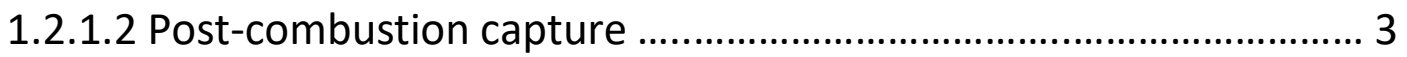

1.2.1.3 Oxy-fuel combustion capture ........................................................ 3

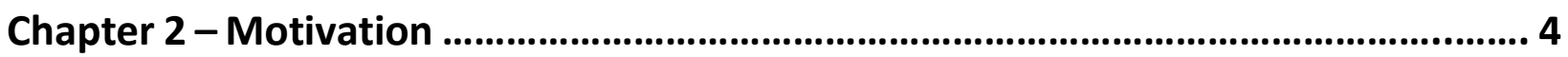

2.1 Process Design and Description .................................................................. 6

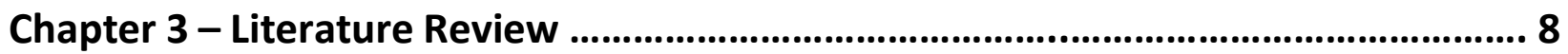

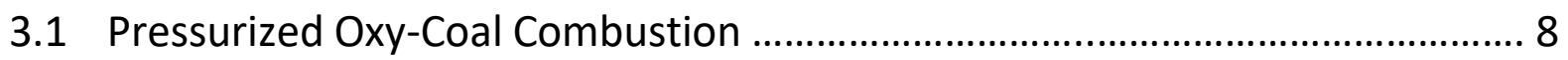

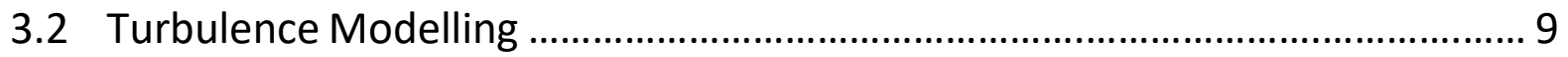

3.3 Computational Fluid Dynamics for Reactor Design ........................................... 11

3.4 CFD Modelling in Oxy-Coal Combustion ....................................................... 12

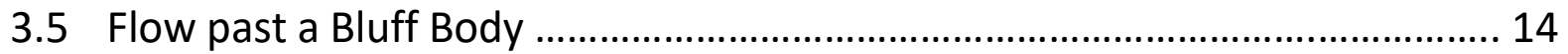

3.6 Radiation Heat Transfer ............................................................................ 15

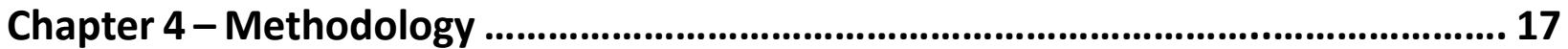

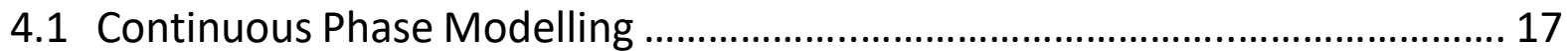

4.1.1 RANS Turbulence Modelling …............................................................ 18

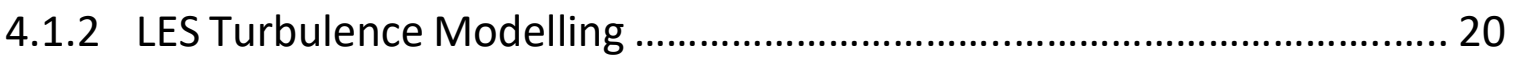

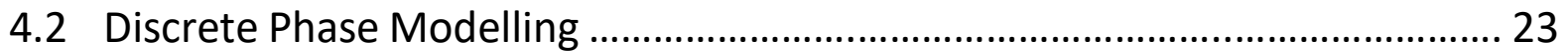

4.3 Domain Discretization and Boundary conditions ……….............................. 27

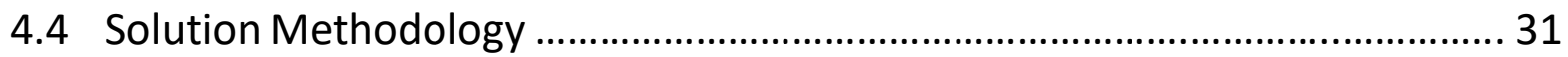

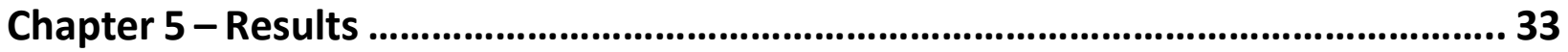

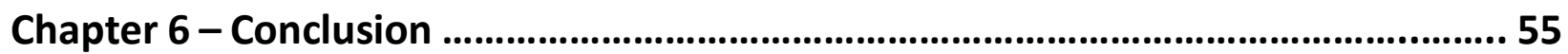

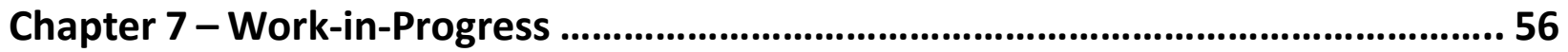

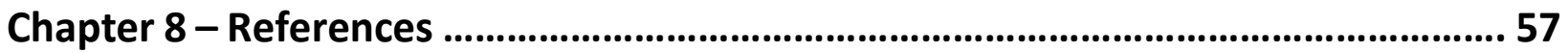

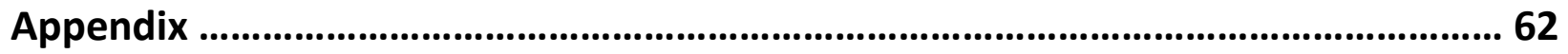




\section{List of Figures}

Figure 1.1: A diagram of an oxy-fuel combustion system [15] ...................................................

Figure 1.2: A schematic diagram of the SPOC process [19] ..................................................... 7

Figure 4.1: A structured mesh of the burner geometry with the respective sections shown ......28

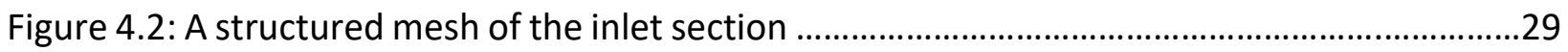

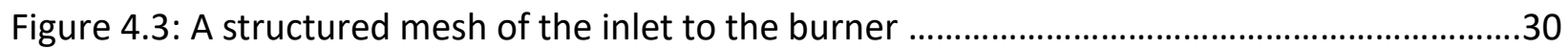

Figure 5.1: Steady RANS temperature snapshot for $90 \mathrm{~kW}$ coal and $10 \mathrm{~kW}$ methane .................33

Figure 5.2: Steady RANS temperature plot at different locations for $90 \mathrm{~kW}$ coal and $10 \mathrm{~kW}$

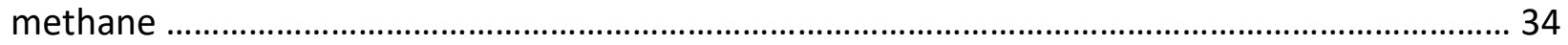

Figure 5.3: Steady RANS turbulent kinetic energy plot at different locations for $90 \mathrm{~kW}$ coal and 10

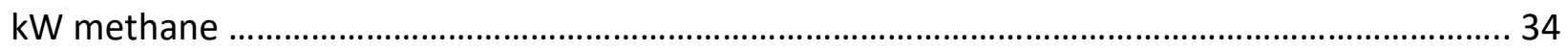

Figure 5.4: Color temperature snapshot for pure methane combustion of power $100 \mathrm{~kW}$...........35

Figure 5.5: (Radial) y-distributions of the turbulent kinetic energy taken at different axial locations, $x=0.2 \mathrm{~m}, 0.5 \mathrm{~m}, 0.8 \mathrm{~m}, 1.2 \mathrm{~m}, 1.4 \mathrm{~m}$, and $1.7 \mathrm{~m}$, for purely methane burning of power $100 \mathrm{~kW}$. 36

Figure 5.6: (Radial) y-distributions of the flow velocity field taken at different axial locations, $x=0.2 \mathrm{~m}, 0.5 \mathrm{~m}, 0.8 \mathrm{~m}, 1.2 \mathrm{~m}, 1.4 \mathrm{~m}$, and $1.7 \mathrm{~m}$, for purely methane burning of power 100 $\mathrm{kW}$

Figure 5.7: A temperature snapshot for the case of $10 \mathrm{~kW}$ generated from coal burning and 90 $\mathrm{kW}$ from that of $\mathrm{CH}_{4}$

Figure 5.8: (Radial) y-distributions of the temperature (T) taken at different axial locations, $x=$ $0.2 \mathrm{~m}, 0.5 \mathrm{~m}, 0.8 \mathrm{~m}, 1.2 \mathrm{~m}, 1.4 \mathrm{~m}$, and $1.7 \mathrm{~m}$, for the case of $10 \mathrm{~kW}$ generated from coal burning and $90 \mathrm{~kW}$ from that of $\mathrm{CH}_{4}$ 38 
Figure 5.9: (Radial) y-distributions of the k taken at different axial locations, $x=0.2 \mathrm{~m}, 0.5 \mathrm{~m}, 0.8$ $\mathrm{m}, 1.2 \mathrm{~m}, 1.4 \mathrm{~m}$, and $1.7 \mathrm{~m}$, for the case of $10 \mathrm{~kW}$ generated from coal burning and $90 \mathrm{~kW}$ from that of $\mathrm{CH}_{4}$ 38

Figure 5.10: A temperature snapshot for $20 \mathrm{~kW}$ generated from coal burning and $80 \mathrm{~kW}$ from that of $\mathrm{CH}_{4}$ 39

Figure 5.11: Temperature (radial) y-distributions taken at different axial locations, $x=0.2 \mathrm{~m}, 0.5$ $\mathrm{m}, 0.8 \mathrm{~m}, 1.2 \mathrm{~m}, 1.4 \mathrm{~m}$, and $1.7 \mathrm{~m}$, for the case of $20 \mathrm{~kW}$ generated from coal burning and $80 \mathrm{~kW}$ from that of $\mathrm{CH}_{4}$ 40

Figure 5.12: (Radial) y-distributions of the flow velocity taken at different axial locations, $x=0.2$ $\mathrm{m}, 0.5 \mathrm{~m}, 0.8 \mathrm{~m}, 1.2 \mathrm{~m}, 1.4 \mathrm{~m}$, and $1.7 \mathrm{~m}$, for $20 \mathrm{~kW}$ generated from coal burning and $80 \mathrm{~kW}$ from that of $\mathrm{CH}_{4}$ 40

Figure 5.13: Time evolution of the temperature taken at the locus: $x=0.02793 \mathrm{~m}, \mathrm{y}=-0.0082726$ m... 41

Figure 5.14: Time evolution of the temperature taken at the locus $\mathrm{x}=0.00629756 \mathrm{~m}, \mathrm{y}=$ 0.0214692

Figure 5.15: Instantaneous temperature snapshot taken at $\mathrm{t}=10 \mathrm{sec}$ in the unsteady RANS with a time step of $0.1 \mathrm{sec}$

Figure 5.16: Time evolution of the temperature taken at the locus: $x=0.02793 \mathrm{~m}, \mathrm{y}=-0.0082726$ $\mathrm{m}$

Figure 5.17: Time evolution of the temperature taken at the locus $\mathrm{x}=0.00629756 \mathrm{~m}, \mathrm{y}=$ $0.0214692 \mathrm{~m}$ 42

Figure 5.18: Instantaneous temperature snapshot taken at $t=4 \mathrm{sec}$ in the unsteady RANS with a time step of $0.01 \mathrm{sec}$

Figure 5.19: An instantaneous temperature contour for a mixed thermal boundary condition. 
Figure 5.20: Time evolution of the temperature measured at the monitor point $x=0.006297 \mathrm{~m}$, $y=0.0214692 m$ 44

Figure 5.21: Time evolution of the temperature measured at the monitor point: $x=0.02793 \mathrm{~m}, \mathrm{y}$ $=-0.008272 \mathrm{~m}$ 44

Figure 5.22: Instantaneous temperature contour for an adiabatic thermal boundary condition 45

Figure 5.23: Time evolution of the temperature measured at the monitor point: $x=0.02793 \mathrm{~m}, \mathrm{y}$ $=-0.0082726 \mathrm{~m}$ 45

Figure 5.24: Time evolution of the temperature measured at the monitor point: $x=0.00629756$ $m, y=0.0214692 m$ 45

Figure 5.25: Validation of my FFT solver: The result of the spectral analysis as obtained from an online source (left) and that obtained using my own Matlab code (right) .46

Figure 5.26: Time evolution of the flow velocity measured at the monitor point: $x=0.35204 \mathrm{~m}, \mathrm{y}$ $=\mathrm{z}=0$.

Figure 5.27: FFT of the velocity signal measured at the monitor point: $x=0.35204 \mathrm{~m}, \mathrm{y}=\mathrm{z}=$ 0. 47

Figure 5.28: Time evolution of the temperature measured at the monitor point: $x=0.35204 \mathrm{~m}, \mathrm{y}$ $=\mathrm{z}=0$.

Figure 5.29: FFT of the temperature signal measured at the monitor point: $x=0.35204 \mathrm{~m}, \mathrm{y}=\mathrm{z}=$ 0 47

Figure 5.30: Time evolution of the temperature measured at the monitor point: $x=0.02539348$ $\mathrm{m}, \mathrm{y}=-0.01483 \mathrm{~m}, \mathrm{z}=8.178438 \times 10^{-5} \mathrm{~m}$ 48

Figure 31: FFT of the temperature signal measured at the monitor point: $\mathrm{x}=0.02539348 \mathrm{~m}, \mathrm{y}=$ $0.01483 \mathrm{~m}, \mathrm{z}=8.178438 \times 10^{-5} \mathrm{~m}$ 48

Figure 5.32: The $x$-component velocity contour for velocity $=5 \mathrm{~m} / \mathrm{s}, \operatorname{Re}=1085.29$. 50 
Figure 5.33: The $x$-component velocity contour at velocity $=12 \mathrm{~m} / \mathrm{s}, \mathrm{Re}=2604.71 \ldots \ldots \ldots \ldots \ldots \ldots . . . . . . . .50$

Figure 5.34: The $x$ component velocity contour at velocity $=15 \mathrm{~m} / \mathrm{s}, \mathrm{Re}=3255.88 \ldots \ldots \ldots \ldots \ldots \ldots . . . . . .50$

Figure 5.35: Radial component velocity contour plot at velocity= $15 \mathrm{~m} / \mathrm{s}$, $\operatorname{Re}=3255.88 \ldots \ldots \ldots \ldots . . .51$

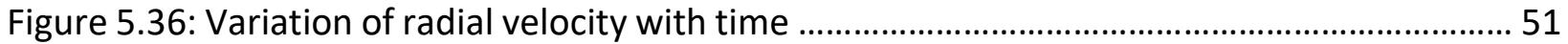

Figure 5.37: FFT analysis at the point near (downstream) the bluff body .................................... 52

Figure 5.38: Instantaneous temperature plot (Case 1 ) without an increased $\mathrm{CO}_{2}$ volume flow rate

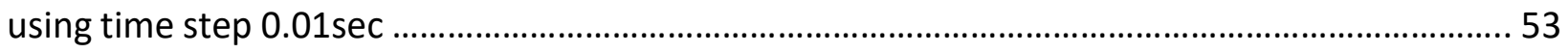

Figure 5.39: Instantaneous temperature plot (Case 2) for increased $\mathrm{CO}_{2}$ volume flow rate ........ 53

Figure 5.40: Instantaneous Dpm concentration contour (Case 1) without an increased $\mathrm{CO}_{2}$ volume

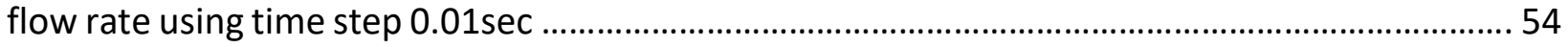

Figure 5.41: Instantaneous Dpm concentration (Case 2) for increased $\mathrm{CO}_{2}$ volume flow rate using

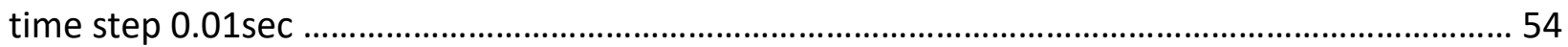




\section{List of Tables}

Table 1: Summary of models used for the simulation ......

Table 2: Summary of boundary conditions for the case of $90 \mathrm{~kW}$ coming from coal burning and

$10 \mathrm{~kW}$ coming from methane combustion

Table 3: Various parameters for the different inlets

Table 4: Inlet conditions for methane and $\mathrm{CO}_{2}$ at the fuel inlet 52 


\section{NOMENCLATURE}

A pre-exponential factor in the Arhenius rate expression

$E \quad$ energy

$k \quad$ turbulent kinetic energy

$E_{a} \quad$ activation energy in Arhenius rate expression

$\omega \quad$ specific dissipation rate in the $k-\omega$ RANS model

$Y_{d} \quad$ droplet mass fraction

$k_{f} \quad$ forward kinetic rate

$k_{b} \quad$ backward kinetic rate

$m_{p} \quad$ mass flow rate of particles

$n \quad$ spread parameter in the Rosin-Rammler particle diameter distribution

$C_{D} \quad$ drag coefficient

$R \quad$ net rate of species production used in species transport equation

j mass diffusivity

$S_{c t} \quad$ turbulent Schmidt number

$D_{t} \quad$ turbulent diffusivity

$\tilde{u} \quad$ Favre averaged velocity fluctuation

$u^{\prime} \quad$ Reynolds averaged velocity fluctuation

$g$ gravity

$\widetilde{G_{k}} \quad$ generation of kinetic energy

$\widetilde{G_{\omega}} \quad$ generation of specific dissipation

$D_{\omega} \quad$ cross diffusion term

$Y_{k} \quad$ dissipation of kinetic energy

$Y_{\omega} \quad$ dissipation of specific dissipation

$S \quad$ strain rate tensor

$V \quad$ cell volume 


\title{
Greek characters
}

\author{
$\mu_{t} \quad$ turbulent viscosity \\ $\rho$ density \\ $\sigma_{k} \quad$ turbulent Prandtl number for kinetic energy equation \\ $\sigma_{\omega} \quad$ turbulent Prandtl number for specific dissipation equation \\ $\alpha^{*} \quad$ turbulent viscosity damping coefficient \\ $\tau_{i j} \quad$ stress tensor
}




\section{Introduction}

\subsection{Combustion Theory}

Combustion is an exothermic process, in which the fuel and the oxidizer reacts chemically to produce heat, light and burnt products. This is also a self-propagating process, i.e. once ignited, the combustion would go on as long as there is a continuous feed of fuel mixed with sufficient oxidizer. Fossil fuels such as coal, natural gas, petroleum, etc. are formed by the anaerobic decomposition of dead organisms containing energy originated from the ancient photosynthesis. The fossil fuels constituted about $85 \%$ of the world's primary energy sources in 2017 [1].

There are two major regimes of burning, namely: premixed and non-premixed combustion. Premixed combustion is characterized by initial mixing of the fuel and oxidizer before the reaction starts. In contrast, non-premixed combustion occurs at the point of mixing such that the oxidizer and the fuel are originally separated and mix only at the point of ignition.

\subsection{Carbon Capture Technology}

The greenhouse effect has over the decades remained a concern to the global populace, due to its unfavorable effect on the atmosphere. This is understood to have been caused by greenhouse gases and has become a major concern to environmental scientists, combustion researchers as well as the governmental bodies in the 2000s and even earlier. The greenhouse gases, when released into the atmosphere, trap heat emitted from the surface of the Earth. The solar light passes through the greenhouse gases in the atmosphere, hence heating up the earth surface. In response to this, the Earth reflects such a short (infrared) wave, which is trapped in the atmosphere by greenhouse, thus, heating up the Earth [2]. Numerous journal articles and reviews 
have pointed at carbon dioxide $\left(\mathrm{CO}_{2}\right)$ to be the major source of the greenhouse effect and an increasing amount of $\mathrm{CO}_{2}$ emission is a leading cause of artic warming as well as elevated temperature of the Earth surface [3-4]. The US Environmental Protection Agency (EPA) has shown that the greenhouse gases arising from the human activities primarily originate from combustion of the fossil fuels, utilized in power generation, transportation and sectors which require large amounts of energy [5]. Therefore, intense research targeted towards the greenhouse emissions control is an active area nowadays.

Various techniques for $\mathrm{CO}_{2}$ capture and sequestration have been proposed and summarized into three prominent methods [6-7]. While two of these techniques will be briefly discussed below, in this thesis, we shall particularly focus on the third technique (oxy-fuel combustion).

\subsubsection{Carbon Capture Techniques}

1.2.1.1 Pre-combustion capture - This technique simply involves the removal of $\mathrm{CO}_{2}$ from the fossil fuels, e.g. coal, before the completion of the combustion process. A gasification process is used to convert the solid fuels into the gaseous ones $\left(\mathrm{H}_{2}, \mathrm{CO}\right)$ by the fuel reacting with either steam, oxygen or air at high temperature and pressure. This gasification process leads to a formation of the synthetic gas, made of hydrogen $\left(\mathrm{H}_{2}\right)$ and carbon monoxide (CO), which is widely used for power generation, e.g. in turbines. This synthetic gas further goes through a water-gas shift reaction, which converts $\mathrm{CO}$ and liquid $\mathrm{H}_{2} \mathrm{O}$ into gaseous $\mathrm{H}_{2}$ and $\mathrm{CO}_{2}$. Several absorbents are being considered to promote the separation of the $\mathrm{CO}_{2}$ and $\mathrm{H}_{2}$ gases [8]. An example of such absorbents for pre-combustion capture are the Layered Double Hydroxide 
(LDH) derived compounds [9]. This is recognized mainly for the sorption-enhanced water-gas shift and the sorption-enhanced steam-reforming processes, where the sorption is defined as a process where two substances are added together physically or chemically.

1.2.1.2 Post combustion capture - This technique involves a separation of $\mathrm{CO}_{2}$ from the flue gas (combustion products). Typically, a fossil fuel is burnt in the presence of air, to form a flue gas. Nitrogen $\left(\mathrm{N}_{2}\right)$ and $\mathrm{CO}_{2}$ are the major components of this flue gas, which form the major challenge associated with this process. Specifically, separation of $\mathrm{CO}_{2}$ from the large streams of $\mathrm{N}_{2}$, from the air, remains the main challenge of this process.

1.2.1.3 Oxy-fuel combustion capture - Oxy-fuel combustion is a burning process with pure oxygen $\left(\mathrm{O}_{2}\right)$ being the oxidizer instead of air. This eventually leads to very hightemperature combustion. In order to control such an elevated temperature, $\mathrm{CO}_{2}$ is recycled back into the combustion region. It is noted that in air-oxidized combustion, $\mathrm{N}_{2}$ acts as an inert gas, thereby reducing the combustion temperature, while in oxyfuel combustion, $\mathrm{CO}_{2}$ is recycled for controlling the combustion temperature as well as the heat transfer due to radiation. The flue gas generated from such a process has a very high concentrations of $\mathrm{CO}_{2}$ and water vapor readily available for capture, which constitutes the major reason for this technology.

In this thesis, a proposed oxy-fuel combustion capture technique named the staged pressurized oxy-coal combustion (SPOC) is studied. A detailed explanation of this process is presented in the next chapter. 


\section{Motivation}

The growing concerns over greenhouse gas $\left(\mathrm{CO}_{2}\right)$ and $\mathrm{NO}_{x}$ emissions from burning coal are major reasons driving extensive research on power generation cycles, which would enable efficient $\mathrm{CO}_{2}$ capture and sequestration as well as enhanced reduction of the $\mathrm{NO}_{x}$ formation.

Although coal-based power plants are among the largest sources of global $\mathrm{CO}_{2}$ emissions, the large reserves of coal deposits as well as low prices still make the projection of coal usage a viable competitor amongst the major energy sources in the foreseeable future [10-12].

For oxy-coal combustion to be a viable competitor for $\mathrm{CO}_{2}$ capture, the energy requirement associated with this process has to diminish significantly. Comparison of various carbon capture techniques proves that oxy-fuel combustion is a favorable method in terms of cost and ability of deployment, however, the combustion temperature associated with this process is unacceptably high [13-14].

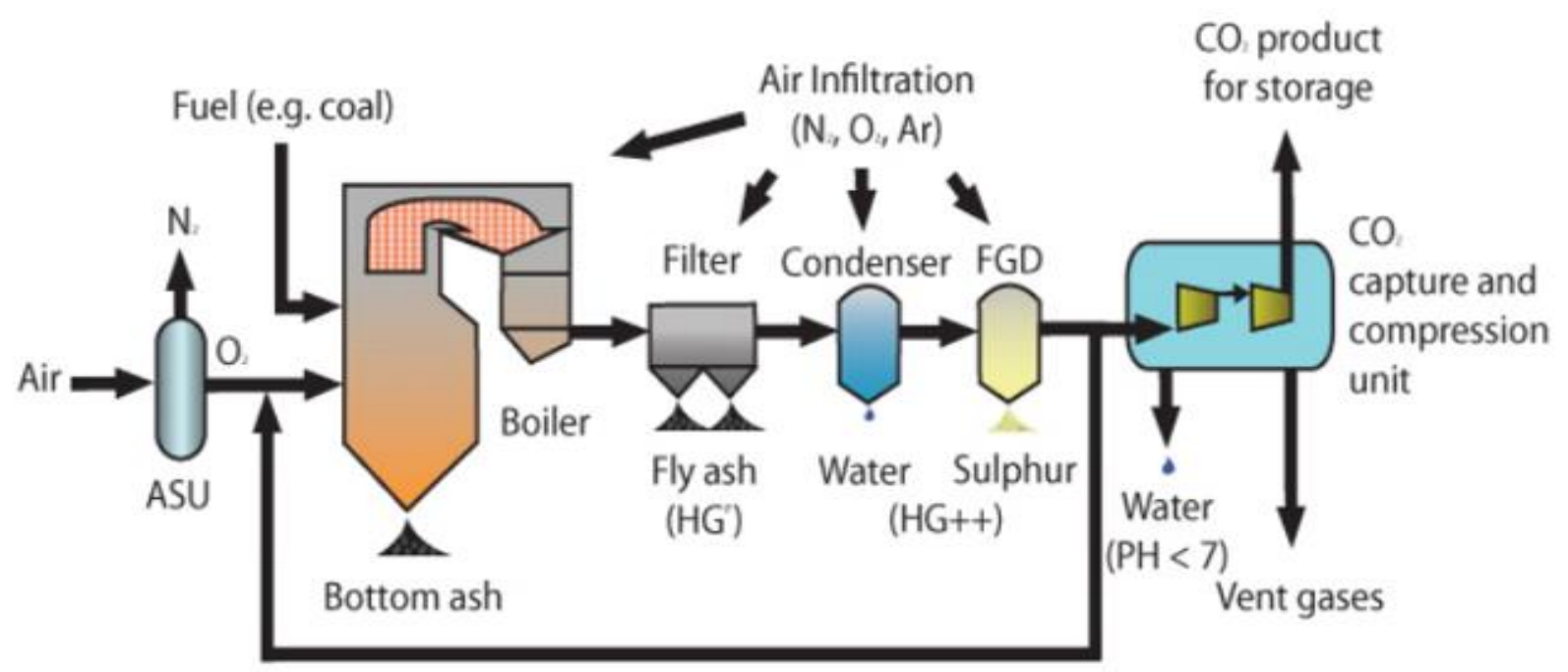

Recirculated flue gas

Figure 1.1: A diagram of an oxy-fuel combustion system [15]. 
First-generation oxy-combustion technology entails burning of coal in the presence of pure $\mathrm{O}_{2}$, while a large volume of $\mathrm{CO}_{2}$ from the combustion products (the flue gas) is recycled, mainly, to control an excessively high combustion temperature. A schematic of such an oxy-combustion process is shown in Fig. 1.1.

In addition, $\mathrm{CO}_{2}$ generated from this process is required at high pressure either for sequestration or for an enhanced oil recovery (EOR). Hence, this unique high-pressure requirement for carbon sequestration and EOR is harnessed towards a potential efficiency increase in this process [16]. In this thesis, the combustion process is maintained at an elevated pressure for the following reason. First, at a high pressure, the temperature, at which the flue gas moisture condenses, is increased, making it possible to recover some latent energy at such a high temperature. Such a recovered latent heat of condensation can potentially be used for enhancing the efficiency of this process. Second, at a high pressure, the volume of the gases is reduced which eventually decreases the equipment size and the associated costs. Third, there is no air in the process, which eliminates $\mathrm{NO}$ x formation, which would eventually reduce or eliminate the cost associated with the flue gas purification i.e. separation of $\mathrm{CO}_{2}$ from $\mathrm{NO}$. Thus, pressurized oxy-coal combustion is a promising technology to produce a clean $\mathrm{CO}_{2}$ stream, readily available for capture and sequestration as well as increased efficiency. In this respect, a significant technological advancement towards reducing the energy requirements for oxy-coal combustion, resulting from the energy penalties of the $\mathrm{CO}_{2}$ capture, has been achieved. Specifically, Jongsup et al. [17] analyzed oxy-fuel combustion at two different pressures, 1.1 bar and 10 bar, and found nearly 3 percent point increase in the net efficiency when operating at 10 bar. Here, percent point is the unit for the arithmetic difference of two percentages. 
There are two major pressurized oxy-combustion technologies explored in the modern literature as viable concepts for increasing the efficiency of oxy-combustion through elevated pressures: staged pressurized oxy-combustion (SPOC) and the flameless combustion technology $\left(\right.$ ISOTHERM ${ }^{\circledR}$ ) [18]. Between these two technologies, SPOC has a lower energy penalty i.e. the energy associated with this process is as low as 3.8 percent point as compared to the flameless technology. This is primarily due to a lesser volume of the flue gas recycled for the moderation of the flame temperature, since the ISOTHERM ${ }^{\circledR}$ requires a larger volume of flue gas recycling. This thesis focuses on the SPOC, which is expected to achieve better efficiency as well as reduced cost by employing an elevated pressure and reduced flue gas recycling. The SPOC experimental setup is currently being developed at the Washington University, St. Louis (WUSTL). The aim of this research is therefore to provide a physics-based approach by means of computational fluid dynamics (CFD) to model the SPOC processes, currently ongoing at the WUSTL, which would eventually guide future scale-up of the experimental facility.

\subsection{Process Design and Description}

Figure 1.2 presents a schematic of the SPOC process comprising of four different stages. The WUSTL team found out that these four stages were sufficient to maintain the adiabatic flame temperature (the temperature that combustion products can theoretically reach when there are no energy loses) similar to that of air-fired combustion when considering the same fuel of the same stoichiometry. The present study focuses on the numerical investigation of the first stage of the SPOC process, when coal is fed into the burner, alongside pressurized oxygen and recycled flue gas. For this thesis, however, there is a little modification to the process described above, 
namely, a little amount of methane $\left(\mathrm{CH}_{4}\right)$ is injected into this burner to assist the combustion process and pressurized $\mathrm{CO}_{2}$ is added to keep the burner at a high pressure.

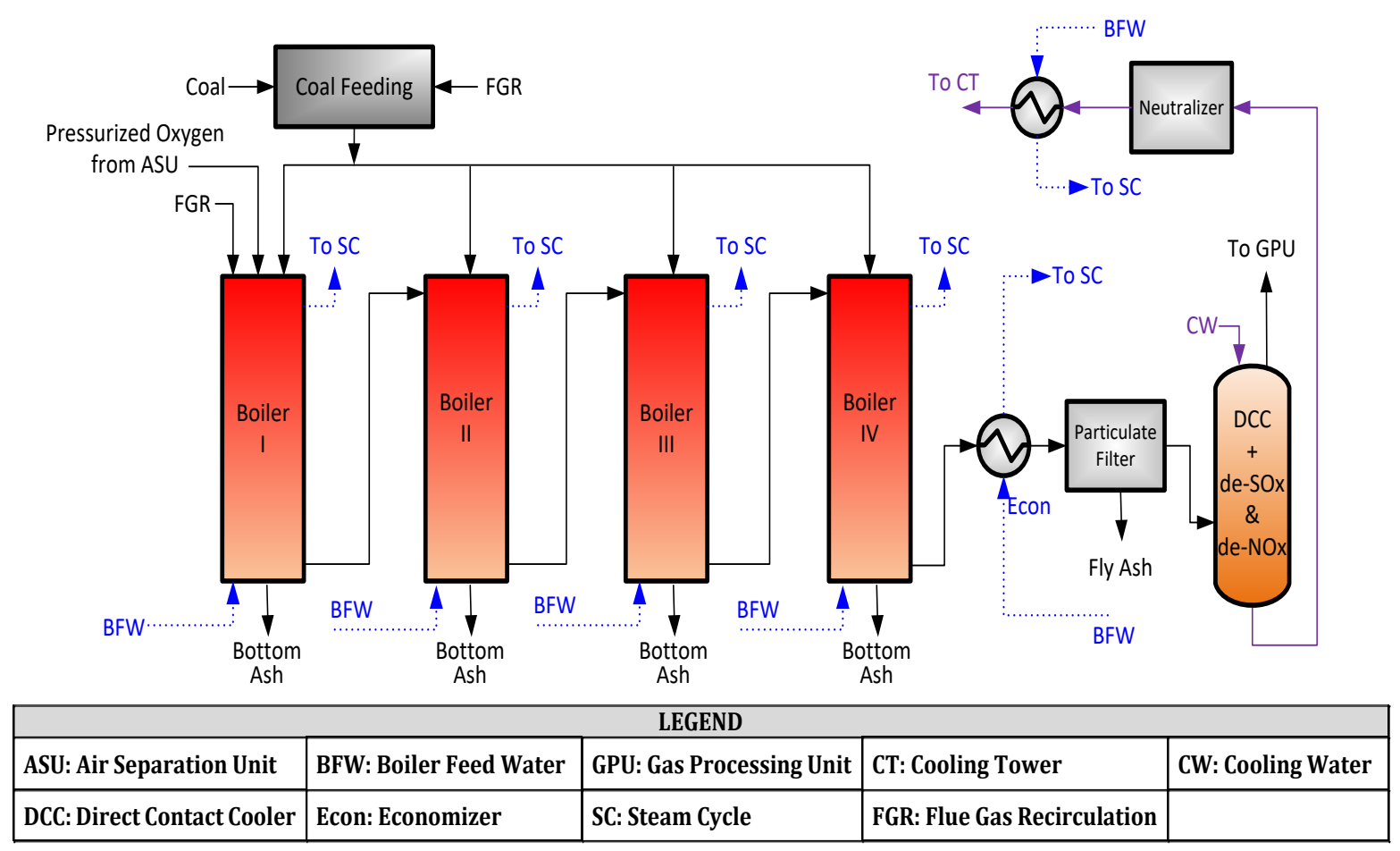

Figure 1.2: A schematic diagram of the SPOC process [19].

In order to control a high temperature of the products of oxy-coal combustion, the fuel delivery is staged, a small amount of $\mathrm{CO}_{2}$ is recycled and then extra $\mathrm{O}_{2}$ is injected. An excess of $\mathrm{O}_{2}$ considered in this research is accounted by the stoichiometric ratio $\lambda>1$ (defined as the ratio of the mass of oxygen supplied to the mass of oxygen required for stoichiometry). For this research, the fuel (coal and $\mathrm{CH}_{4}$ methane) is burnt in the presence of $20 \%$ excess oxygen i.e. $\lambda=$ 1.2.

The cooled combustion products from stage 1, are carried on to stage 2 , where more fuel and oxygen is injected. This process continues throughout the stages $2-4$ until the entire $\mathrm{O}_{2}$ is consumed. 


\section{Literature Review}

\subsection{Pressurized Oxy-Coal Combustion}

Pressurized oxy-fuel combustion techniques have been utilized in various combustion systems for various reasons. In particular, Janusz et al. [20] conducted an experimental study of the effect of pressurized fluidized bed combustor on the emissions of $\mathrm{NO}_{\mathrm{x}}$ and other compounds, with the finding that the $\mathrm{NO}_{\mathrm{x}}$ emissions diminish at an elevated pressure. Although in this thesis we are not very concerned about the $\mathrm{NO}_{\mathrm{x}}$ formation (since the oxidizer used is a pure oxygen and nitrogen constitutes a very small fraction of the coal used, about $1 \%)$, it is important to note that $\mathrm{NO}_{\mathrm{x}}$ formation causes acid rain and photochemical smog.

Gopan et al. [21] conducted the performance analysis on a SPOC power plant and showed that the energy penalty for the plant efficiency is reduced from 10 percent point in atmospheric pressure oxy-combustion to about 4 percent point in SPOC. For an efficient design of SPOC, Gopan et al. [16] conducted research on the effect of the operating pressure and fuel moisture on the net efficiency. It was found that the effect of high pressure on the net efficiency of SPOC is insignificant when the pressure goes over 16 bar. Thus, to take the maximal advantage of the effect of pressurized combustion, this SPOC technique is employed at an elevated pressure not exceeding 15 bar.

Hong et al. [17] conducted research on the effect of high pressure on the output thermal energy recovery and the gross power output, and they compared the results obtained at an elevated pressure to that obtained at the atmospheric pressure conditions. It was concluded that the pressurized coal combustor showed better performance in terms of thermal energy recovery 
and gross power output as compared to the atmospheric conditions. This research was taken a step further in conducting the pressure sensitivity analysis for determining an optimal combustor operating pressure for a pressurized oxy-fuel combustion power cycle using a $300 \mathrm{MW}$ coal-fired power plant. Hong et al. [22] concluded that increasing the operating pressure of an oxy-fuel combustor would eventually increase the overall performance of the combustor.

\subsection{Turbulence Modelling}

Accurate computational description of a turbulent flow field remains a very challenging problem to solve, since flow properties change randomly in space and time. Thus, obtaining a numerical solution, which would exactly match the experimental data from this peculiar case, remains a very difficult task. In addition, the properties of a turbulent flow remain the key factors for successful combustion, primarily, because of its mixing capabilities. The presence of eddies of various scales in motion provides the possibility for adequate mixing, which is a characteristic of turbulence. Since a good mixing between the oxidizer and the fuel streams is needed, turbulence is therefore taken into consideration such that the effect of fluctuations is included.

There are various approaches for calculating turbulent flow fields based on the Navier-Stokes equations: the direct numerical simulation (DNS), the Reynolds-averaged Navier-Stokes (RANS) simulation, and the large-eddy simulation (LES). DNS involves direct solving of the Navier-Stokes equations for all temporal and spatial scales of turbulence such that no turbulence model is employed. This simply means that all ranges of length scales from the smallest scale, i.e. the Kolmogorov scale, to the largest scale, i.e. the integral length scale, must be resolved. Obviously, 
it generally requires enormous computational facilities for such a method to be very accurate, so DNS is a difficult and very time consuming process for complex geometries and reacting flows.

In this light, RANS remains the most widely used methodology because it requires lesser computational resources as compared to other turbulence models. RANS models the effect of turbulence on all scales. Time and spatial averaging of the Navier-Stokes equation is done, which introduces new terms that are modelled using the turbulent models such as the $k-\varepsilon, k-\omega$, mixing length and Spalart-Allmaras models. The k- $\varepsilon$ RANS turbulence model is a two-equation system i.e. the $k$-equation and $\varepsilon$-equation model proposed by Launder and Spalding [23]. The solution of this two-equation system results in the independent calculation of the turbulent velocity and the turbulent length scale, while the k-w RANS model [24] incorporates a modification for the low-Reynolds number effects, compressibility and shear flow spreading.

LES stays between RANS and DNS in terms of computational costs. Specifically, LES resolves the large-scale eddies but models the small-scale features since it is easier to get a universal subgrid-scale (SGS) model for smaller scales. A filter method (in most cases the mesh size) is used to filter out the small scales such that the effect of the small-scale eddies will be accounted through an SGS model.

Although RANS is still a widely used tool for various advantages, LES is promptly becoming a preferable turbulence modelling approach for many reacting flow simulations due to a significant advancement of available and emerging computational resources. Chen et al. [25] compared the results of RANS and LES in a $100 \mathrm{~kW}$ test facility and demonstrated that LES predicted the flame characteristics in the test facility better than RANS, in terms of the flame length, internal 
recirculation zone etc. However, recognizing that LES is rapidly becoming a major research and engineering tool for various engineering problems, it is necessary to formulate or measure the accuracy of the LES results. For this purpose, Celik et al. [26] developed such a measure, which was applied to various reacting and non-reacting LES cases, and it was validated by means of both experiments and DNS. The work [26] was subsequently extended by developing a correction factor for the laminar flow regions [27].

\subsection{Computational Fluid Dynamics Studies of Reactor Design}

Computational fluid dynamics (CFD) simply refers to the use of numerical procedures for solving mathematical models, which represents physical behaviors. Specifically, CFD has evolved as a powerful computational tool for the modelling of representative physical phenomena, which either compliments an experimental setup or acts as the sole technique for modelling and thereby understanding the fluid flow behaviors. For an experimental outcome to be accurate, usually, a substantial amount of time and financial resources is invested. To address such a demand, the advancement of the computational resources as well as representative mathematical models of the physics from practical reality are solved using developed numerical procedures in obtaining the fluid flow solution for various industrial flow problems, which may help to optimize the experiments and reduce their costs and the associated efforts [28].

In this respect, CFD remains very useful for the design of the complex flow processes as well as to predict the heat, mass and momentum transfer for either reacting or non-reacting flows. In fact, benefited from the growing availability of the computational resources, CFD has been implemented in designing and modelling of the combustion process for a biomass furnace [29] 
and power generation [30], thereby yielding robust and comprehensive solutions. The results obtained from the CFD modelling are further used as the process optimization tools.

There are several advantages of the CFD implementation in a reactor design process [31], including but limited to:

a) Detailed understanding of the flow distribution, particulate separation, weight losses and mass and heat transfer can be obtained;

b) Problems associated with a scale-up can be significantly reduced because the models are based on the fundamental physics and can be scale-invariant;

c) Effect of geometry change can be evaluated in a much shorter time and at a lesser cost as compared to a laboratory setup;

d) Conditions, where detailed measurement cannot be achieved, could be computationally simulated and conclusions could be made e.g. at the high temperature regions.

Accuracy of a CFD result requires attention to be paid to the nature of the problem being solved as well as to the available numerical schemes. For instance, for obtaining a reasonably accurate simulation for a reacting flow, attention needs to be paid to the fineness of the mesh sizes as well as the selection of a turbulence model suitable for a particular flow being studied.

\subsection{CFD Modelling of Oxy-Coal Combustion}

The usage of CFD is increasingly becoming a useful tool for scrutinizing various combustion processes as well as predicting formation and characteristics of species in the burning matter. It is important to perform a numerical study of various combustion processes before they are actually implemented in a real-life power plant. 
Al-Abbas et al. [32] performed a numerical investigation on combustion of pulverized dry lignite in the presence of two various oxidizer streams: air and pure oxygen. This was done for four different cases: air-fired and three different volumetric fractions of the oxygen streams: vol. $\%$ of $25 \%, 27 \%$ and $29 \%$. This CFD modelling was based on the experimental research conducted by Hjärtstam et al. [33] for a lab-scale 100 kW lignite-firing unit. The CFD results showed very good agreement with the experiment in terms of the temperature distribution profiles as well as the $\mathrm{O}_{2}, \mathrm{CO}_{2}$, and $\mathrm{H}_{2} \mathrm{O}$ species concentration profiles at the most intense combustion location in the furnace. Al-Abbas et al. [34] then further extended their work [32] to oxy-fuel combustion in a full-scale tangentially fired pulverized coal burner using the Victorian brown coal. This was modelled based on the real conditions of the Loy Yang power plant in Australia. The results obtained were in good agreement with the experiment. In particular, the predictions of 29 vol. $\%$ combustion case were much similar to the standard firing result as compared to the cases of $25 \%$ and $27 \%$, considering the gas temperature levels and radiative heat transfer.

Chen et al. [25] conducted a numerical study of oxy-coal combustion in a $100 \mathrm{~kW}$ test facility using both RANS and LES. The velocity contour profiles, species concentrations, gas temperatures and particle temperature for different turbulence model were compared to experimental results. It was observed that the SST k- $\omega$ RANS model captures most of the flow characteristics and improves the prediction of oxygen diffusion as compared to other RANS models. The LES result better resolves some of the large-scale turbulent structures of the swirl flow as well as captures the dynamic characteristics of oxy-coal combustion. Toporov et al. [35] performed a numerical study of a $100 \mathrm{~kW}$ pilot-scale furnace available at the Institute of Heat and Mass Transfer, Aachen University (RWTH), Germany. The authors of [35] have developed a novel approach towards oxy- 
coal flame stabilization. Specifically, a swirl burner design and operation was implemented such that CO was formed, which, in turn, stabilized the flame as well as provided full burnout when different levels of $\mathrm{O}_{2}$ were used in the $\mathrm{O}_{2} / \mathrm{CO}_{2}$ mixture similar to the air.

\subsection{Flow Past a Bluff Body}

High volume combustion requires that velocities of different streams should also be sufficiently high. This, in turn, increases the Reynolds number and changes the whole combustion dynamics as the burning process becomes turbulent. At this point, flame stabilization becomes a challenge, which needs to be resolved. Researchers have used recirculation zones as a measure of flame stabilization, primarily because the recirculation zones affect the mass and energy transfer from the burnt to the unburnt gases. In order to ensure continuous ignition through a fuel mixture at a fixed point in a combustion chamber, either a bluff body, a pilot flame technique, a deflected jet or a swirl jet are used.

In my thesis, I focus on flame stabilization by means of a bluff body because we are interested in such an essential feature of this stabilizing method as the formation of a recirculation zone behind the bluff body. For a flame stability to occur there must be a system, which provides continuous ignition of the fresh fuel/oxidizer stream fed into the burner. A recirculation zone is therefore created by the bluff body, where burnt gases are being brought back to ignite the fresh or incoming streams. This recirculation zone in the wake of this bluff body would act as a wellstirred burner, thereby providing ignition of the fresh fuel/oxidizer streams.

Hanna et al. [36] estimated the blow off velocity of the flame, in the wake of a bluff body in a high velocity stream, using a semi-empirical formula. Specifically, a conical bluff body with 
different diameters and cone angles were used in conjunction with different fuels. The model developed showed good agreement with the experimental results [34]. Bespalov [37] conducted an extensive study on the effect of bluff bodies on the stabilization of turbulent premixed flames. It was concluded that when a flow passes over a bluff body, there is an appearance of a symmetric eddy, which further amounts to shedding of vortex upon continuous increase of the mainstream velocity. Hence, when the velocity around this bluff body (stabilizer) increases beyond a critical value, the flame blows off.

Finally, Ahmed et al. [38] employed a numerical method as well as the current visualized and ionization techniques to evaluate the flame stability and characteristics for a bluff-body-stabilized flow, where the ionization technique refers to a process whereby DC volts is applied between two electrodes in a flame to determine the amount of species (electrons and ions). Specifically, twelve various bluff body shapes were investigated and their effect on the flame characteristics were recorded. It was concluded that the disk-shaped bluff bodies behave the best as compared to the other shapes in terms of blow-off air/fuel limit, the temperature in the recirculation zone and the blockage ratio. Therefore, the bluff bodies are used for safety reasons, easiness of the combustion control, excellent turbulent mixing and the improvement of the flame stability.

\subsection{Radiation Heat Transfer}

Radiative heat transfer is one of the aspect, which should be scrutinized in oxy-coal combustion. The partial pressure of $\mathrm{CO}_{2}$ and $\mathrm{H}_{2} \mathrm{O}$ during the combustion process is higher in the case of oxycoal combustion as compared to that in air-fuel combustion, which makes higher absorption and radiation in oxy-combustion as compared to air-fired one. Unlike symmetric diatomic molecules 
such as $N_{2}$, which do not emit significantly because of its transparency to infrared radiation, heteropolar gases (such as $\mathrm{H}_{2} \mathrm{O}$ and $\mathrm{CO}_{2}$ ), which form the major constituents of the oxy-coal combustion flue gas, provide a significant absorption and emission as they are not transparent to infrared radiation [39]. When a radiation beam of wavelength, $\lambda$, travels an infinitesimal beam length, $d s$, through a gas, the gas absorbs a fraction of its radiation intensity. Hence, the change in spectral radiation intensity, $d I_{\lambda}$, is calculated as [40],

$$
d I_{\lambda}=-k_{\lambda} I_{\lambda} d s
$$

where $k_{\lambda}$ is the spectral absorption coefficient, which is a function of the gas temperature, composition, pressure and the beam wavelength. Upon integrating equation (3.1) over the beam length, the spectral absorptivity and emissivity of the gas is given by

$$
\alpha_{\lambda}=\varepsilon_{\lambda}=1-\exp \left[-k_{\lambda} s\right]
$$

where $\alpha_{\lambda}$ is the spectral absorptivity and $\varepsilon_{\lambda}$ is the emissivity of the gas.

Edward [41] studied the spectral absorptivity as a function of wavelength for three gas streams i.e. $\mathrm{H}_{2} \mathrm{O}, \mathrm{CO}_{2}, \mathrm{CH}_{4}$ during combustion and found that absorption is discontinuous and concentrated in several moderately wide spectral bands. To mitigate this difficulty, the Weighted Sum of Grey Gas (WSGG) model in CFD is used. Here, the grey gas approximation assumes constant absorption coefficient for emitting infrared wavelength, thereby simplifying the radiative heat equation such that the optical thickness is independent of the wavelength. The WSGG model is that between the simple Grey Gas model and a more computationally expensive complete model. The heat transfer rate is calculated independently by replacing the non-gray gas with several grey gases and, hence, the total heat transfer is accounted by the summation of the heat fluxes of grey gases obtained by multiplication with a certain factor [42]. 


\section{Methodology}

This thesis presents a numerical study of SPOC by means of the ANSYS FLUENT, a commercially available computational package, with the mesh structure and geometry implemented by ICEM, a commercial software with robust and efficient meshing capabilities for complex geometries. The combustion process is modelled as a multiphase flow comprising of a solid or dispersed phase and a gaseous or continuous phase. The Euler-Lagrange (EL) method is used to describe this twophase flow. Specifically, this method solves the continuous flow using the Euler method while the discontinuous (particles) are tracked using the Lagrangian method. Such an approach (EL) is more intuitive because it highlights trajectories of particles (or droplets), which are of great interest to a CFD user. However, these particles are often not real particles but parcels, which can contain thousands of real droplets, since the modern computational facilities cannot handle millions of droplets per second created by standard fuel injectors. Therefore, models are required for these parcels, which sometimes makes modelling more difficult [43-44].

\subsection{Continuous Phase Modelling}

The Navier-Stokes equations are solved for the aerodynamics of the continuous phase using the Shear-Stress Transport (SST) k-w RANS model, developed by Menter [45], as well as by the LES approach using the dynamic Smagorinky-Lilly subgrid-scale (SGS) model. The SST k-w model is used because it effectively blends the robust and accurate formulation of the $k-\omega$ model in the near-wall region with the free-stream independence of the $k-\omega$ model in the far region, i.e. the modified $k-\varepsilon$ model is used at regions away from the wall [46]. It is important to note that more accurate solutions are obtained when turbulence models are avoided (DNS) or reduced. Thus, 
LES is used for solving the Navier-Stokes equation where the large scale vortices are captured but small scale vortex are modelled. In the general tensor form, the continuity and the Navier-Stokes equations read

$$
\begin{aligned}
& \frac{\partial}{\partial t} \rho+\frac{\partial}{x_{i}}\left(\rho u_{i}\right)=0, \\
& \frac{\partial}{\partial t}\left(\rho u_{i}\right)+\frac{\partial}{\partial x_{j}}\left(\rho u_{j} u_{i}\right)=-\frac{\partial}{\partial x_{i}} p+\frac{\partial}{\partial x_{j}} \tau_{j i},
\end{aligned}
$$

where, $p$ is pressure and $\tau_{j i}$ is stress tensor.

4.1.1 RANS Turbulence Modelling: RANS turbulence model is generally used for its robustness, relatively low computational cost as well as reasonable accuracy for different industrial flow applications. For the RANS approach, the governing equations are averaged which, in turn, generates additional terms that have to be modelled in order to obtain closure. For this approach, all scales of turbulence are modelled. The incompressible RANS model with a variabledensity approach also known as the Favre-averaged Navier-Stokes (FANS) equations is used. The FANS equations read [26]:

$$
\begin{aligned}
& \rho=\bar{\rho}+\rho^{\prime}, \\
& \frac{\partial \bar{\rho}}{\partial t}+\frac{\partial}{\partial x_{i}}\left(\bar{\rho} U_{i}+\overline{\rho^{\prime} u_{i}^{\prime}}\right)=0, \\
& \tilde{u_{l}}=\frac{1}{\bar{\rho}} \lim _{T \rightarrow \infty} \frac{1}{T} \int_{t}^{t+T} \rho(x, T) u_{i}(x, T) d T, \\
& \bar{\rho} \widetilde{u_{l}}=\overline{\rho u_{i}}, \\
& \frac{\partial \bar{\rho}}{\partial t}+\frac{\partial}{\partial x_{i}}\left(\bar{\rho} \tilde{u_{\imath}}\right)=0, \\
& \frac{\partial}{\partial t}\left(\bar{\rho} \tilde{u_{\imath}}\right)+\frac{\partial}{\partial x_{j}}\left(\bar{\rho} \tilde{u_{\imath}} \widetilde{u_{J}}\right)=-\frac{\partial \bar{p}}{\partial x_{i}}+\frac{\partial}{\partial x_{j}}\left[\mu\left(\frac{\partial \widetilde{u_{l}}}{\partial x_{j}}+\frac{\partial \widetilde{u_{j}}}{\partial x_{i}}-\frac{2}{3} \delta_{i j} \frac{\partial \widetilde{u_{k}}}{\partial x_{k}}\right)\right]+\frac{\partial}{\partial x_{j}}\left(-\overline{\rho u_{\imath}^{\prime} u_{\jmath}^{\prime}}\right),
\end{aligned}
$$


where $\widetilde{u}_{l}, \widetilde{u}_{j}$ and $\tilde{u}_{k}$ are the Favre-averaged velocities and $u_{i}{ }^{\prime}, u_{j}{ }^{\prime}$ are the velocity fluctuations in the Cartesian coordinates; $\mu$ is the molecular viscosity of the fluid, $\bar{p}$ is the time-averaged static pressure and $\bar{\rho}$ is the time-averaged density. The pressure and density are coupled through the ideal gas law.

$$
p=\rho R T .
$$

The Reynolds stresses $-\overline{\rho u_{\imath}{ }^{\prime} u_{\jmath}{ }^{\prime}}$ are modelled according to the Boussinesq hypothesis, which relates the Reynolds stress to the mean velocity fluctuations and turbulent viscosity $\mu_{t}$ as

$$
\begin{aligned}
& -\overline{\rho u_{\imath}{ }^{\prime} u_{\jmath}^{\prime}} \approx \mu_{t}\left(\frac{\partial \widetilde{u_{l}}}{\partial x_{j}}+\frac{\partial \widetilde{u_{J}}}{\partial x_{i}}-\frac{2}{3} \delta_{i j} \frac{\partial \widetilde{u_{k}}}{\partial x_{k}}\right)-\frac{2}{3} \bar{\rho} k \delta_{i j}, \\
& \mu_{t}=\frac{\rho k}{\omega} \frac{1}{\max \left[\frac{1}{\alpha^{*}} \frac{S F_{2}}{a_{1} \omega}\right]^{\prime}} \\
& \omega=\varepsilon / k
\end{aligned}
$$

where $S$ is the strain rate magnitude, $F_{2}$ represents the blending function and $\alpha^{*}$ is the turbulent viscosity damping coefficient. The specific turbulent kinetic energy $k$ and the specific dissipation rate $\omega$ are thus obtained from the set of equations

$$
\begin{aligned}
& \frac{\partial}{\partial t}(\rho k)+\frac{\partial}{\partial x_{i}}\left(\rho k u_{i}\right)=\frac{\partial}{\partial x_{j}}\left(\Gamma_{k} \frac{\partial k}{\partial x_{j}}\right)+\tilde{G}_{k}-Y_{k}, \\
& \frac{\partial}{\partial t}(\rho \omega)+\frac{\partial}{\partial x_{i}}\left(\rho \omega u_{i}\right)=\frac{\partial}{\partial x_{j}}\left(\Gamma_{\omega} \frac{\partial k}{\partial x_{j}}\right)+\tilde{G}_{\omega}-Y_{\omega}+D_{\omega}, \\
& \Gamma_{k}=\mu+\frac{\mu_{t}}{\sigma_{k}}, \\
& \Gamma_{\omega}=\mu+\frac{\mu_{t}}{\sigma_{\omega}},
\end{aligned}
$$

where $\tilde{G}_{k}$ and $\tilde{G}_{\omega}$ represent the generation of $k$ and $\omega$, due to the mean velocity gradients, $Y_{\omega}$ and $Y_{k}$ denotes the dissipation of $k$ and $\omega$ due to turbulence, $\Gamma_{k}$ and $\Gamma_{\omega}$ are the effective diffusivity 
of $k$ and $\omega$, while $D_{\omega}, \sigma_{k}, \sigma_{\omega}$ represents the cross diffusion term, the turbulent Prandt number for $k$ and turbulent Prandtl number for $\omega$.

4.1.2 LES Turbulence Modelling: An alternative to the RANS approach is LES. As the name implies, the quantities of the momentum, mass and energy are directly resolved for the largescale eddies, while the sub-grid-scale (SGS) models are employed to mimic the small-scale eddies. LES explicitly resolves the large-scale eddies in a transient simulation using the filtered NavierStokes equation. Such a filtering is a mathematical operation performed on the Navier-Stokes equations to remove the eddies smaller than the filter size, which is usually the mesh size when spatial filtering is employed [47]. A filtered variable is defined as

$$
\bar{\phi}(x)=\int_{D} \phi\left(x^{\prime}\right) G\left(x, x^{\prime}\right) d x^{\prime},
$$

where $D$ is a fluid domain and $G\left(x, x^{\prime}\right)$ is the filter function determining the scale of the resolved eddies. The filter function is applied in the finite-volume discretization scheme as

$$
G\left(x, x^{\prime}\right)=\left\{\begin{array}{l}
1 / v, x^{\prime} \in v \\
0, \quad x^{\prime} \notin v
\end{array}\right.
$$

where $v$ is the computational cell and $V$ is the volume of this cell. Hence, the filtered variable is

$$
\bar{\phi}(x)=1 / V \int_{v} \phi\left(x^{\prime}\right) d x^{\prime}, x^{\prime} \in v .
$$

The Favre-filtered Navier-Stokes equations are

$$
\begin{aligned}
& \frac{\partial}{\partial t} \bar{\rho}+\frac{\partial}{\partial x_{i}}\left(\bar{\rho} \widetilde{u_{l}}\right)=0, \\
& \frac{\partial}{\partial t}\left(\bar{\rho} \widetilde{u}_{l}\right)+\frac{\partial}{\partial x_{j}}\left(\bar{\rho} \widetilde{u_{l}} \widetilde{u}_{\jmath}\right)=-\frac{\partial \bar{p}}{\partial x_{i}}+\frac{\partial}{\partial x_{j}}\left[\mu\left(\frac{\partial \widetilde{u}_{l}}{\partial x_{j}}+\frac{\partial \widetilde{u_{\jmath}}}{\partial x_{i}}-\frac{2}{3} \delta_{i j} \frac{\partial \widetilde{u_{k}}}{\partial x_{k}}\right)\right]-\frac{\partial \tau_{i j}}{\partial x_{j}},
\end{aligned}
$$

where $\tau_{i j}$ is the SGS stress tensor defined as

$$
\tau_{i j}=\rho\left(\overline{u_{\imath} u_{\jmath}}-\overline{u_{l}} \bar{u}_{\jmath}\right) .
$$


The SGS turbulent model in the ANSYS FLUENT employs the Boussinesq hypothesis [48] similar to the RANS model, namely:

$$
\begin{aligned}
\tau_{i j} & =\frac{1}{3} \tau_{k k} \delta_{i j}-2 \mu_{t} \bar{S}_{i j}, \\
\bar{S}_{i j} & \equiv \frac{1}{2}\left(\frac{\partial \bar{u}_{i}}{\partial u_{j}}+\frac{\partial \bar{u}_{j}}{\partial u_{i}}\right)
\end{aligned}
$$

where $\tau_{k k}$ is the isotropic part of the SGS stress tensor and $\bar{S}_{i j}$ is the strain tensor rate. The Smagorinsky-Lilly model [49] was used to model the SGS turbulent viscosity $\mu_{t}$, namely:

$$
\mu_{t}=\rho L_{s}^{2}|\bar{S}|
$$

where $L_{s}$ is the mixing length for subgrid scales and $|\bar{S}|$ is the strain tensor rate,

$$
\begin{aligned}
& |\bar{S}|=\sqrt{2 \bar{S}_{i j} \bar{S}_{i j}}, \\
& L_{s}=\min \left(k d, C_{s} \Delta\right),
\end{aligned}
$$

where $k$ is the von Karman constant, $d$ the distance to the lowest closest wall, $C_{s}$ the Smagorinsky constant and $\Delta$ the local grid scale computed as the cubic root of the cell volume. However, a modified approach for the dynamically computing Smagorinsky constant $C_{s}$, known as the Dynamic Smagorinsky-Lilly model [50-51] is employed, with a Smagorinsky constant obtained from the data gotten from the resolved scales of motion.

Furthermore, mixing and transport of the chemical species is modelled using the species transport model [52], where mixing and transport of chemical species in the continuous phase is obtained by solving the balance equations for convection, diffusion and reaction of sources for each component species [53]. To predict the local mass fraction of each species, we have to solve the species transport equation,

$$
\frac{\partial}{\partial t}\left(\rho Y_{i}\right)+\nabla \cdot\left(\rho \vec{v} Y_{i}\right)=-\nabla \cdot \vec{J}_{l}+R_{i}+S_{i}
$$


where $R_{i}$ is the net rate of production of species $i, S_{i}$ the rate of creation by addition from the dispersed phase plus any other user-defined source, and $\vec{J}_{l}$ the mass diffusion flux of species $i$, due to temperature and concentration gradients, which is also considered for turbulent flows. The turbulent Schmidt number is further calculated from the turbulent viscosity and diffusivity,

$$
S_{c t}=\mu_{t} / \rho D_{t}
$$

where $\mu_{t}$ is the turbulent viscosity while $D_{t}$ is the turbulent diffusivity.

The reaction rate $R_{i}$ is computed using a turbulence-chemistry interaction known as the finite-rate/eddy-dissipation model, which is suitable for a wide variety of applications. In the ANSYS FLUENT, this model calculates the reaction rates using the finite-rate model and the eddydissipation model and takes a net reaction rate as the minimum of both. The laminar finite-rate model is suitable for laminar flames and combustion with weak turbulence-chemistry interaction. To be specific, this model neglects the effect of turbulent fluctuations and calculates the reaction rates from the Arrhenius kinetic expressions.

The eddy-dissipation model of Magnussen \& Hjertager [54] considers that most fuels burn fast, which means that the turbulent time scales are large as compared to the chemical time scale and, as a result, turbulent mixing controls the net reaction rate. The large-eddy mixing time scale, $k / \varepsilon$, controls the chemical reaction rate.

In addition, since burning is a high-temperature exothermal process, a $4^{\text {th }}$-order temperature dependence in the combustion process makes heat transfer a dominant mode due to thermal radiation. The effect of radiation is taken into account by solving the radiative transfer equation (RTE) for a participating media with absorption, emission and scattering being considered, 


$$
\frac{d I(\vec{r}, \vec{s})}{d s}+\left(a+\sigma_{s}\right) I(\vec{r}, \vec{s})=a n^{2} \frac{\sigma T^{4}}{\pi}+\frac{\sigma_{s}}{4 \pi} \int_{0}^{4 \pi} I\left(\vec{r}, \vec{s}^{\prime}\right) \Phi\left(\vec{s} \cdot \vec{s}^{\prime}\right) d \Omega^{\prime},
$$

where $\vec{r}$ is the position vector, $\vec{s}$ the direction vector, $\vec{s}^{\prime}$ the scattering direction vector, $a$ the absorption coefficient, $n$ the refractive index, $\sigma_{s}$ the scattering coefficient, $I$ the radiation intensity, $\Phi$ the phase function and $\Omega^{\prime}$ the solid angle. The discrete-ordinate model is used to solve the RTE (4.23) such that the radiation exchange between the gas and particle phases is accounted for.

\subsection{Discrete Phase Modelling}

The description of coal combustion is characterized as that comprising three different processes:

Evaporation of Moisture - At this stage, the coal particles typical exchange energy with the continuous phase without a change of phase or interchange of mass. Coal particles are therefore heated up to a point, where the moisture contained in the particles begin to evaporate. This process continues until the temperature of the particles reaches the vaporization temperature of the liquid phase. The energy balance for the particles in this stage is modelled to account for the radiation interchange with the particles, convection and latent heat energy. The latent heat energy is added to the particle energy balance only when the temperature of the particles overcomes the value of the vaporization temperature of the liquid phase.

Devolatilization or Pyrolysis stage - This process starts when a temperature of the coal particles attains its vaporization value and, in turn, the mass of the volatile in the coal particles becomes lower than the mass of the particles. Thus, coal particles releases its volatiles into the continuous phase. While there are various devolatilization methods explored in the literature, in this thesis I model devolatilization of coal using the chemical percolation devolatilization (CPD) model. This 
model accounts for the lattice statistics, which are important to model the coal devolatilization process. The percolation theory describes the size distribution of discrete coal clusters consisting of molecular sites that are joined together by intact bridges but are isolated from the remaining sites by broken bridges [55].

Unlike other options to describe devolatilzation in the ANSYS FLUENT, based on the empirical rate relationships, the CPD model characterizes the devolatilization behavior of a rapidly heated coal based on the physical and chemical transformations of the coal structure. The CPD model also predicts the effect of pressure on tar and total volatiles yields observed in a grid experiment for both bituminous coal and lignite [56-57].

A two-step reaction mechanism is further used to define the oxidation process of these volatiles. The volatiles imitate a generic hydrocarbon, and they are obtained from the proximate and ultimate analysis of coal. To be specific, four gas phase reactions were considered, namely:

$$
\begin{aligned}
& \text { Volatiles }+v_{1} \mathrm{O}_{2} \rightarrow v_{2} \mathrm{CO}+v_{3} \mathrm{H}_{2} \mathrm{O}+v_{4} \mathrm{~N}_{2}+v_{5} \mathrm{SO}_{2}, \\
& \mathrm{CO}+\frac{1}{2} \mathrm{O}_{2} \rightarrow \mathrm{CO}_{2} \\
& \mathrm{CH}_{4}+1.5 \mathrm{O}_{2} \rightarrow \mathrm{CO}+2 \mathrm{H}_{2} \mathrm{O} \\
& \mathrm{H}_{2}+\frac{1}{2} \mathrm{O}_{2} \rightarrow \mathrm{H}_{2} \mathrm{O}
\end{aligned}
$$

where $v_{1}, v_{2}, v_{3}, v_{4}$ and $v_{5}$ are the number of moles for each species.

Char Oxidation Stage - The solid particles remaining after devolatilization stage are called char. In our case, the char is composed of carbon in the graphite phase. This carbon is usually oxidized by $\mathrm{O}_{2}$ and in oxy-coal combustion, which is our case, this carbon reacts with $\mathrm{CO}_{2}$. The char oxidation is defined as follows: 


$$
\begin{aligned}
& C(s)+\frac{1}{2} \mathrm{O}_{2} \rightarrow \mathrm{CO}, \\
& C(s)+\mathrm{H}_{2} \mathrm{O} \rightarrow \mathrm{CO}+\mathrm{H}_{2}, \\
& C(s)+\mathrm{CO}_{2} \rightarrow 2 \mathrm{CO} .
\end{aligned}
$$

The fluid-solid reaction models depend on the particle size as well as the ability of the fluid to diffuse into the solid particle. During the oxidation process, the particle diameter could either change or remain constant. The relationship between the temperature, pressure and density is calculated using the ideal gas law (4.4).

When the volatile component of the particles must have completely evolved, a surface reaction starts, consuming the combustible fraction. In this thesis, I model the char oxidation process using the multiple surface reaction model, which exhibits similar pattern to the wall surface reaction model, where the particle surface species could either be consumed or produced. Furthermore, since the ANSYS FLUENT package cannot model a reversible surface reaction, only the forwards reaction rate constants were modelled. The overall forward rate constant during the char oxidation process is therefore calculated using the empirical Arrhenius expression, where the pre-exponential factor, temperature exponent and activation energy are specified. The Arrhenius expresses the rate constants of any chemical reaction as a function of pre-exponential factor, temperature exponent and activation energy.

During the particle combustion process, the particle trajectory is calculated by integrating the force balance equation on a particle written in the Lagrangian reference frame. This equation accounts for the gravity force (only if turned on in the simulations), the drag force in terms of the force per unit particle mass, as well as any other forces which the user wishes to account for. 
However, in this particular research project, we are concerned about the gravitational force acting on a particle, particle-radiation interaction, and the drag force on a particle. The latter is calculated using the particle velocity, fluid phase velocity, molecular viscosity of the fluid, fluid density, density of the particles, the Reynolds number and the particle diameter. The drag coefficient is calculated using the spherical drag law with the constants, which are applied for smooth spherical particles over several ranges of the Reynolds number [58],

$$
C_{D}=\alpha_{1}+\frac{\alpha_{2}}{R e}+\frac{\alpha_{3}}{R e^{2}},
$$

where $C_{D}$ is the drag coefficient and $\alpha_{1}, \alpha_{2}, \alpha_{3}$ are the constants applied for several Re.

A stochastic tracking model was employed to model the turbulent dispersion of the particles. This approach uses the discrete random walk (DRW) model, which incorporates, with the stochastic methods [57], the impact of the instantaneous turbulent velocity fluctuations on the particle trajectories.

For pulverized coal, there exist various particle size diameters even when the particles have been milled to fine grains, raising curiosity on the most effective way to capture these varying particle sizes. In this thesis, the Rosin-Rammler diameter distribution method is used to represent the particle distribution sizes. This method assumes an exponential relationship between the droplet diameter $d$ and the mass fraction of droplets with a diameter greater than the droplet diameter. Hence, describing the cumulative distribution of particle sizes, when originally coarse coal particles are crushed into very fine particles [60-61]. This is described by as

$$
Y_{d}=e^{-\left(\frac{d}{\bar{d}}\right)^{n}},
$$


where $Y_{d}$ is the droplet mass fraction, $d$ the droplet diameter, $n$ the spread parameter and $\bar{d}$ the size constant. For the coal used in this thesis, the maximum diameter is $200 \mu \mathrm{m}$, the minimum diameter is $5 \mu \mathrm{m}$ and the mean diameter is $65 \mu \mathrm{m}$. A summary of the different models used for this thesis can be found in Table 1.

Table 1: Summary of the models used for the simulation

\begin{tabular}{|l|l|}
\hline Gas Phase & Eulerian \\
\hline Particle Phase & Lagrangian \\
\hline Turbulence & K- $\omega$ SST model \\
\hline Mixing and transport of chemical species & Species transport model \\
\hline Species considered & Coal volatiles, $\mathrm{O}_{2}, \mathrm{CO}_{2}, \mathrm{H}_{2} \mathrm{O}, \mathrm{CO}, \mathrm{N}_{2}, \mathrm{H}_{2}$ \\
\hline Turbulence-interaction chemistry & Finite-Rate/Eddy-Dissipation \\
\hline Volumetric reaction & Two-step reaction mechanism \\
\hline Particle combustion & Global reaction \\
\hline Particle Size distribution & Rosin-Rammler \\
\hline Turbulent particle dispersion & Random walk model \\
\hline Coal devolatilization & Chemical percolation devolatilization (CPD) \\
\hline Char Oxidation & Multiple surface reaction model \\
\hline Radiation heat transfer & Discrete ordinates \\
\hline
\end{tabular}

\subsection{Domain Discretization and Boundary Conditions}

CFD usage requires a variety of conditions to be specified when the basic governing equations are solved. The domain of interest is separated from the environment by specifying the boundary conditions that are either values gotten from an experimental setup or condition based on the basic physical principals e.g. slip/non-slip, adiabatic/isothermal walls. The domain of interest, i.e. where the flow will be calculated, is divided into a large number of grid cells also known as mesh. The conservation equations for mass and momentum, turbulent flow, chemical species, heat transfer for both the continuous phase and the discrete phase are solved using a control-volume 
method known as the finite-volume method. This method discretizes the governing equations by first dividing the physical space into a number of arbitrary polyhedral volumes, then integrating the governing equations on the individual control volumes to construct algebraic equations for the discrete dependent variables ("unknowns") such as velocities, pressure, temperature, and conserved scalars. Finally, the discretized equations are linearized and this resulting linear set of equations are solved to find the updated values of the dependent variables [62-63].

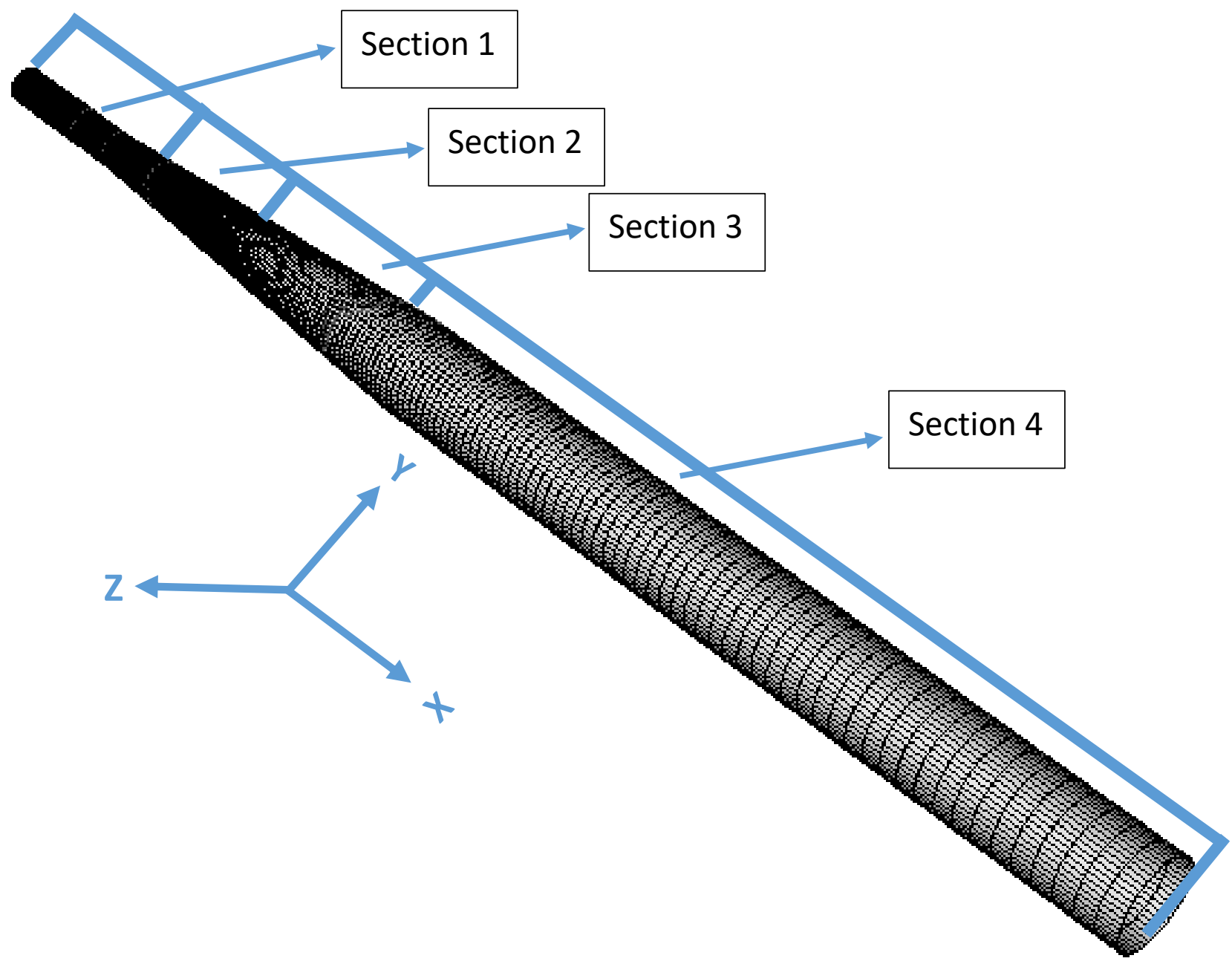

Figure 4.1: A structured mesh of the burner geometry with respective sections. 
The geometry and domain grid cells are generated using the ICEM for a structured mesh. The structured mesh is generated for proper capture of the boundary layer near the wall and simplification of the gradients and fluxes.

Figure 4.1 shows the geometry for the first stage of the SPOC burner in a form of a structured mesh. Section 1 presents the inlet to the burner. This section comprises the inlet and the inner tubes delivering the oxidizers as well as the fuel streams to the burner. A better view of the inlet is presented in Fig. 4.2. Section 2 represents an annular quartz region, which is a transparent part enabling visual observation of the flame dynamics and morphology. Section 3 is also an annular region connected to the quartz region but made of a different material. Section 4 represents the furnace wall. This is a region, where the flue gas as well as the burnt and unburnt products are recovered. A percentage of the flue gas recovered from this section is delivered to the next stage of the SPOC burner, while the remainder of the gas is recirculated back into this burner.

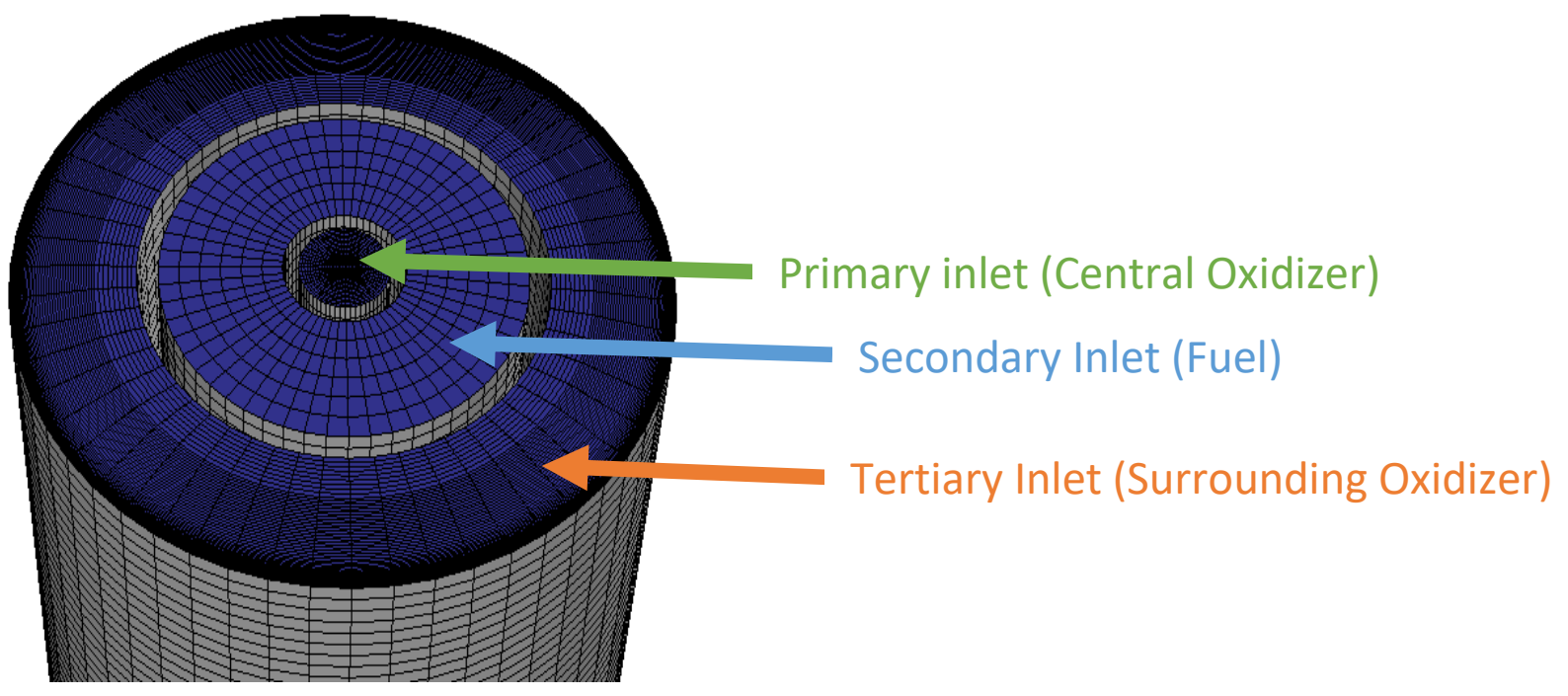

Figure 4.2: A structured mesh of the inlet section. 
Figure 4.2 shows the inlet section to the burner comprising three different inlet subsections, namely: the primary inlet, the secondary one, and the tertiary Inlet. The primary inlet, also known as the central oxidizer, delivers a fraction of $\mathrm{O}_{2}$ and $\mathrm{CO}_{2}$, while the secondary inlet delivers the fuel needed for combustion. The fuel injected into the secondary inlet comprises coal (which burning will generate $90 \mathrm{~kW}$ ) and a little fraction of methane (which burning will provide $10 \mathrm{~kW}$ ). Finally, the tertiary inlet delivers another stream of oxidizer i.e. $\mathrm{O}_{2}$ and $\mathrm{CO}_{2}$.

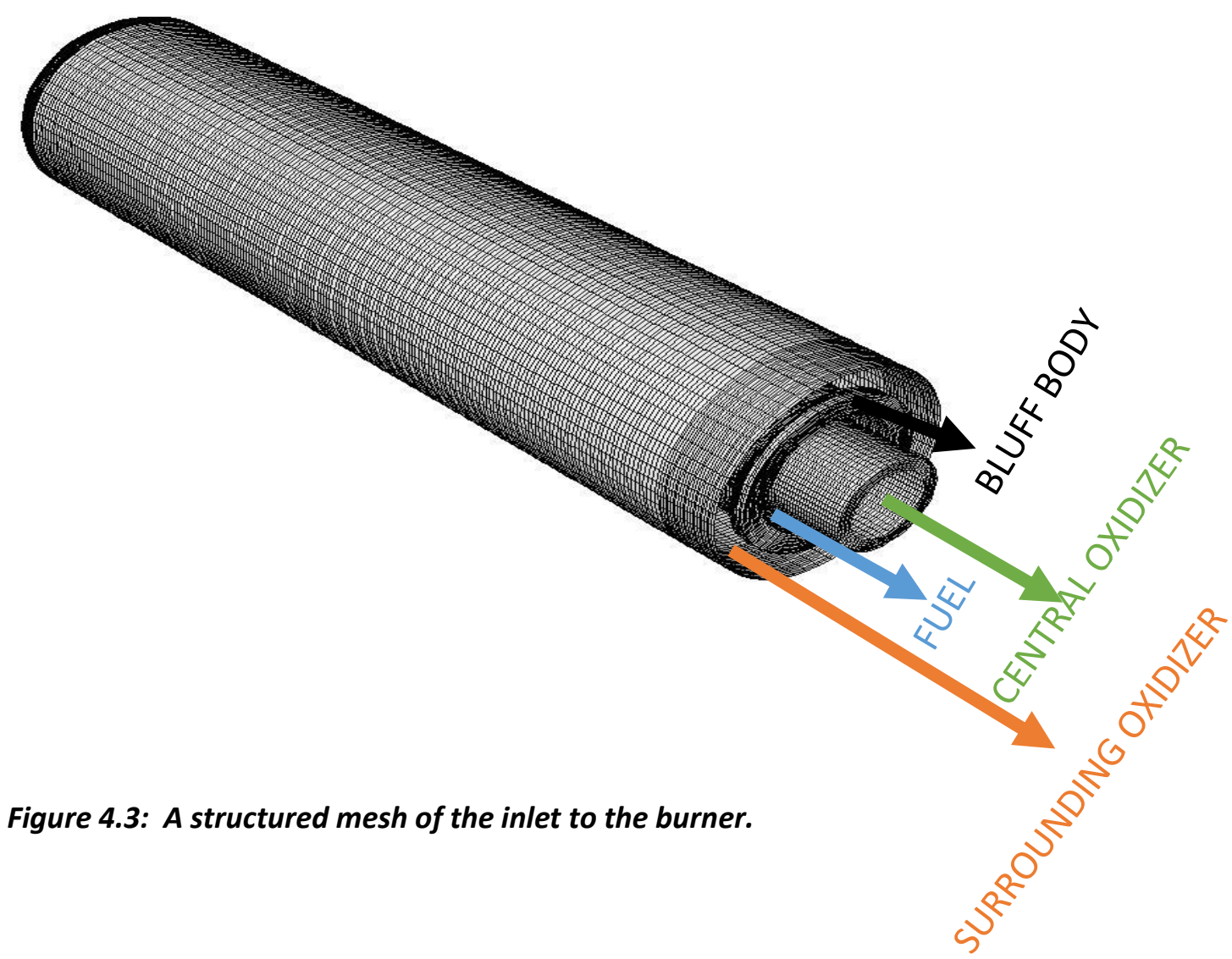

Figure 4.3 shows the exit of Section 1, where mixing of the different streams occurs. A bluff body, which separates the surrounding oxidizer and the fuel, is seen here. As explained earlier in the literature review, this bluff body is used as a flame stabilizer, thereby creating a recirculation zone that ensures continuous burning of fresh incoming streams. 
Table 2: Summary of boundary conditions for the case of $90 \mathrm{~kW}$ coming from coal burning and $10 \mathrm{~kW}$ coming from methane combustion.

\begin{tabular}{|l|l|}
\hline Parameters & Configuration Value \\
\hline Secondary inlet methane mass flow rate & $0.0006 \mathrm{~kg} / \mathrm{s}$ \\
\hline Secondary inlet mole fractions distribution & $50 \%$ of $\mathrm{CH}_{4}$ and $50 \%$ of $\mathrm{CO}_{2}$ \\
\hline Primary inlet: mass flow rate & $0.0088 \mathrm{~kg} / \mathrm{s}$ \\
\hline Primary inlet: mole fractions & $50 \%$ of $\mathrm{CO}_{2}$ and $50 \%$ of $\mathrm{O}_{2}$ \\
\hline Tertiary inlet: mass flow rate & $0.0218 \mathrm{Kg} / \mathrm{s}$ \\
\hline Tertiary inlet: mole fractions & $70 \%$ of $\mathrm{CO}_{2}$ and $30 \%$ of $\mathrm{O}_{2}$ \\
\hline Coal mass flow rate & $0.0035 \mathrm{~kg} / \mathrm{s}$ \\
\hline Coal flow velocity & $0.066 \mathrm{~m} / \mathrm{s}$ \\
\hline Wall quartz temperature & $1000 \mathrm{~K}$ \\
\hline Temperature of the coal tip & $1300 \mathrm{~K}$ \\
\hline Length & $2.0032 \mathrm{~m}$ \\
\hline
\end{tabular}

\subsection{The Solution Methodology}

For RANS and LES, the pressure-based solver with double precision was chosen to solve both the steady-state and the transient governing equations. Specifically, the COUPLED scheme, which simultaneously solves the pressure and momentum equation through an iterative process, is employed to account for the pressure-velocity coupling alongside the STANDARD scheme for pressure interpolations in the transient case, while the SIMPLE scheme [64] is used for the steady state case in both RANS and LES.

For RANS, the $2^{\text {nd }}$-order upwind scheme is used to solve the momentum, turbulent, species, energy and radiation equations. A converged solution was obtained for the cold flow field as well as for $\mathrm{CH}_{4}-\mathrm{O}_{2}$ combustion when the radiative heat transfer SGS model was incorporated into the system. Steady RANS was first obtained before converting to a transient simulation.

For LES (Ch. 7), the dynamic Smagorinsky-Lilly SGS model [47-49] is employed, such that the Smagorinsky constant $\left(C_{s}\right)$ is computed dynamically. The $2^{\text {nd }}$-order bounded central-differencing 
scheme is used to solve the momentum equation, while the turbulent equations, species, energy and radiation equations are solved with the $2^{\text {nd }}$-order upwind scheme. The time-dependent terms are discretized using the bounded $2^{\text {nd }}$-order implicit scheme. Transient LES simulation was done from a transient RANS simulation, i.e., a fully develop transient RANS was obtained, first, and then further converted into the LES. 


\section{Results}

In this chapter, the results of the numerical simulation for the $100 \mathrm{~kW}$ burner are presented.

Firstly, steady RANS is analyzed followed by unsteady RANS calculation for different time steps.

\subsection{Steady RANS Calculation}

Figure $5.1,5.2,5.3$ respectively present the instantaneous temperature snapshot as well as the radial distribution of the temperature and the turbulent kinetic energy obtained from steady RANS in a $100 \mathrm{~kW}$ burner, where $90 \mathrm{~kW}$ comes from coal and $10 \mathrm{~kW}$ from $\mathrm{CH}_{4}$ combustion.

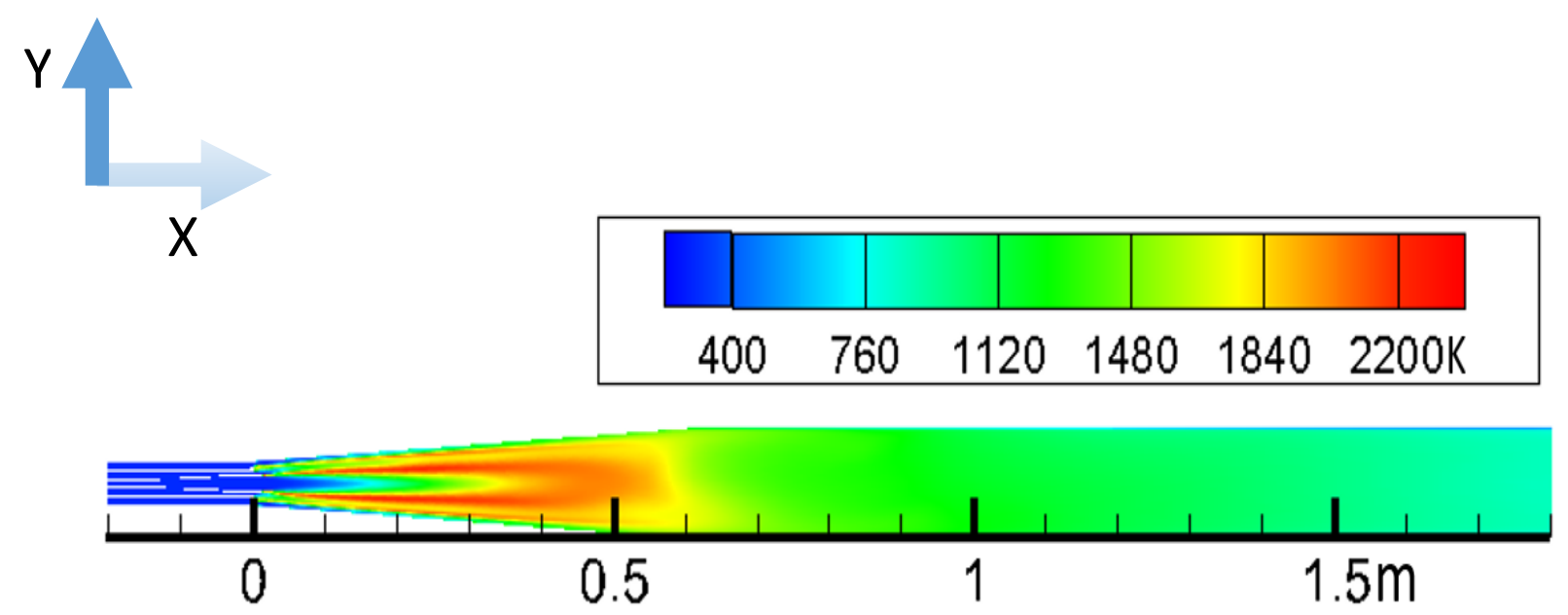

Figure 5.1: Steady RANS: temperature snapshot for $90 \mathrm{~kW}$ from coal and $10 \mathrm{~kW}$ form $\mathrm{CH} 4$ combustion.

As can be seen in Fig. 5.1, the temperature contour plot shows some flame asymmetry although this geometry has been designed to be a symmetric. In other to identify the possible causes of such an asymmetric behavior and, perhaps, to know at which conditions this unique behavior emerges, the temperature and turbulent kinetic energy distributions are plotted at different locations, see Figs. 5.2 and 5.3. Specifically, Fig 5.2 shows the radial temperature distribution at different locations in the axial axis. It is observed from this figure that flame asymmetry increases downstream in the axial direction. Moreover, this could be a result of the combustion process 
occurring at the burner inlet, namely, i.e. there could be a shear layer instability which occurs upstream where the fuel is ignited.

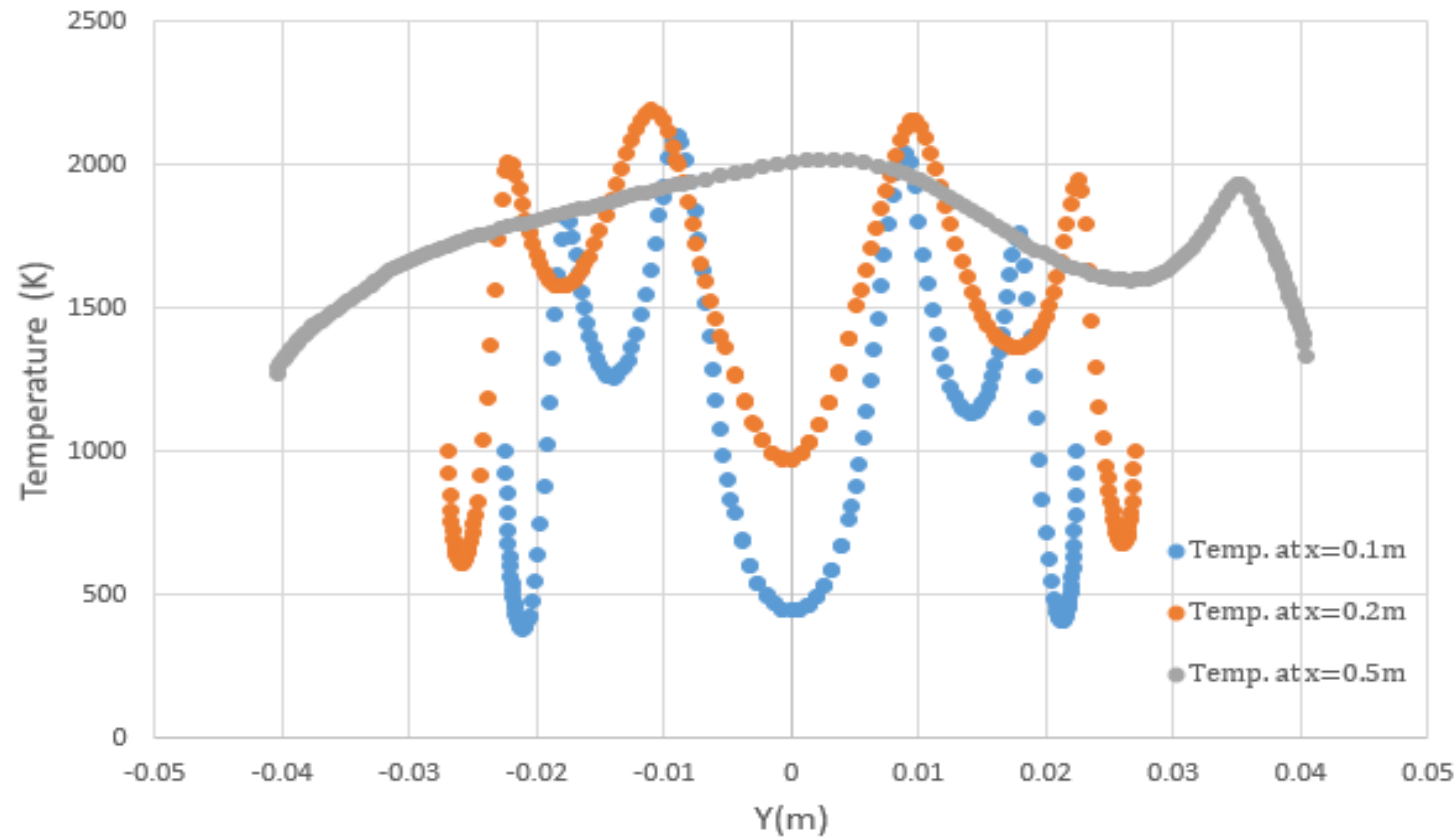

Figure 5.2: Steady RANS: temperature at various locations for $90 \mathrm{~kW}$ from coal and $10 \mathrm{~kW}$ from $\mathrm{CH}_{4}$.

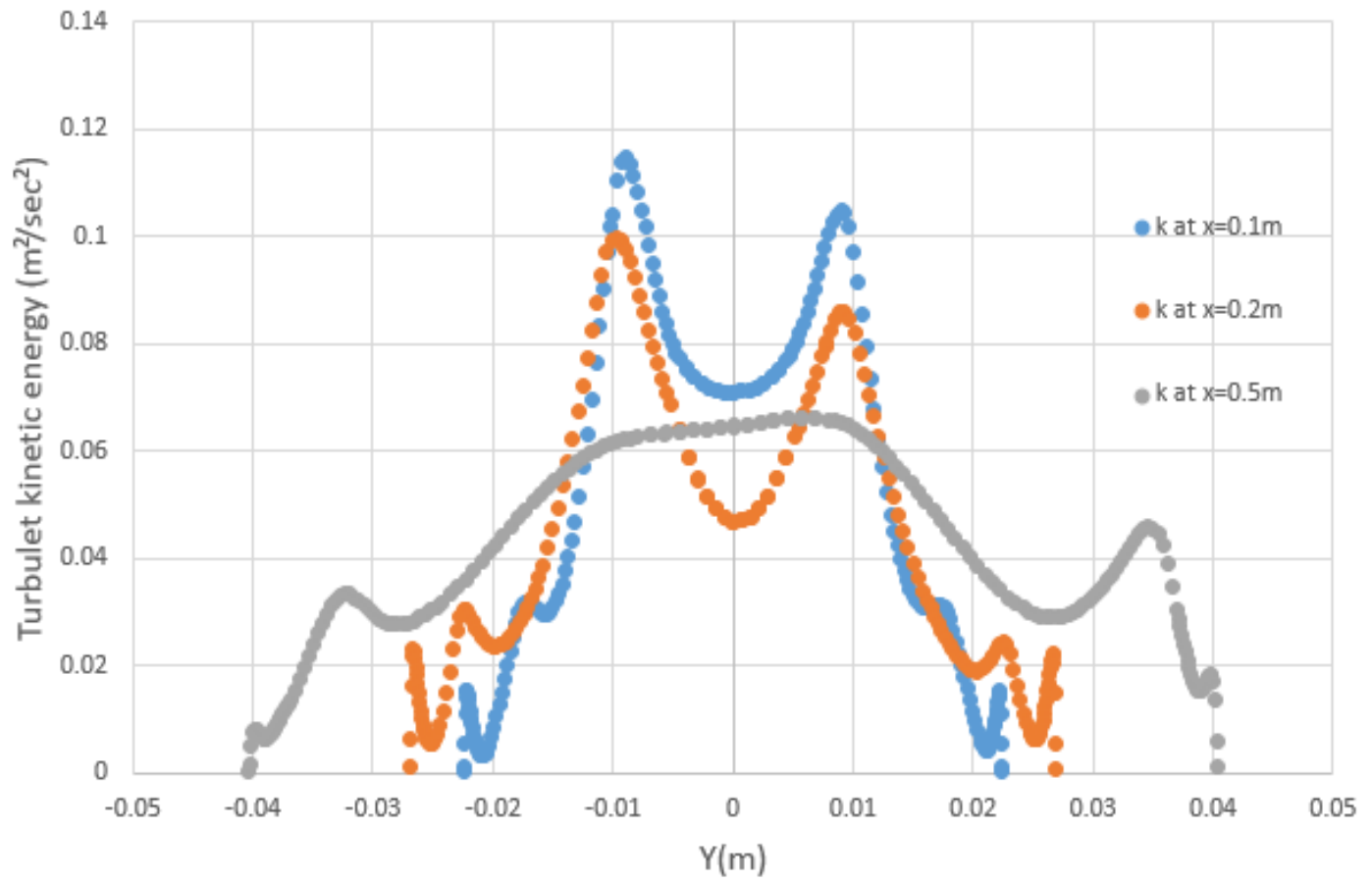

Figure 5.3: Steady RANS: specific turbulent kinetic energy at various locations for $90 \mathrm{~kW}$ from coal and $10 \mathrm{~kW}$ from $\mathrm{CH}_{4}$ burning. 
Figure 5.3 shows the same effect. As seen, there is clearly flame asymmetry which poses serious challenge to the stability of the burner. Thus, different strategies to solve this problem have been undertaken as discussed below.

5.1.1 Study of an Impact of Coal - Steady RANS simulation is conducted to investigate the influence of various streams of the fuel on flame symmetry. In this respect, the energy of the system is matched to the previous lab-scale reactor of $100 \mathbf{k W}$. Specifically, methane-oxygen simulation is done first and coal is subsequently added to the system.

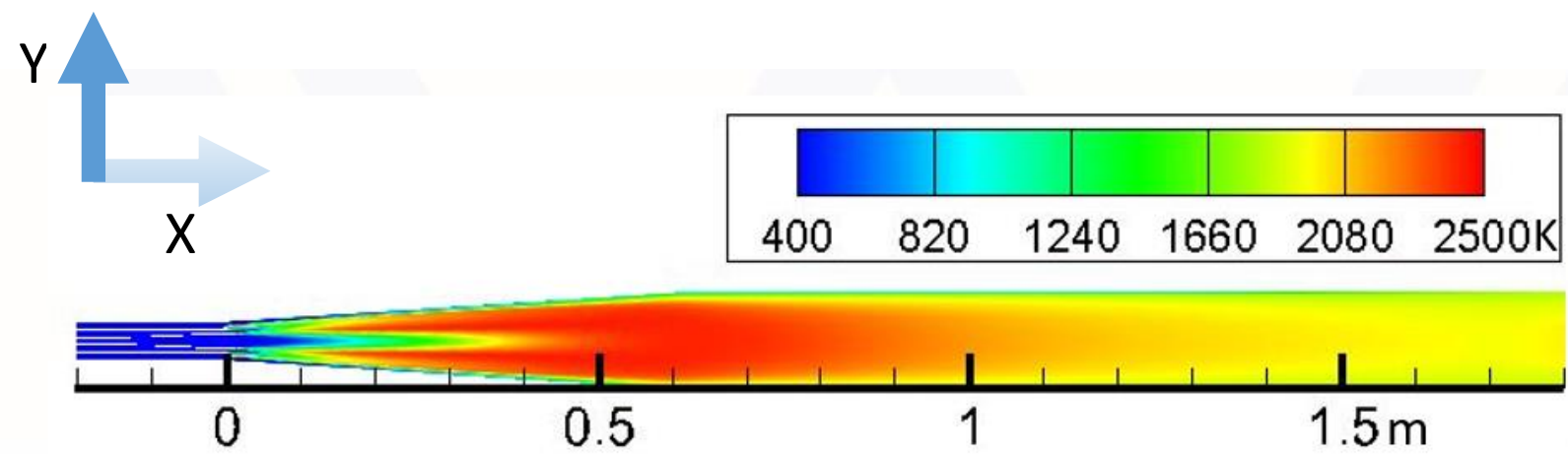

Figure 5.4: Color temperature snapshot for pure methane combustion of power $100 \mathrm{~kW}$.

5.1.1.1 Pure Methane - Oxygen Combustion - We started with the situation of purely gaseous methane-oxygen $\left(\mathrm{CH}_{4}+\mathrm{O}_{2}\right)$ inlet flow, burning of which generates a power of $100 \mathrm{~kW}$. The fuel in this case is therefore pure $\mathrm{CH}_{4}$ such that $100 \mathrm{~kW}$ of power is generate by $\mathrm{CH}_{4}-\mathrm{O}_{2}$ combustion. It is noted, in this respect, that while it is coal combustion which is of our ultimate interest, this particular case has been simulated to check flame stability. Figures 5.4, 5.5 and 5.6 respectively present the color temperature snapshot as well as the radial distributions of the turbulent kinetic energy $(\mathrm{k})$ and the flow velocity taken at different axial locations. It is seen that the flame is symmetric as there is no any trace of the combustion instability (asymmetry) which proves that the system is hydrodynamically stable. The results for this case are obtained by steady RANS. 


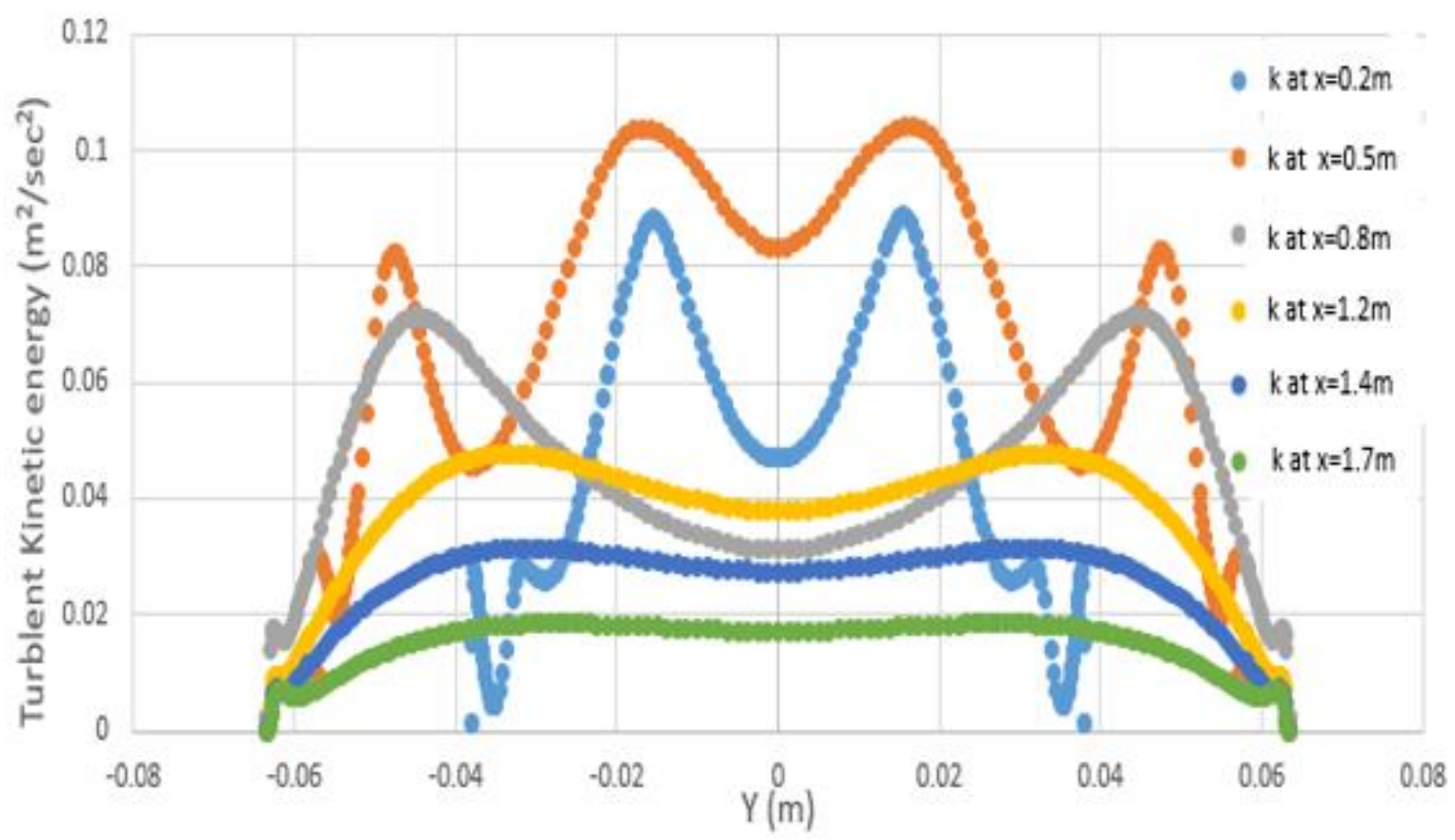

Figure 5.5: (Radial) y-distributions of the turbulent kinetic energy $k$ taken at different axial locations, $x=0.2 \mathrm{~m}, 0.5 \mathrm{~m}, 0.8 \mathrm{~m}, 1.2 \mathrm{~m}, 1.4 \mathrm{~m}$, and $1.7 \mathrm{~m}$, for purely methane burning of power $100 \mathrm{~kW}$.

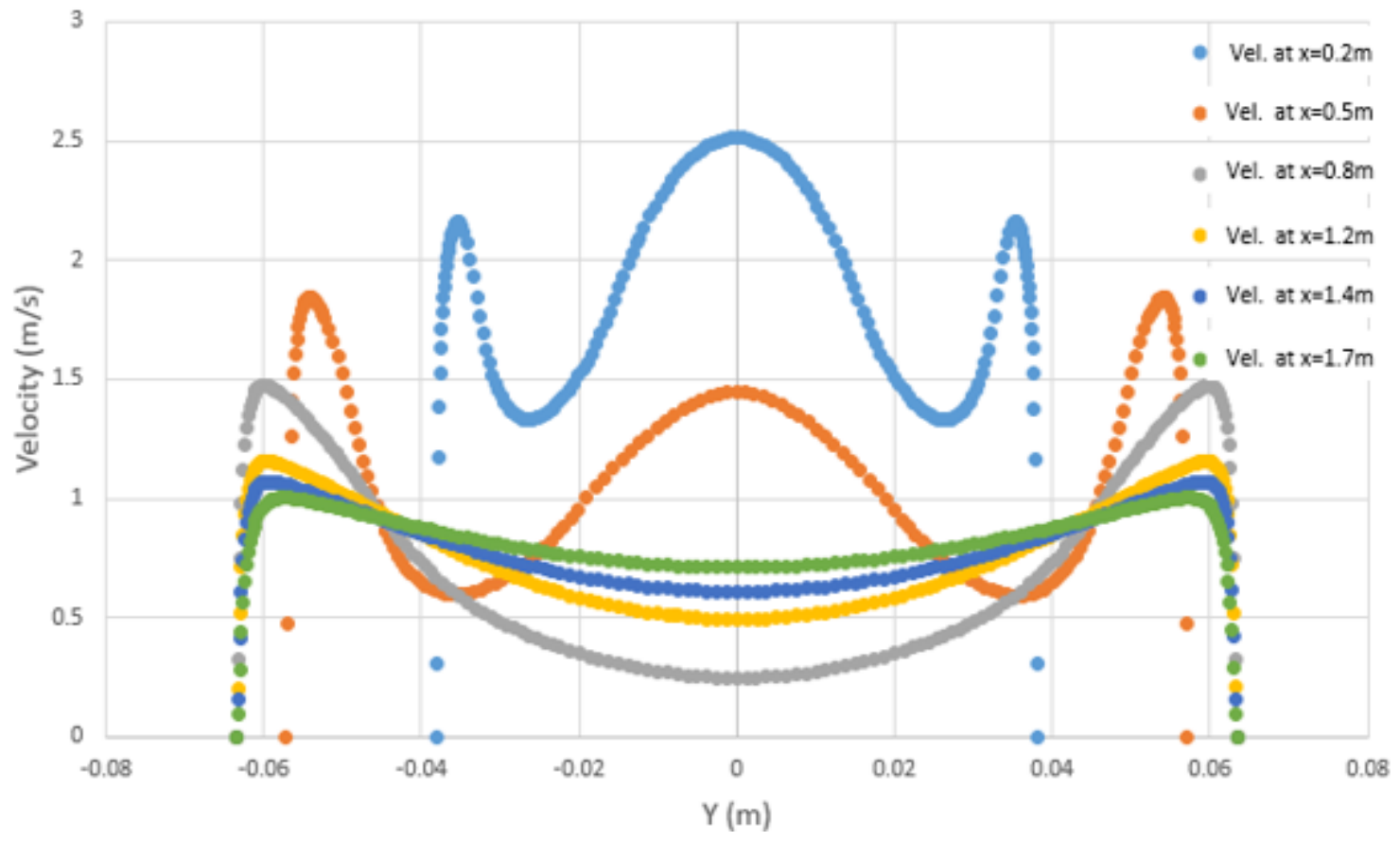

Figure 5.6: (Radial) y-distributions of the flow velocity field taken at different axial locations, $x=0.2 \mathrm{~m}, 0.5 \mathrm{~m}, 0.8 \mathrm{~m}, 1.2 \mathrm{~m}, 1.4 \mathrm{~m}$, and $1.7 \mathrm{~m}$, for purely methane burning of power $100 \mathrm{~kW}$. 
5.1.1.2 10\% Coal and 90\% Methane - Oxygen Combustion - In contrast to the previous case, we next injected a portion of coal, which burning will produce a power of $\mathbf{1 0} \mathbf{k W}$, while the power originated from $\mathrm{CH}_{4}$ burning is reduced to $90 \mathrm{~kW}$, with the total power remained at $\mathbf{1 0 0 ~} \mathbf{k W}$. In fact, this is in line with our systematic approach of determining if there is an influence of coal on the flame symmetry. Specifically, Figures. 5.7, 5.8, and 5.9 respectively show the instantaneous color temperature snapshots as well as the radial distributions of the temperature and specific turbulent kinetic energy $(k)$ at various axial locations. It is seen that symmetry is violated in this case. Again, this simulation run was performed using steady RANS.

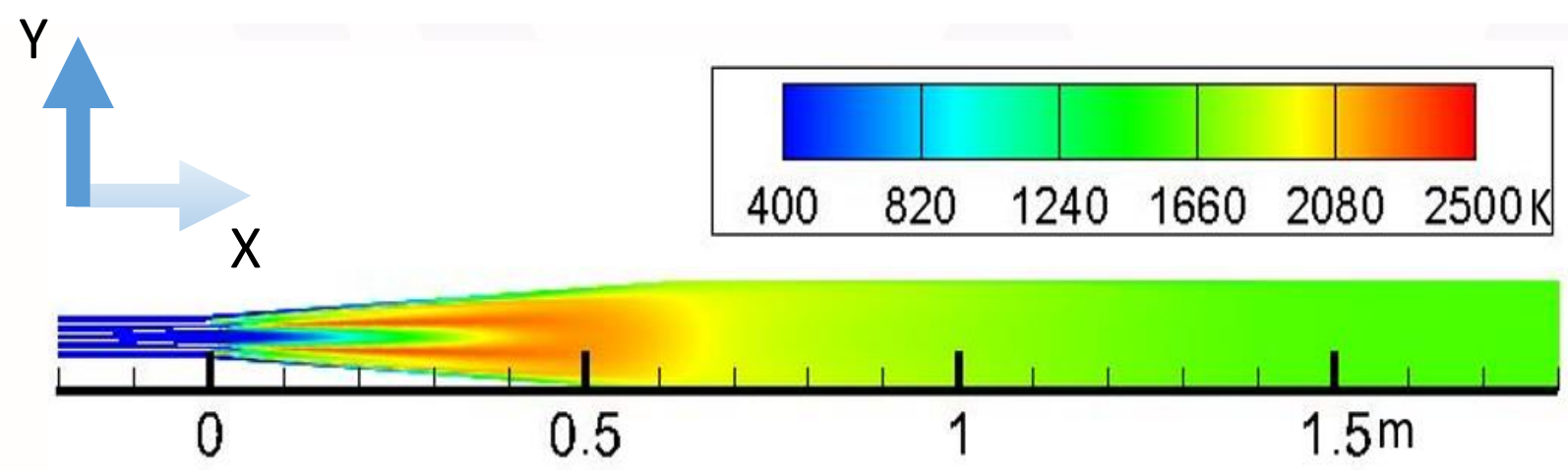

Figure 5.7: A temperature snapshot for the case of $10 \mathrm{~kW}$ generated from coal burning and $90 \mathrm{~kW}$ from that of $\mathrm{CH}_{4}$. 


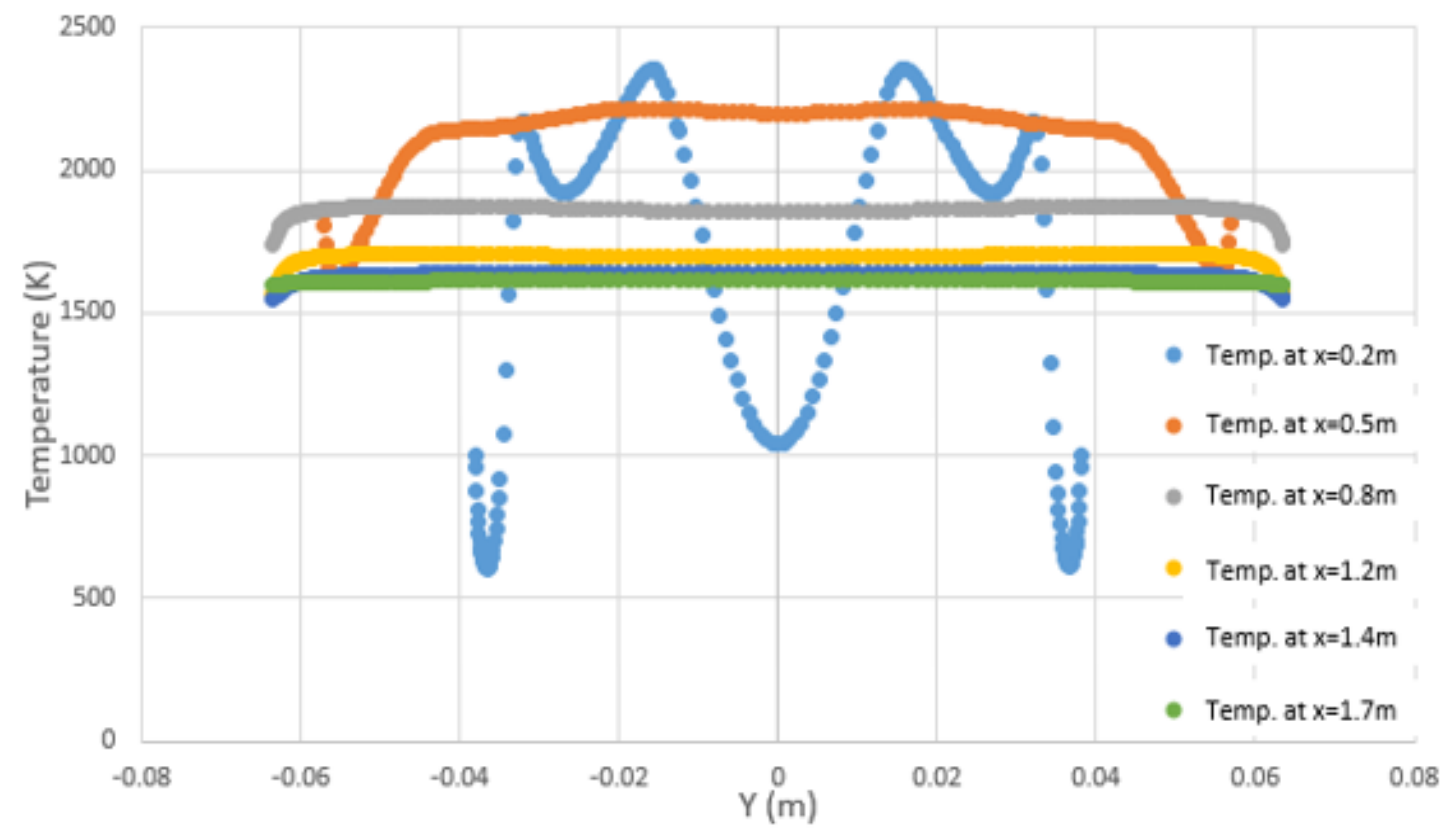

Figure 5.8: (Radial) $y$-distributions of the temperature (T) taken at different axial locations, $x=0.2 \mathrm{~m}$, $0.5 \mathrm{~m}, 0.8 \mathrm{~m}, 1.2 \mathrm{~m}, 1.4 \mathrm{~m}$, and $1.7 \mathrm{~m}$, for the case of $10 \mathrm{~kW}$ generated from coal burning and $90 \mathrm{~kW}$ from that of $\mathrm{CH}_{4}$.

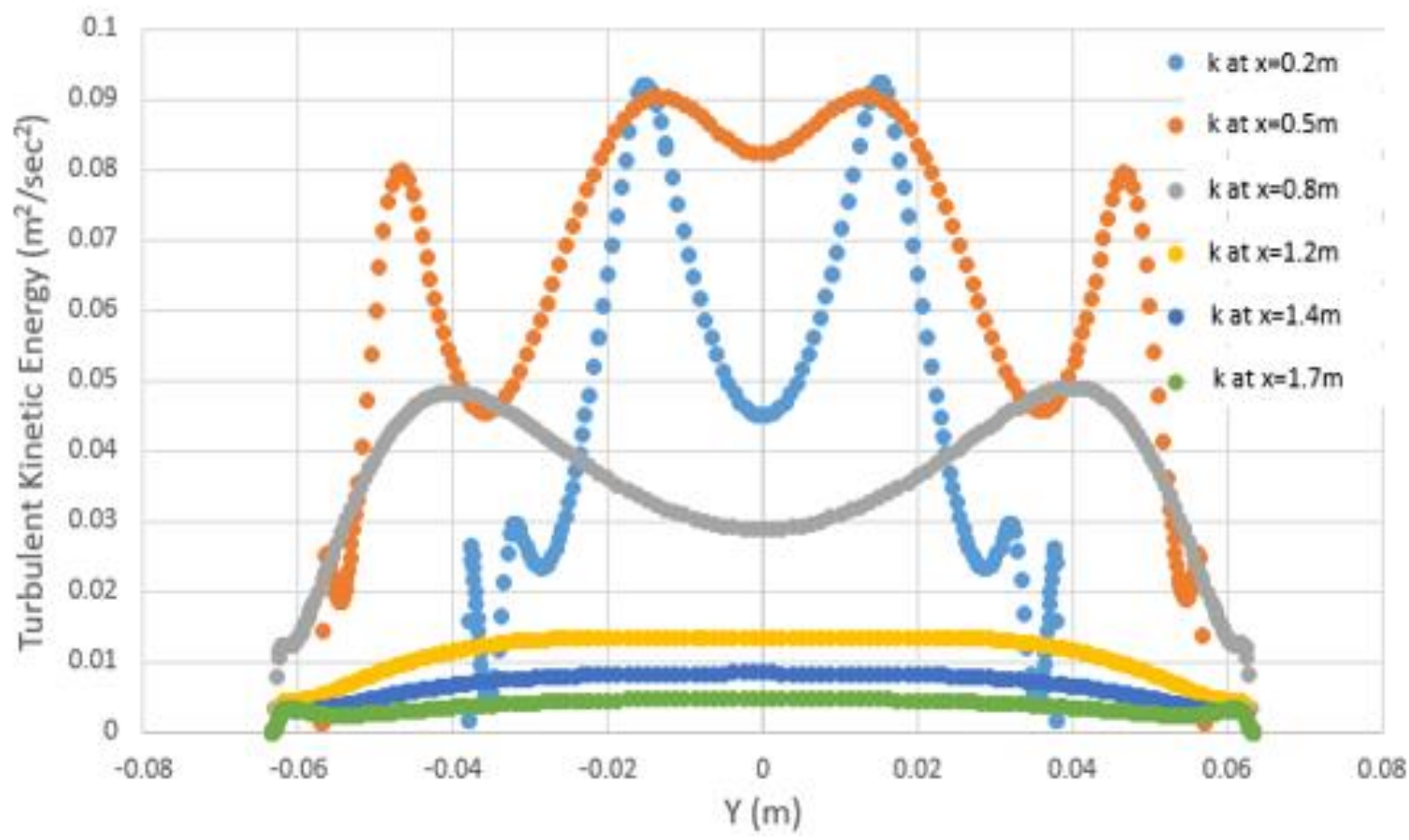

Figure 5.9: (Radial) y-distributions of the specific turbulent kinetic energy taken at different axial locations, $x=0.2 \mathrm{~m}, 0.5 \mathrm{~m}, 0.8 \mathrm{~m}, 1.2 \mathrm{~m}, 1.4 \mathrm{~m}$, and $1.7 \mathrm{~m}$, for the case of $10 \mathrm{~kW}$ from coal burning and $90 \mathrm{~kW}$ from that of $\mathrm{CH}_{4}$. 


\subsubsection{20\% Coal - 80\% Methane - Oxygen Combustion - We subsequently increased the}

injected portion of coal further such that coal burning generated a power of $\mathbf{2 0} \mathbf{~ k W}$, with the reduction of methane burning to generate a power of $80 \mathrm{~kW}$, such that the total power remained $100 \mathrm{~kW}$. The results are shown in Figures 5.10, 5.11, and 5.12 for the color temperature snapshot as well as the $y$-distributions of temperature and velocity at various axial locations, respectively. A very close look would reveal slight asymmetry of the flame shape in that case. Consequently, I can reasonably conclude that a (but not the only) reason for flame asymmetry is coal injection.
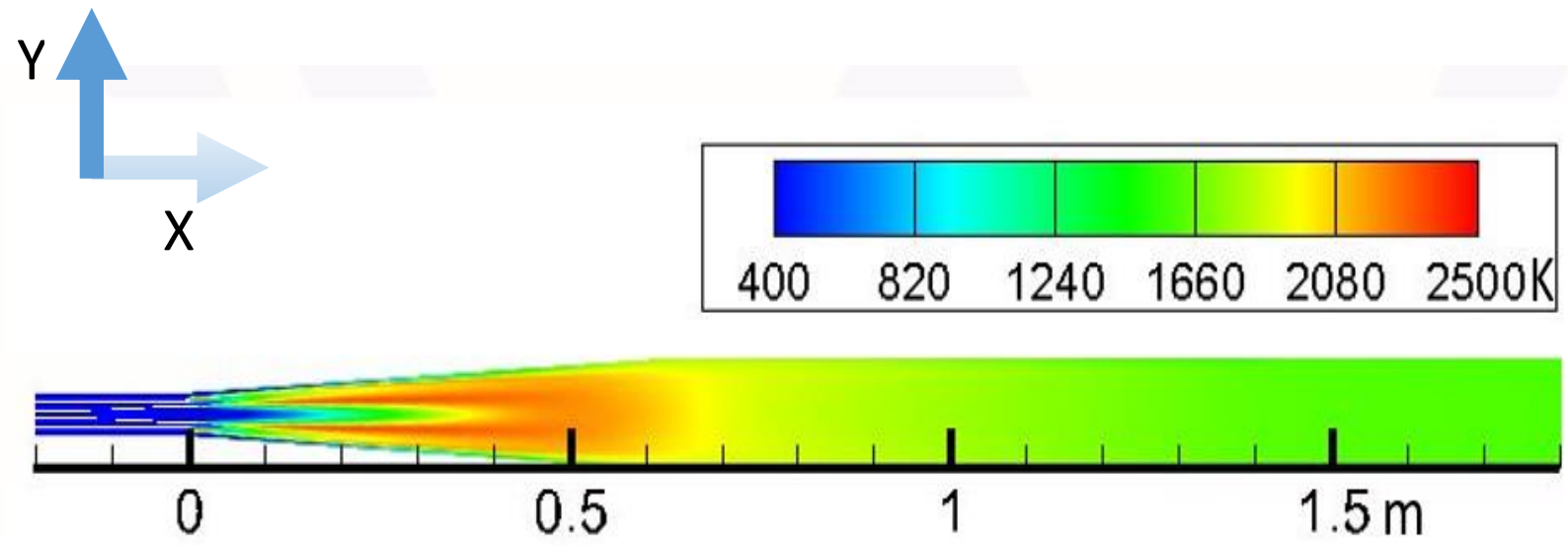

Figure 5.10: A temperature snapshot for $20 \mathrm{~kW}$ generated from coal burning and $80 \mathrm{~kW}$ from $\mathrm{CH}_{4}$. 


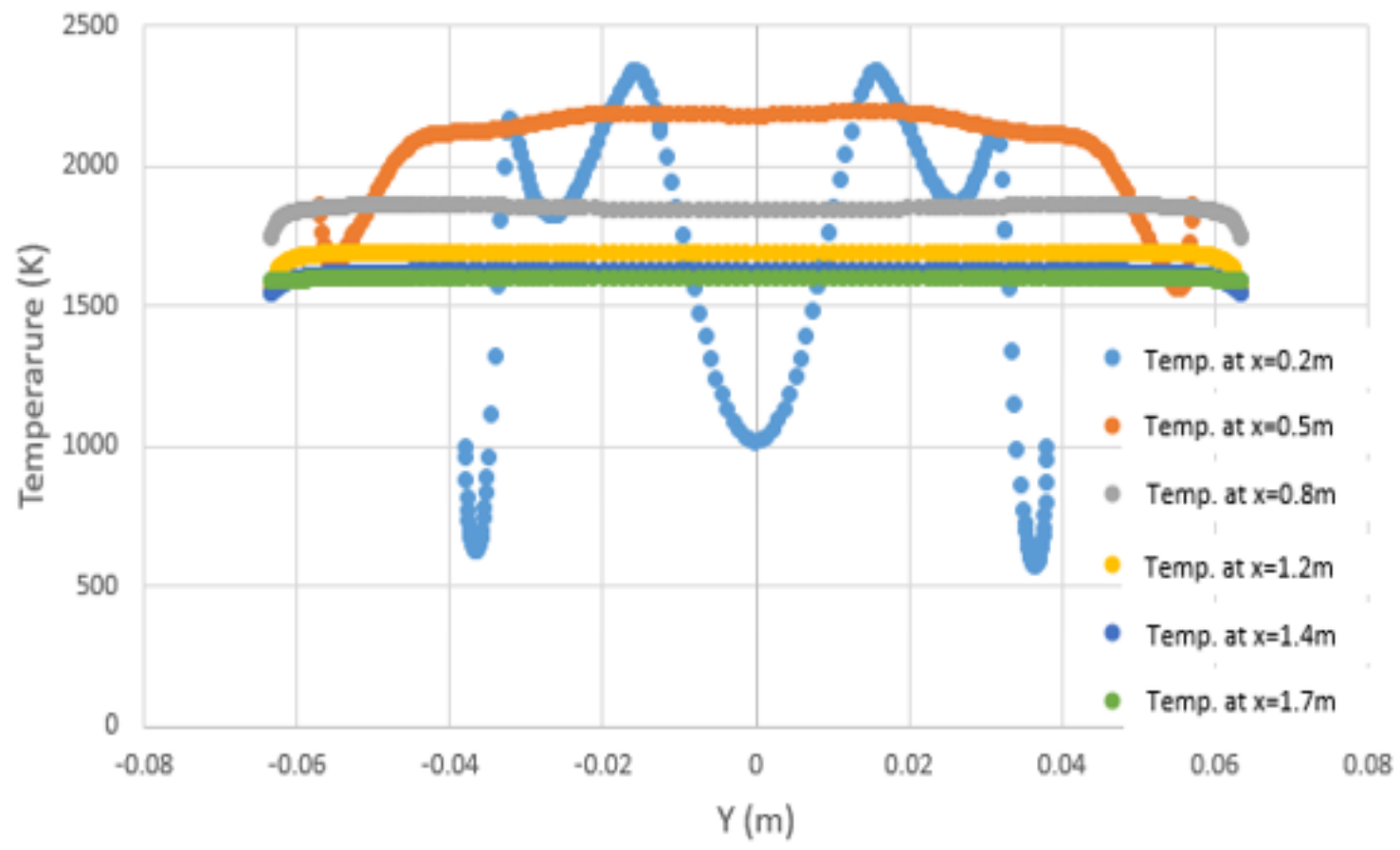

Figure 5.11: Temperature (radial) y-distributions taken at different axial locations, $x=0.2 \mathrm{~m}, 0.5 \mathrm{~m}, 0.8$ $\mathrm{m}, 1.2 \mathrm{~m}, 1.4 \mathrm{~m}$, and $1.7 \mathrm{~m}$, for the case of $20 \mathrm{~kW}$ generated from coal burning and $80 \mathrm{~kW}$ from $\mathrm{CH}_{4}$.

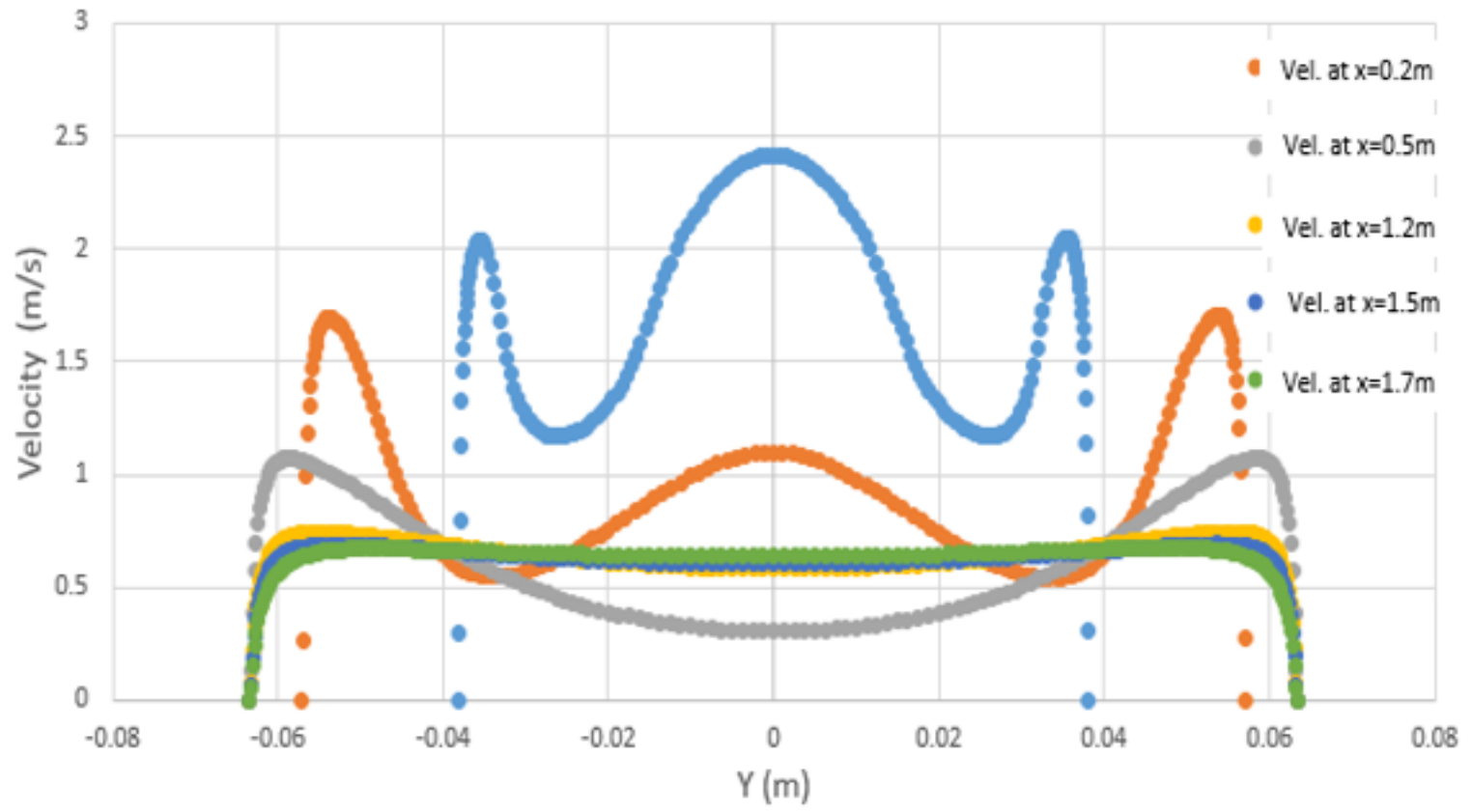

Figure 5.12: (Radial) y-distributions of the flow velocity taken at different axial locations, $x=0.2 \mathrm{~m}, 0.5$ $\mathrm{m}, 0.8 \mathrm{~m}, 1.2 \mathrm{~m}, 1.4 \mathrm{~m}$, and $1.7 \mathrm{~m}$, for $20 \mathrm{~kW}$ generated from coal burning and $80 \mathrm{~kW}$ from that of $\mathrm{CH}_{4}$. 


\subsection{Unsteady RANS Calculation}

Unsteady RANS simulations have been performed to get saturation in time to a steady solution. Various saled time steps were employed in these simulation runs, namely: $0.1 \mathrm{~s}, 0.01 \mathrm{~s}$ and 0.001 $\mathrm{s}$, and all the results show periodic oscillations. These simulations are performed to support the experimental setup in the WUSTL, which has been designed to produce $100 \mathrm{~kW}$ of power. In our simulations, $90 \mathrm{~kW}$ is supplied from coal burning and $10 \mathrm{~kW}$ from that of $\mathrm{CH}_{4}$.

\subsubsection{Unsteady RANS Using Time Step of 0.1sec}

Figures $5.13,5.14$ and 5.15 show the transient RANS for the time step of $0.1 \mathrm{~s}$. Specifically, the temperature fluctuations at various locations are shown in Figs. 5.13 and 5.14, Fig. 5.15 shows the temperature contour plot. It is clearly seen from these figures that there is a large variation in temperature, with high temperature observed in the shear layer.

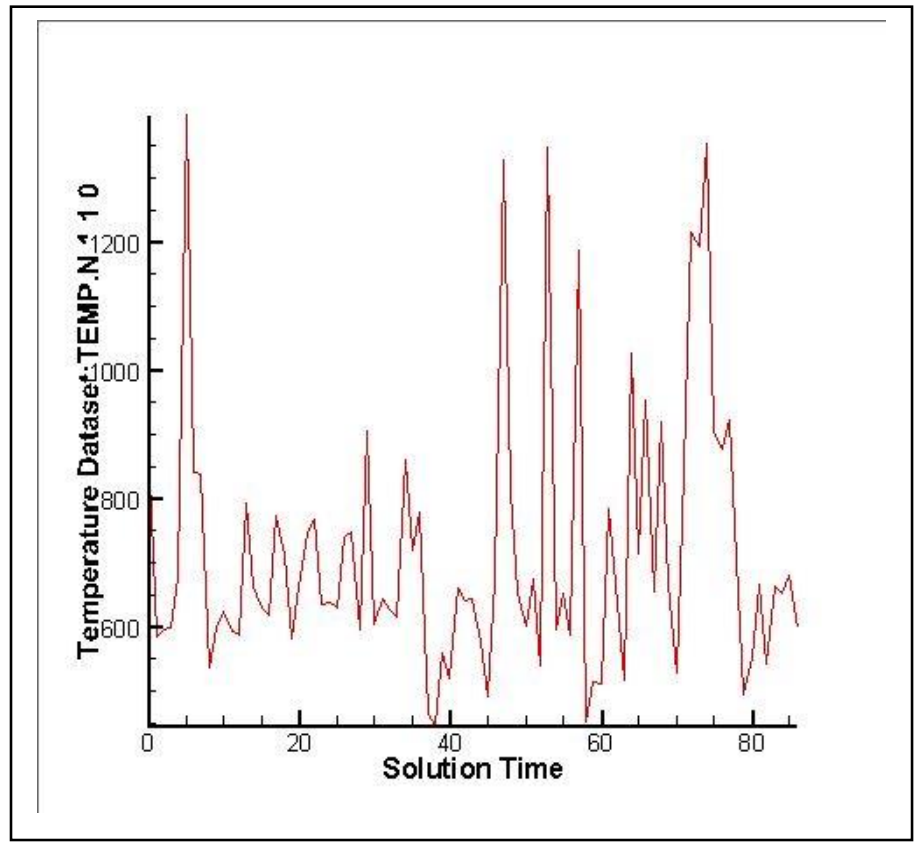

Figure 5.13: Time evolution of the temperature taken at the locus: $x=0.028 m, y=-0.008 m$

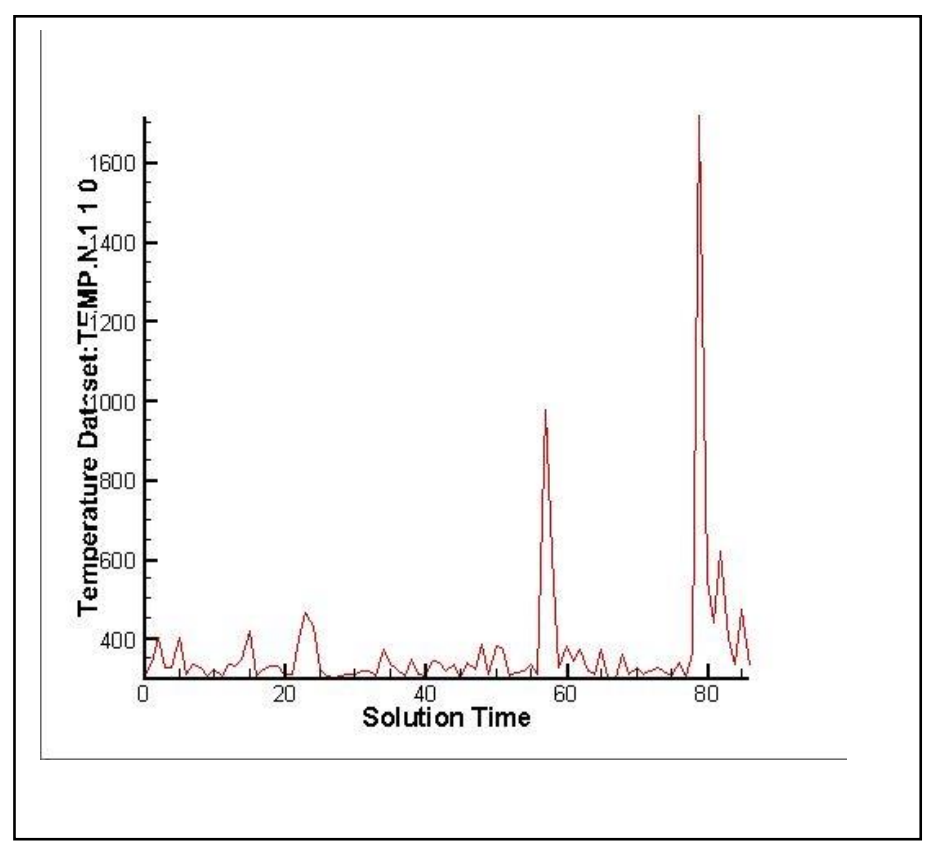

Figure 5.14: Time evolution of the temperature taken at the locus $x=0.006 \mathrm{~m}, y=0.021 \mathrm{~m}$. 


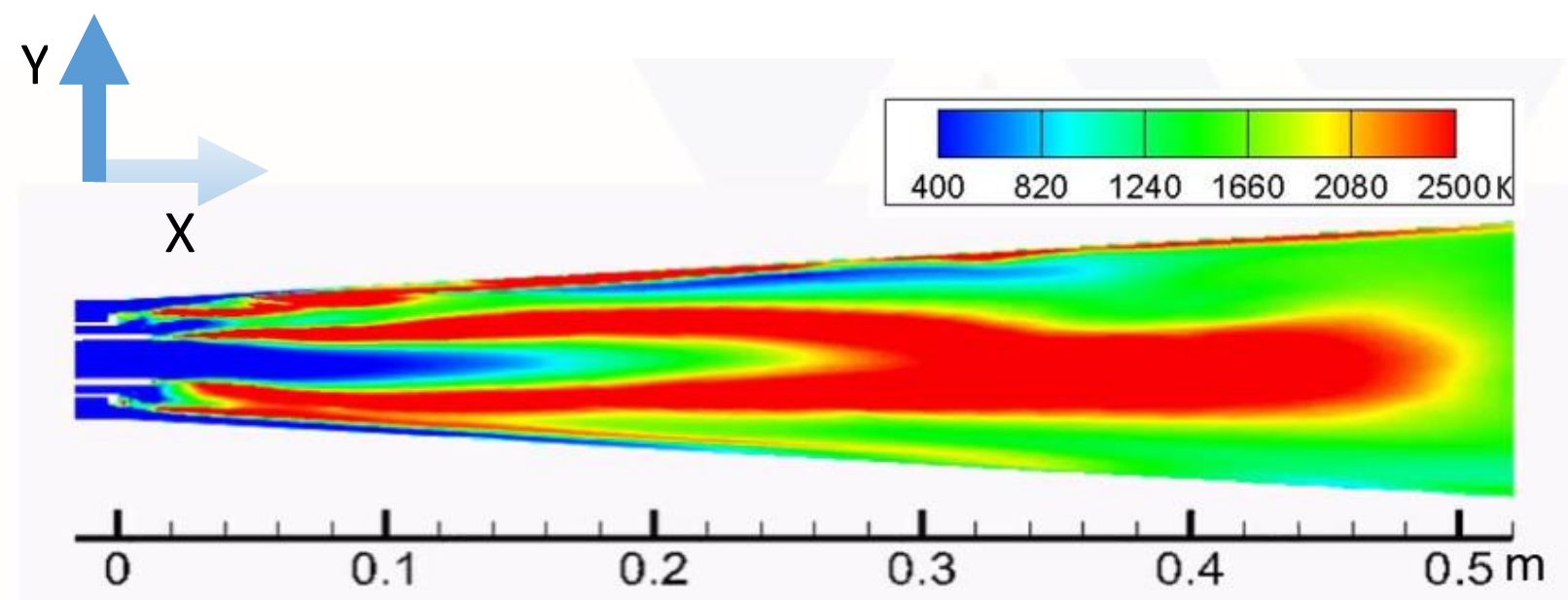

Figure 5.15: An instantaneous temperature snapshot taken at $t=10$ sec in unsteady RANS with a time step of $0.1 \mathrm{sec}$.

\subsubsection{Unsteady RANS Using Time Step of 0.01sec}

Figures $5.16,5.17$ and 5.18 show the temperature fluctuations at two locations close to the burner tip as well as the instantaneous temperature contour plot using time step of $0.01 \mathrm{sec}$. As clearly seen, the flame still fluctuates but a more symmetric flame is observed.

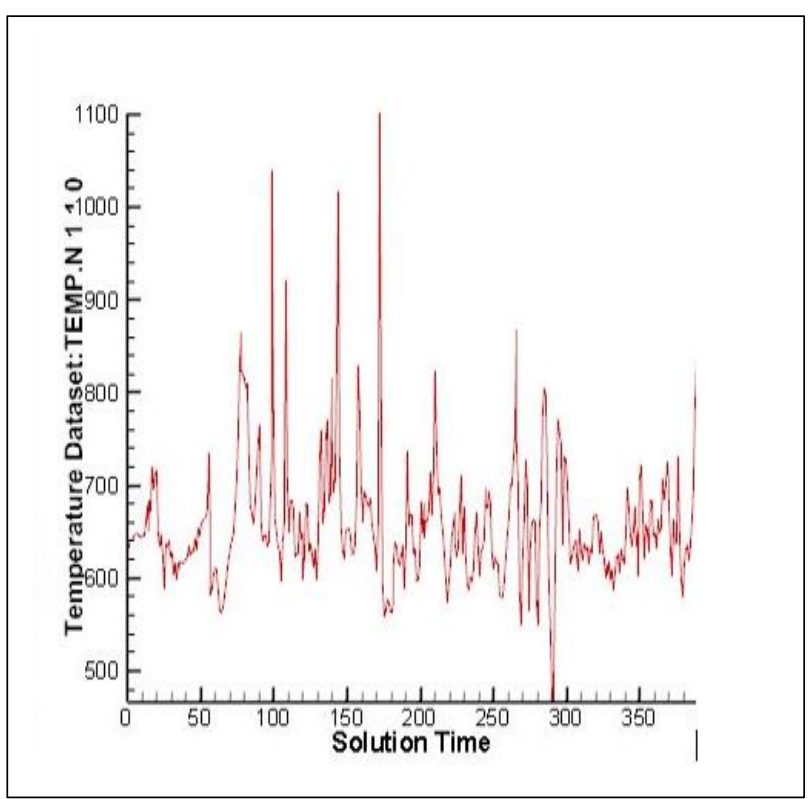

Figure 5.16: Time evolution of the temperature taken at the locus: $x=0.028 \mathrm{~m}, y=-0.008 \mathrm{~m}$.

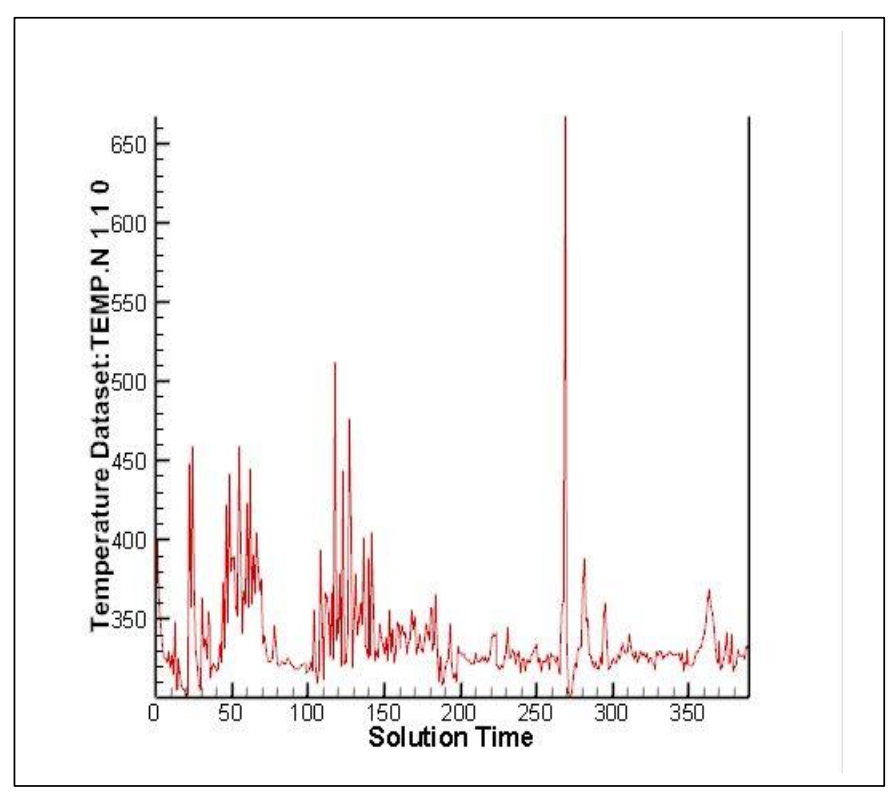

Figure 5.17: Time evolution of the temperature taken at the locus $x=0.006 \mathrm{~m}, y=0.021 \mathrm{~m}$. 


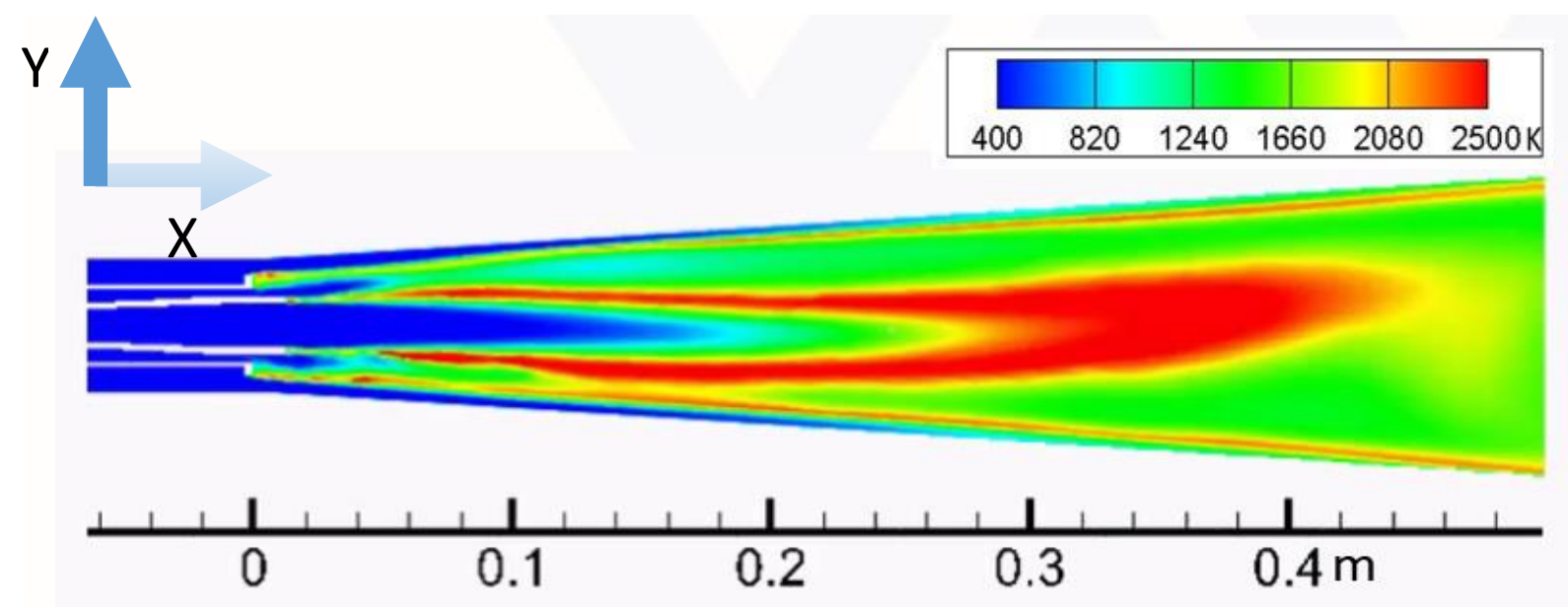

Figure 5.18: An Instantaneous temperature snapshot taken at $t=4 \mathrm{sec}$ in unsteady RANS with a time step of $0.01 \mathrm{sec}$.

Furthermore, a discrete look at the temperature fluctuations in Figs. 5.17 and 5.18 shows some instantaneous temperature jump close to the burner region. This is suspected to be the result of the thermal boundary conditions at the bluff body. In addition, qualitative analysis of these results showed occurrence of the vortex shedding when a combination of $\mathrm{O}_{2}$ and $\mathrm{CO}_{2}$ gases ( 50 $\%$ and $50 \%$ ), flowing from the tertiary inlet passes over the bluff body in the burner used to stabilize a flame. This is also predicted to be a potential reason for the periodic flame oscillations observed in the current simulations.

\subsection{Analysis of Flame Oscillations}

Furthermore, this thesis is focused on identifying the possible causes of the methane-assisted oxy-coal flame oscillations observed earlier. Specifically, we decided to proceed as follows:

1) First, we studied the impact of varying thermal boundary conditions at the coal tip (bluff body), which is assumed to be the best representation of the physical behavior.

2) Second, we aimed to identify the (range of) frequency at which such an oscillating trend occurs. 


\subsubsection{Effect of Thermal Boundary Conditions at the Coal Tip}

Detailed observation of the combustion process nearby the coal tip has driven us to a hypothesis about an influence of a high temperature therein. To verify this hypothesis, various thermal boundary conditions for the coal tip have been employed and scrutinized as summarized below.

5.3.1.1 Mixed Thermal Condition - The temperature of the free stream was set to $650 \mathrm{~K}$, with the heat transfer coefficient being $150 \mathrm{~W} / \mathrm{m}^{2} \mathrm{~K}$. Figure 5.19 presents the temperature contour plot for such a mixed thermal boundary condition. It has been seen that the oscillations still exist in that case. In addition, Figs. 5.20 - 5.21 monitor the temperature evolution in the two selective locations in this simulation run.

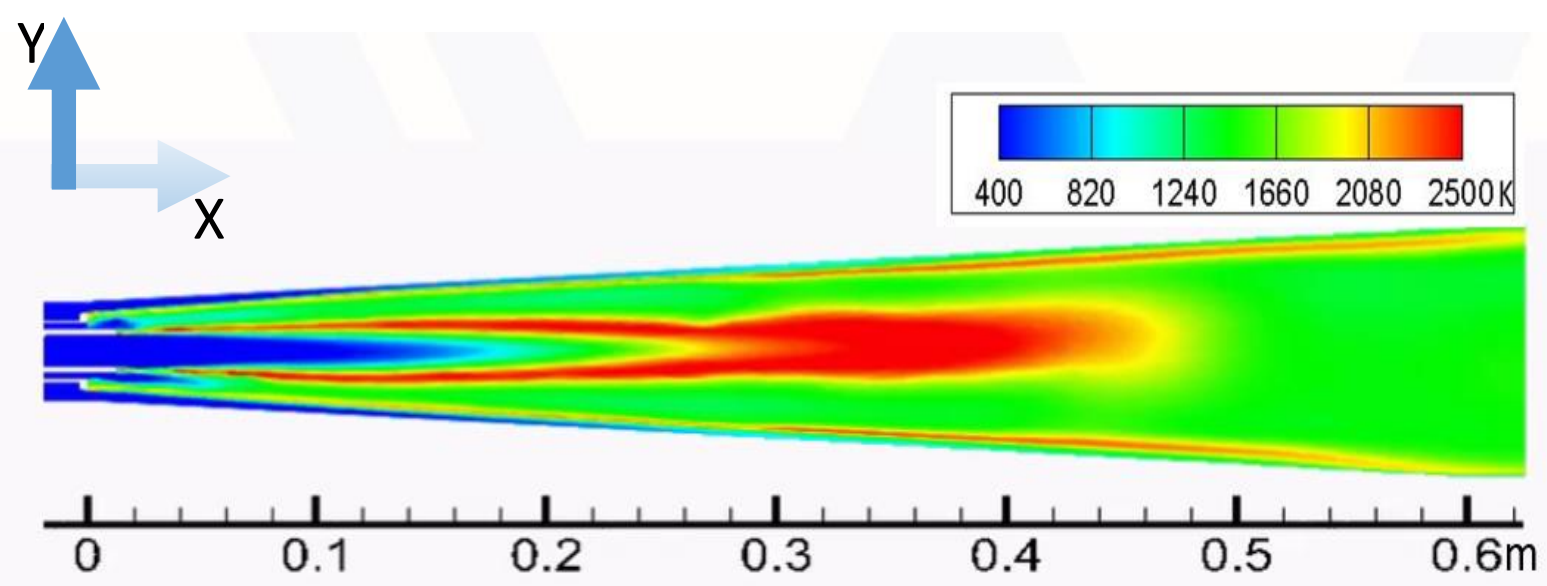

Figure 5.19: An instantaneous temperature contour for a mixed thermal boundary condition.

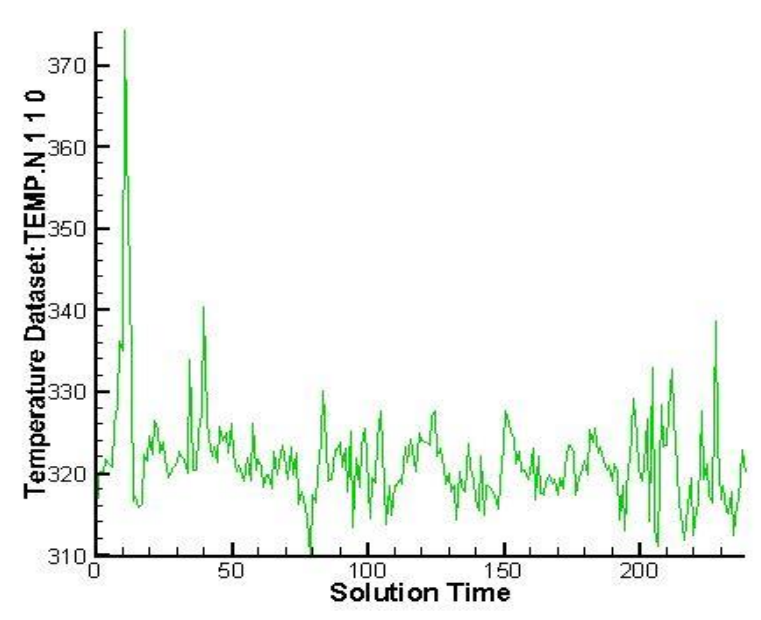

Figure 5.20: Time evolution of the temperature measured at the monitor point $x=0.006 \mathrm{~m}$, $y=0.021 \mathrm{~m}$

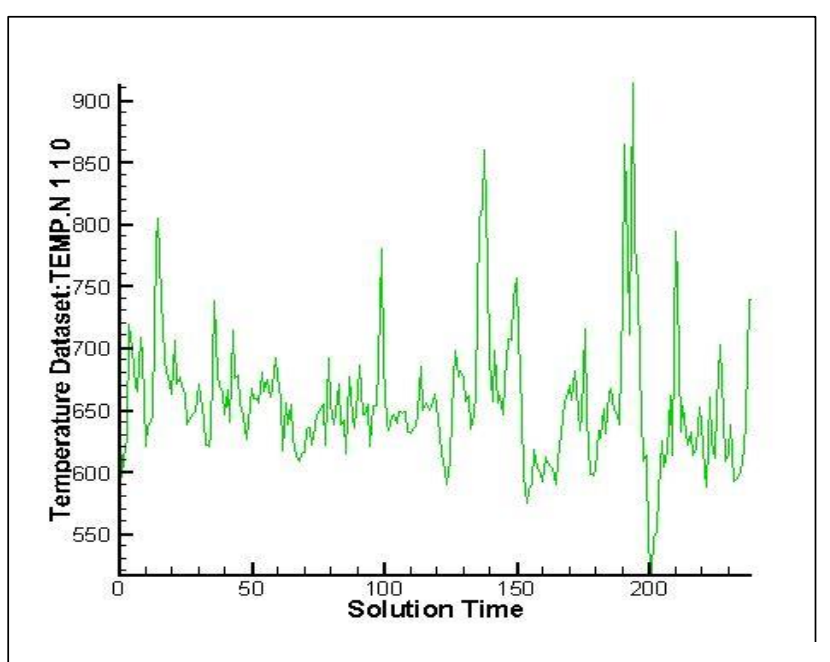

Figure 5.21: Time evolution of the temperature measured at the monitor point: $x=0.02793 \mathrm{~m}$, $y=-0.008272 m$ 
5.3.1.2 Adiabatic wall conditions - Subsequently, we have set the walls of the coal tip to be adiabatic in order to eliminate the effect of heat transfer at the walls. Figure 5.22 below shows the respective temperature contour taken after the simulation has processed two flow through times (FTT), with the FTT defined as the time it takes for the flow to go through the computational domain. Figures 5.23 and 5.24 monitor for temperature evolution in the two selective locations.

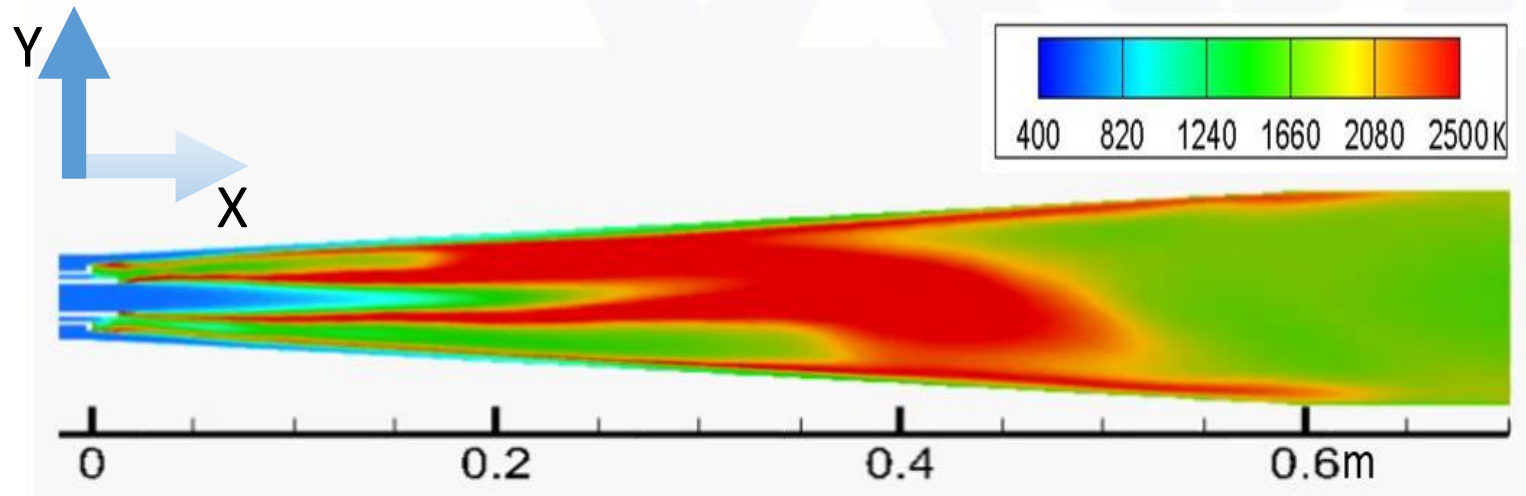

Figure 5.22: Instantaneous temperature contour for an adiabatic thermal boundary condition

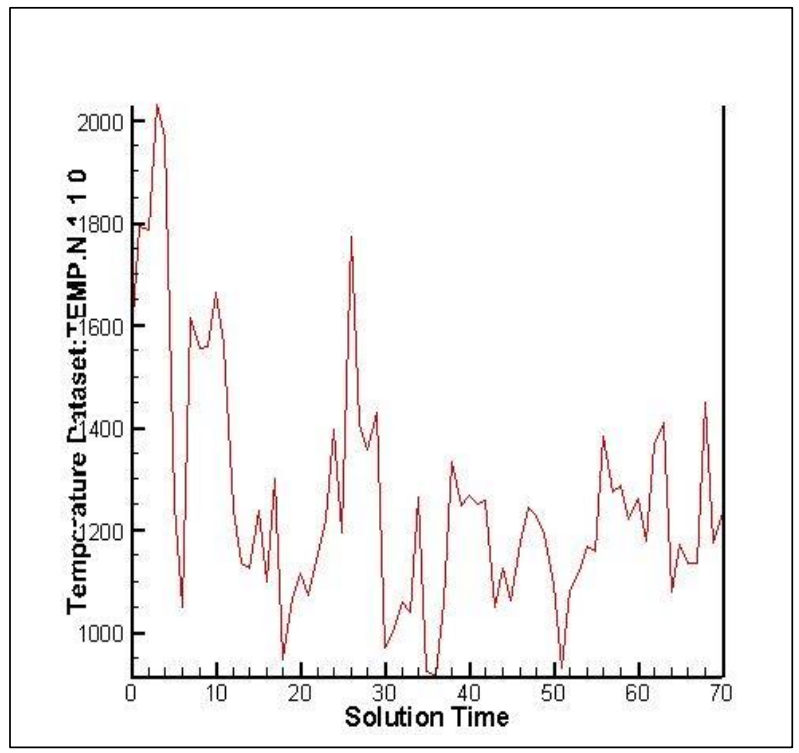

Figure 5.23: Time evolution of the temperature measured at the monitor point: $x=0.028 \mathrm{~m}$, $y=-0.008 m$.

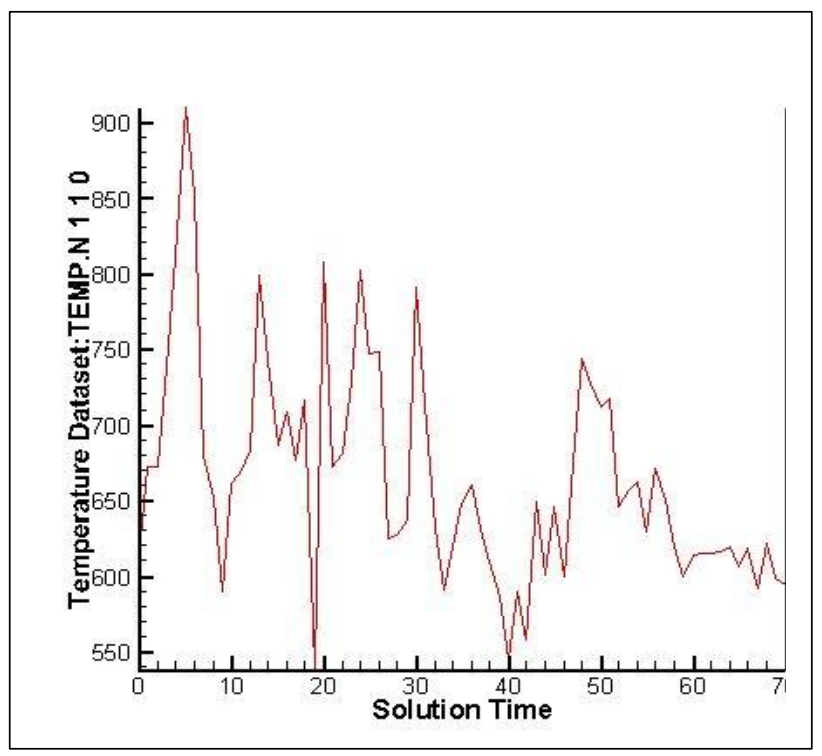

Figure 5.24: Time evolution of the temperature measured at the monitor point: $x=0.006 \mathrm{~m}$, $y=0.021 \mathrm{~m}$. 
Overall, a discrete scrutiny of Figs. $5.19-5.24$ yields that there was no significant change in the results obtained, namely, the flame oscillations were neither dampened nor attenuated when the thermal boundary conditions of the coal tip had been modified. Consequently, we may conclude that an oscillating trend is independent of the thermal conditions at the coal tip.

\subsubsection{Spectral Analysis}

To understand the nature of these flame oscillations better, I also undertook the respective spectral (Fourier) analysis as briefly summarized below. Namely, the unsteady RANS simulation with the time step of $0.01 \mathrm{sec}$ are performed for the case of $\mathbf{9 0} \mathbf{k W}$ of power coming from coal burning and $10 \mathrm{~kW}$ coming from that of $\mathrm{CH}_{4}$ (out of total $100 \mathrm{~kW}$ ). Specifically, the evolution of the flow velocity and temperature are recorded at various locations and transformed into the frequency domain by a fast Fourier transform (FFT) technique implemented into a Matlab code.
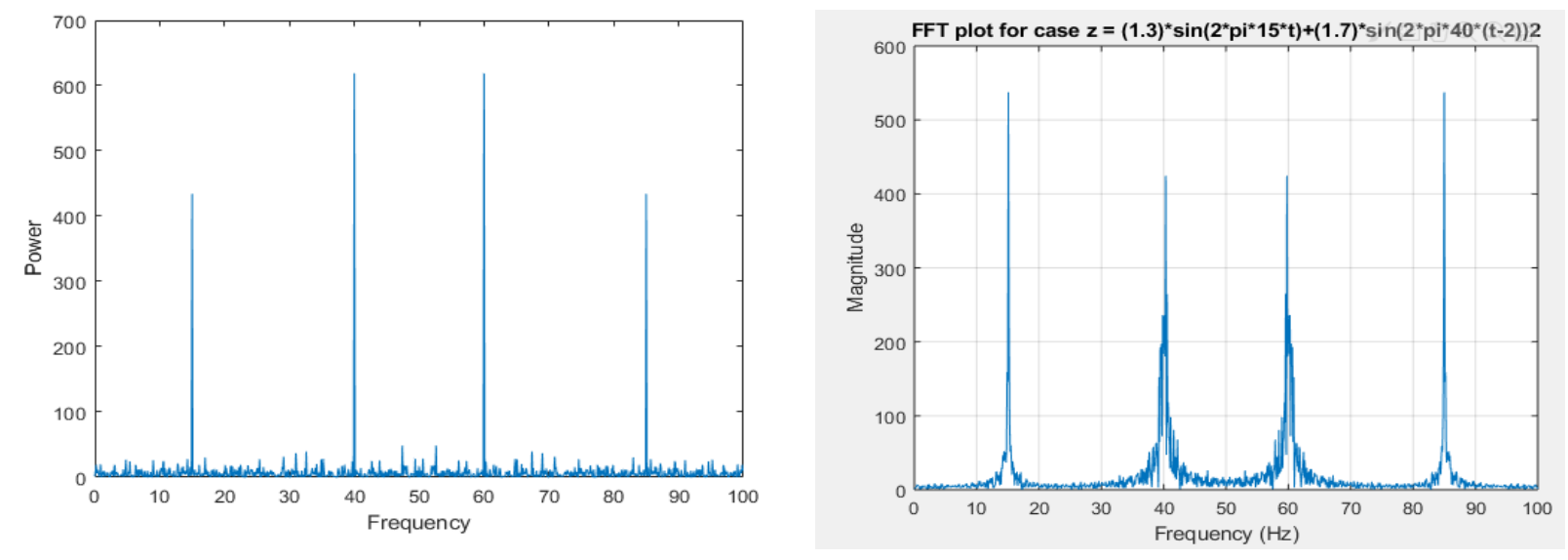

Figure 5.25: Validation of my FFT solver: The result of the spectral analysis as obtained from an online source (left) and that obtained using my own Matlab code (right)

Firstly, to validate the FFT solver, it has been tested through an already known function

$$
z=1.3 \sin (2 \pi \cdot 15 t)+1.7 \sin (2 \pi \cdot 40(t-2)) .
$$


Since the angular velocity is given by $\omega=2 \pi f$, then, comparing my test case to the function (5.1), I expected the spectral analysis to show peaks at the frequencies of $15 \mathrm{~Hz}$ and $40 \mathrm{~Hz}$. Indeed, a careful look at Fig. 5.25 shows a very close similarity between the two plots. In particular, they both have peak frequencies at $15 \mathrm{~Hz}$ and $40 \mathrm{~Hz}$, which thereby validates my code.

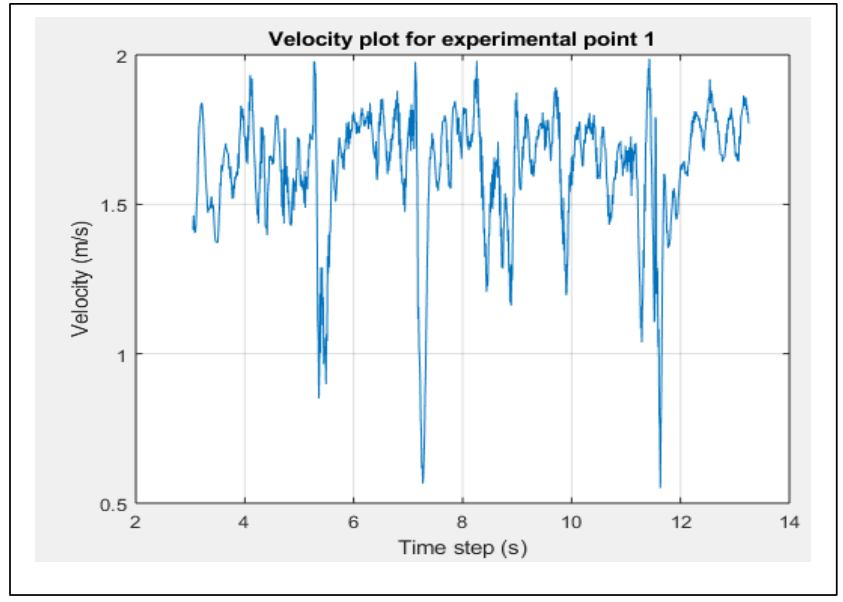

Figure 5.26: Time evolution of the flow velocity measured at the monitor point: $x=0.352 \mathrm{~m}, y=z=0$

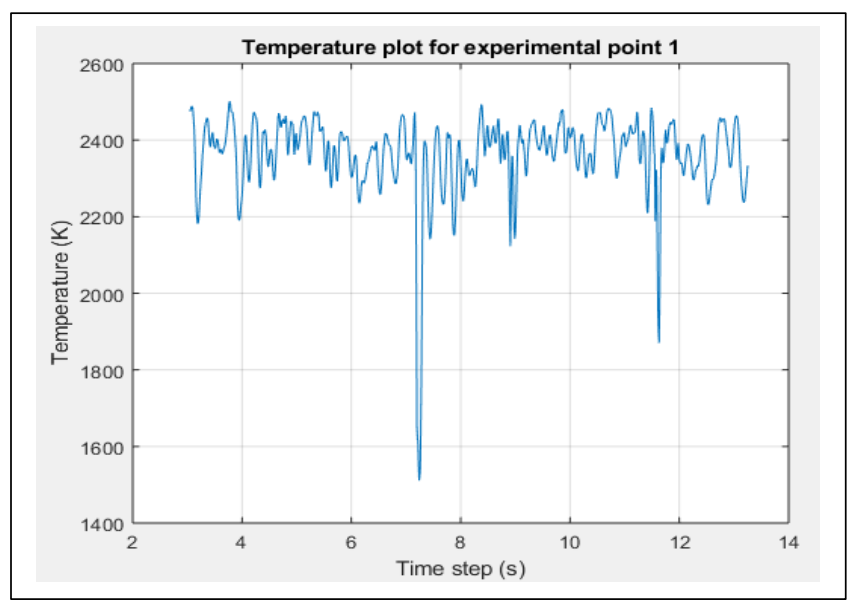

Figure 5.28: Time evolution of the temperature measured at the monitor point: $x=0.354 m, y=z=0$.

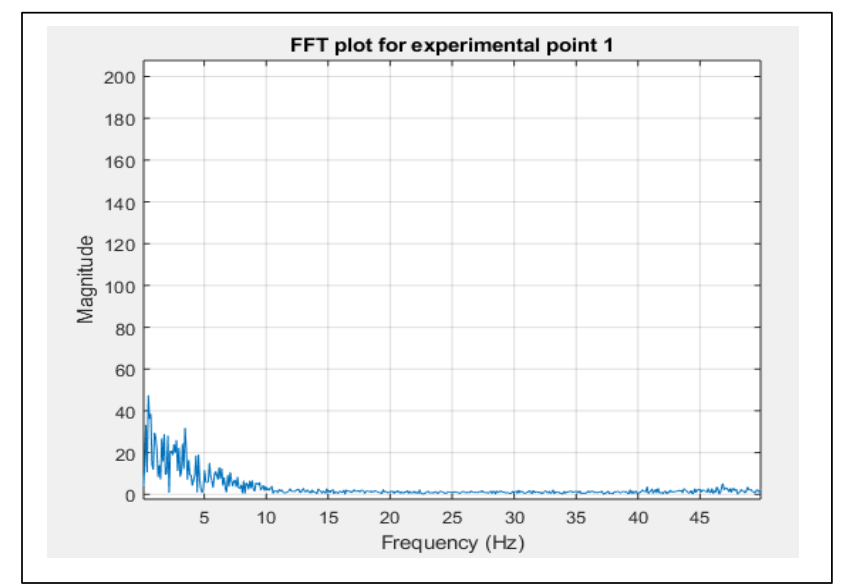

Figure 5.27: FFT of the velocity signal measured at the monitor point: $x=0.352 \mathrm{~m}, y=z=0$

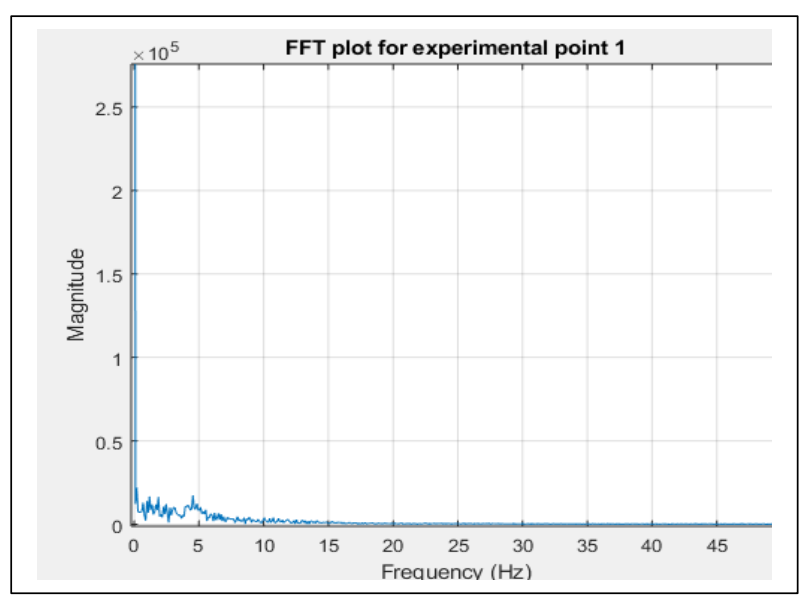

Figure 5.29: FFT of the temperature signal measured at the monitor point: $x=0.352 \mathrm{~m}, y=z=0$.

The results of Figs. $5.26-5.31$ shows the temperature and velocity (left) evolutions in time at different locations and the transformation in the frequency domain (right). The spectral analysis 
showed no distinct frequency when the FFT transformation is done. This simply means that this flame oscillation may not be due to vortex shedding created as a result of the bluff body. Thus, though there might be an influence of vortex shedding, this might not be the major cause of the flame oscillation observed.

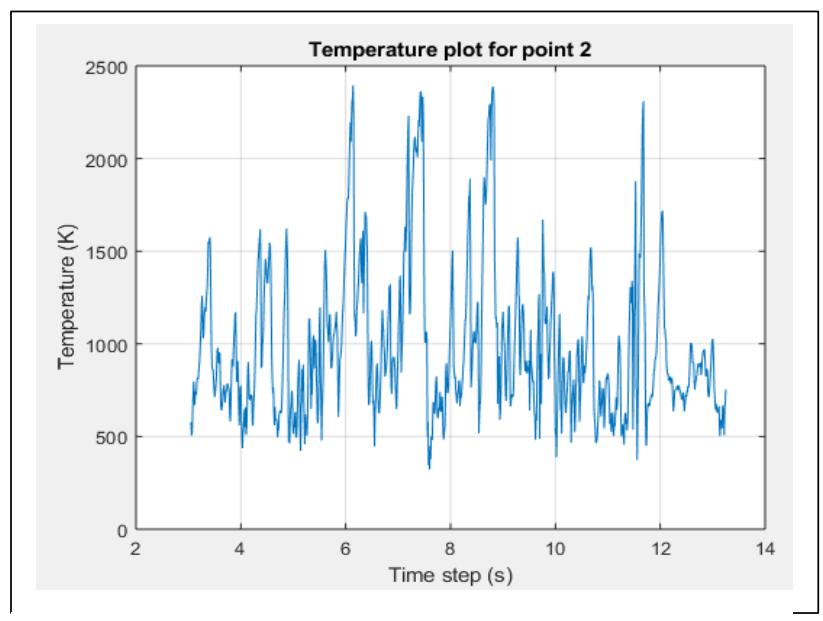

Figure 5.30: Time evolution of the temperature measured at the monitor point: $x=0.025 \mathrm{~m}, y=-$ $0.015 \mathrm{~m}, \mathrm{z}=8.2 \times 10^{-5} \mathrm{~m}$

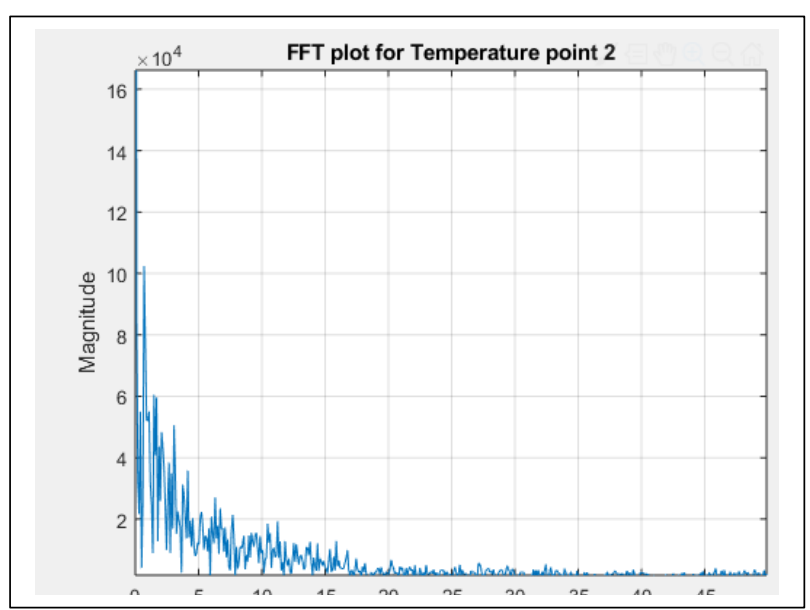

Figure 31: FFT of the temperature signal measured at the monitor point: $x=0.025 \mathrm{~m}, y=-0.015 \mathrm{~m}, \mathrm{z}=8.2$ $\times 10^{-5} \mathrm{~m}$

As my primary focus here was the nature of the flame oscillations, I suspected the bluff body to be one of the causes of the oscillations. Consequently, I decided to conduct the aerodynamic investigation - which deals with the velocity/motion of gases - of a flow past a bluff body. The key parameter for our parametric study is the Reynolds number $(R e=\rho l v / \mu)$, determined by a characteristic length $I$, for the various inlets considered. The respective hydraulic diameter was used as a characteristic length for the fuel inlet (coal and methane) and the primary inlet (inner oxidizer) while, the height of the bluff body was used as the characteristic length for the tertiary inlet (surrounding oxidizer). As the reactor has annulus inlet geometry with the bluff body, the hydraulic diameter is an appropriate parameter to be used as the characteristic length scale of 
the problem. It should be noted, in this respect, that the hydraulic diameter is commonly used for the Reynolds number calculation in a non-circular geometry. It is mathematically defined as

$$
\mathrm{D}_{\mathrm{H}}=4 * \frac{\text { Area }}{\text { Wetted perimeter }} .
$$

The Reynolds numbers for the $100 \mathrm{~kW}$ burner consisting of $\mathrm{CH} 4$ and coal at the respective inlets, i.e. the primary inlet, the secondary inlet and the tertiary inlet were calculated as 92701.29, 1874.3 and 3267.903 , respectively. Table 3 shows the various parameter at the different inlets for the lab scale reactor (coal and methane).

Table 3: Various parameters for the different inlets

\begin{tabular}{|l|l|l|l|}
\hline Parameter & Primary Inlet & Secondary Inlet & Tertiary Inlet \\
\hline Density $\left(\mathrm{kg} / \mathrm{m}^{3}\right)$ & 22.85 & 18.05 & 24.30 \\
\hline Velocity $(\mathrm{m} / \mathrm{s})$ & 9.92 & 0.07 & 0.73 \\
\hline Viscosity $(\mathrm{kg} \mathrm{m} / \mathrm{s})$ & $1.72 \times 10^{-5}$ & $1.72 \times 10^{-5}$ & $1.72 \times 10^{-5}$ \\
\hline Characteristic length $(\mathrm{m})$ & $7.03 \times 10^{-3}$ & $27 \times 10^{-3}$ & $31 \times 10^{-4}$ \\
\hline
\end{tabular}

\subsubsection{Bluff Body Analysis}

In other to investigate the causes of the flow oscillations suspected to be caused by a bluff body, we performed an aerodynamic simulation using air where the condition for the lab-scale reactor was matched. Specifically, the Reynolds numbers for the primary and secondary inlets from the lab-scale reactor were matched to the aerodynamic case, while the Reynolds number for the tertiary inlet, where the bluff body is located, is varied in increasing order until it matches the inlet condition of the lab-scale reactor. The characteristic length scale was kept constant for the simulations performed on the same geometry (bluff body). Figures 5.32, 5.33, 5.34, and 5.35 show the velocity contours in the x-direction as the Reynolds number is increased. 


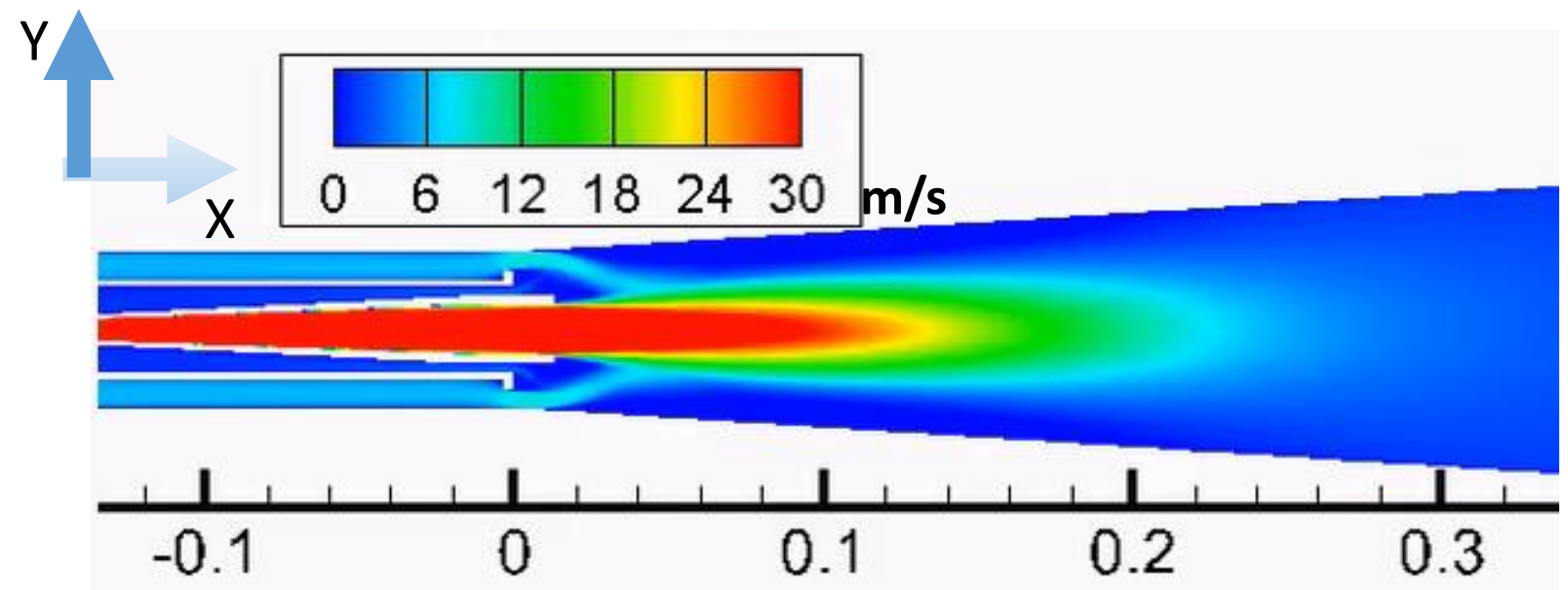

Figure 5.32: The $x$-component velocity contour for the tertiary inlet velocity $5 \mathrm{~m} / \mathrm{s}, R e=1085.29$.

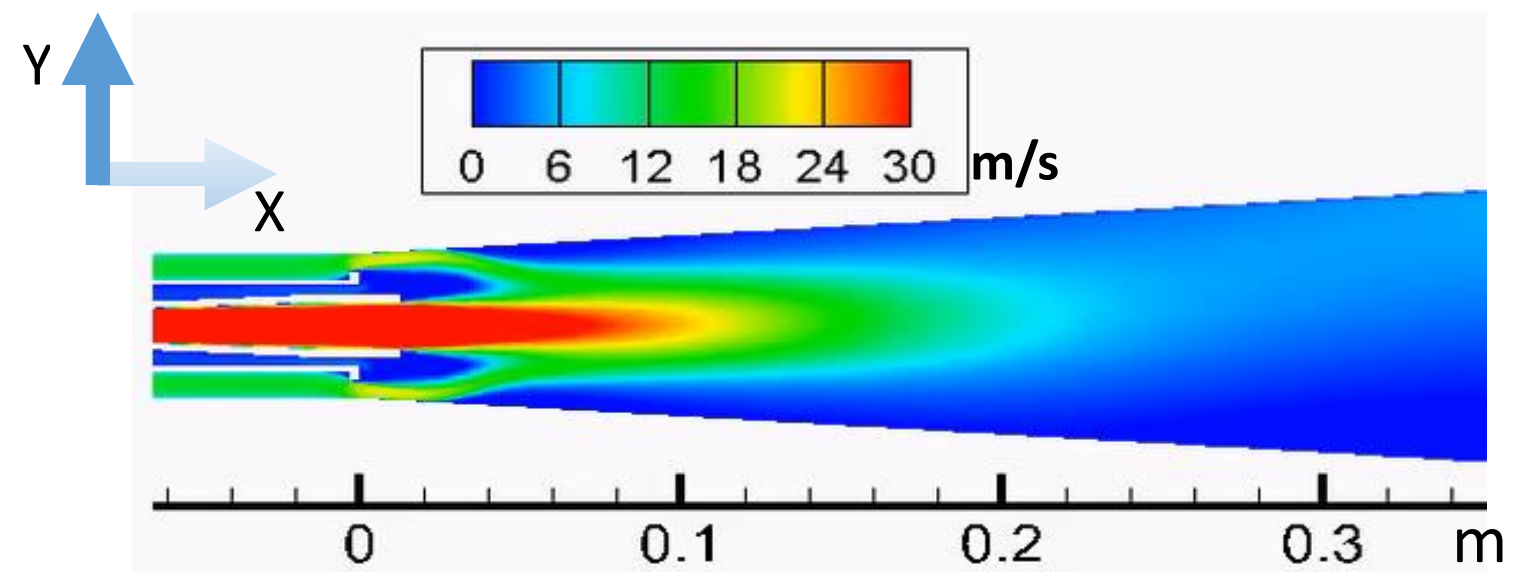

Figure 5.33: The x-component velocity contour for tertiary inlet velocity $12 \mathrm{~m} / \mathrm{s}, \operatorname{Re}=\mathbf{2 6 0 4 . 7 1}$.

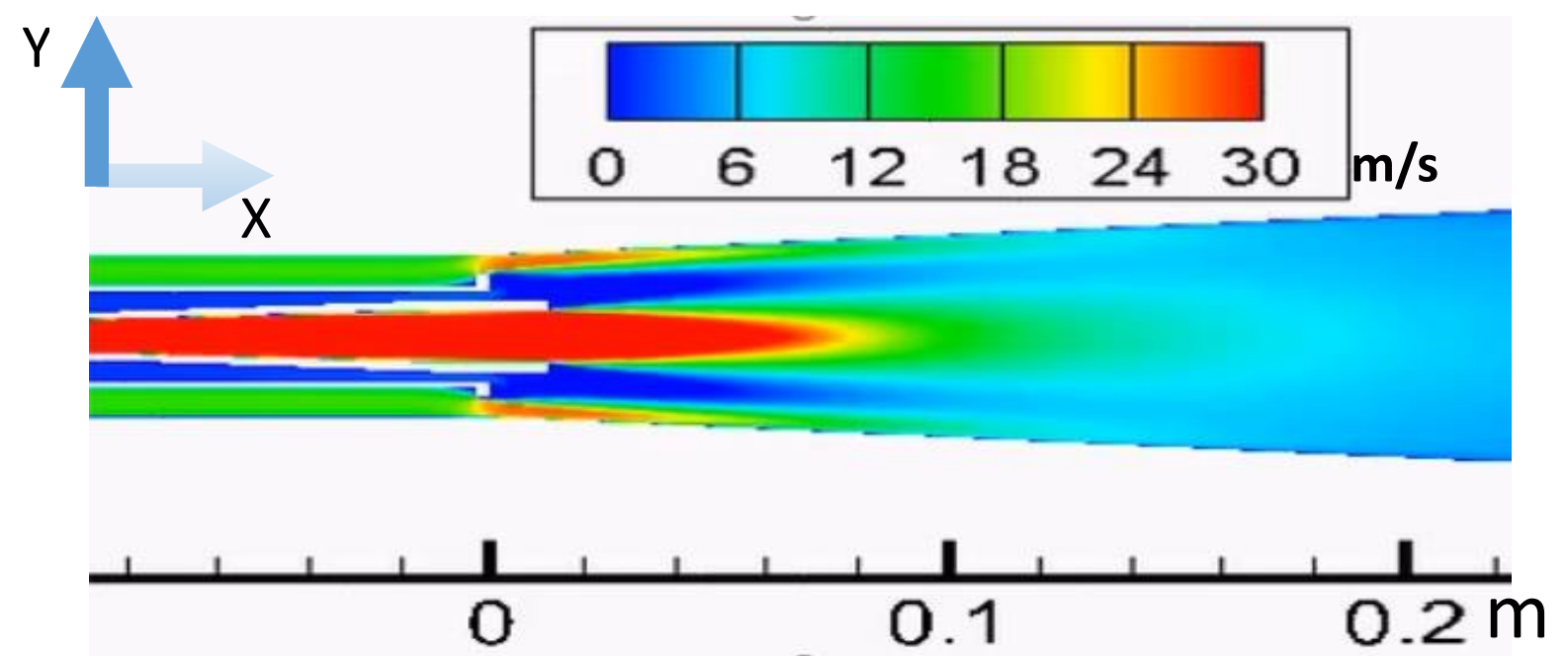

Figure 5.34: The x-component velocity contour for tertiary inlet velocity $15 \mathrm{~m} / \mathrm{s}, \operatorname{Re}=3255.88$. 


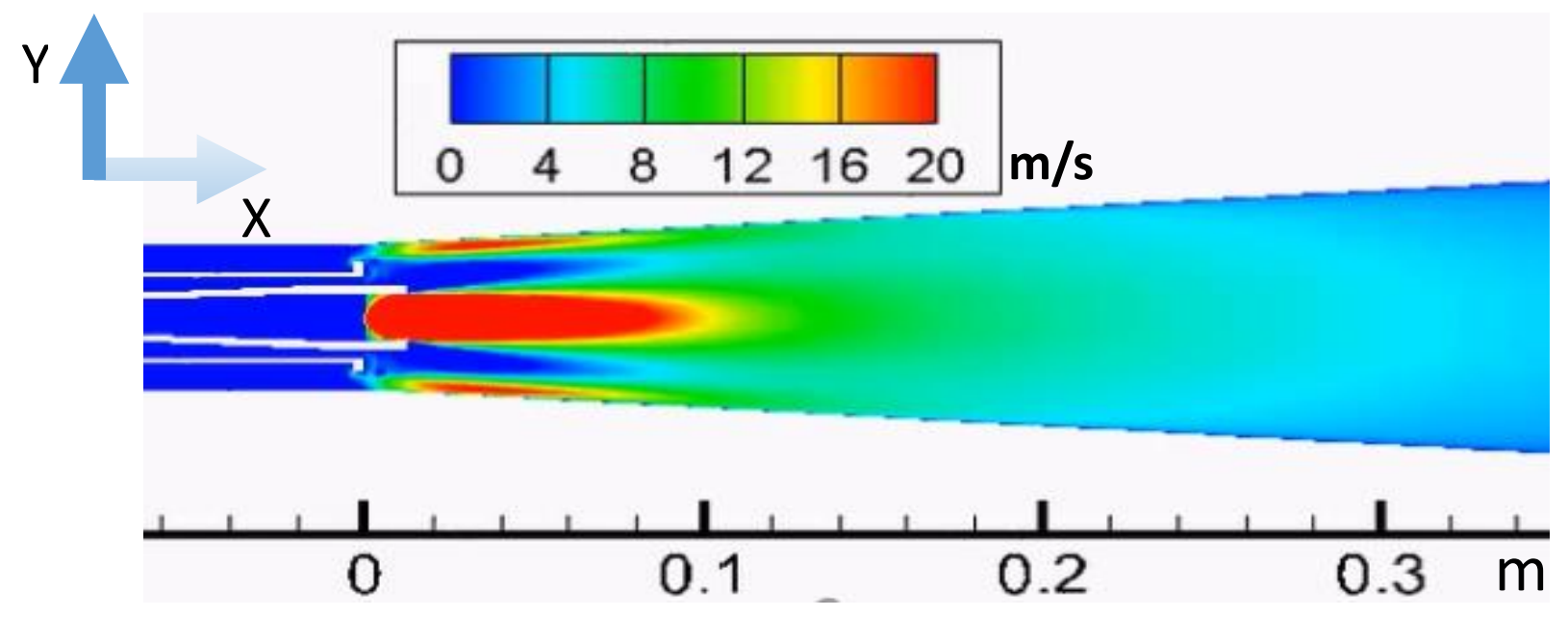

Figure 5.35: Radial component velocity contour plot for the tertiary inlet velocity $15 \mathrm{~m} / \mathrm{s}, \operatorname{Re}=3255.88$

Figure 5.32 shows the velocity contour for low Reynolds number i.e. $R e=1085.29$. It is clearly seen from this figure that the flow field is very symmetric and stable. Thus, we may conclude that for Reynolds number close to 1085 there are no oscillations and thus flow field is stable.

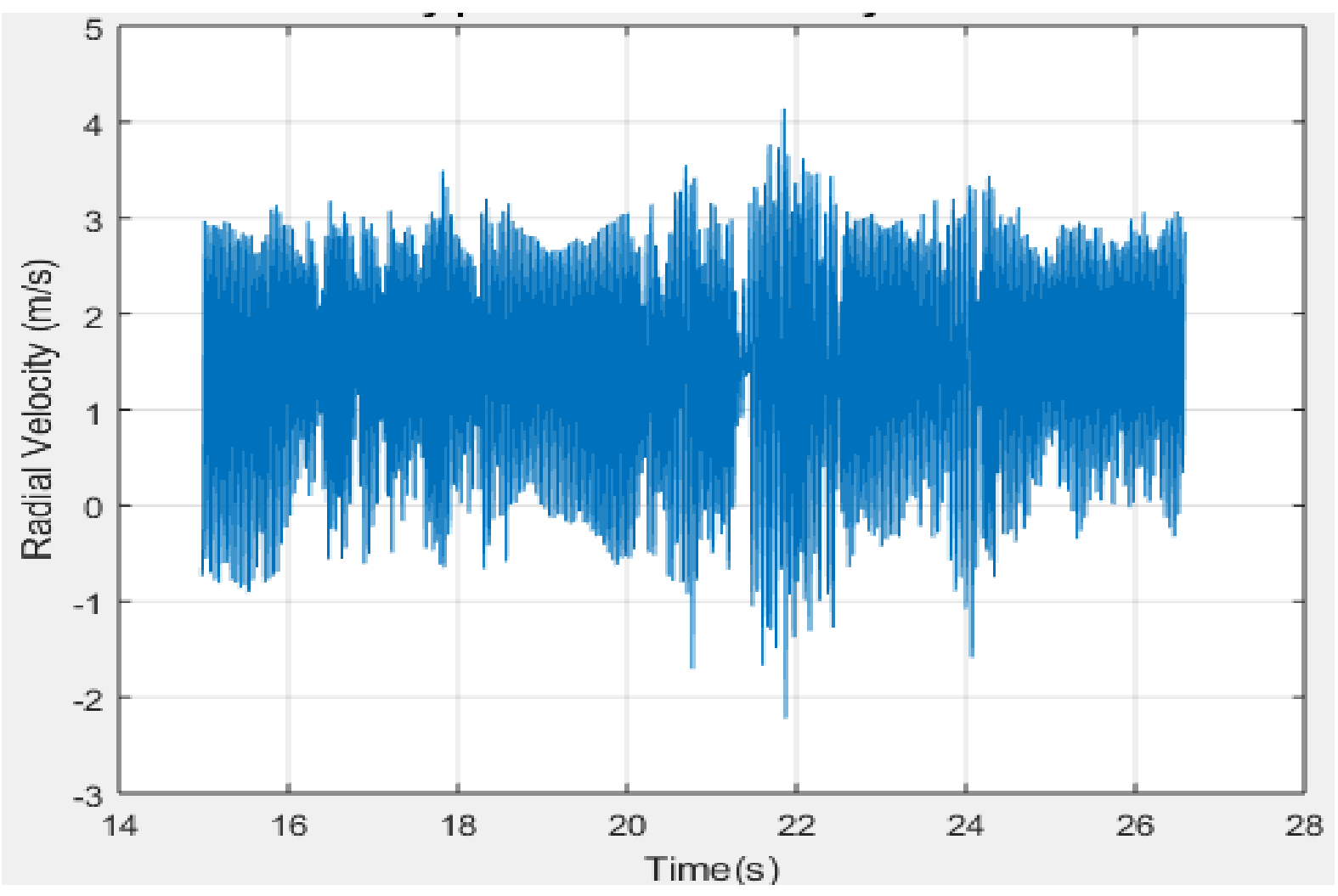

Figure 5.36: Variation of the radial flow velocity with time 


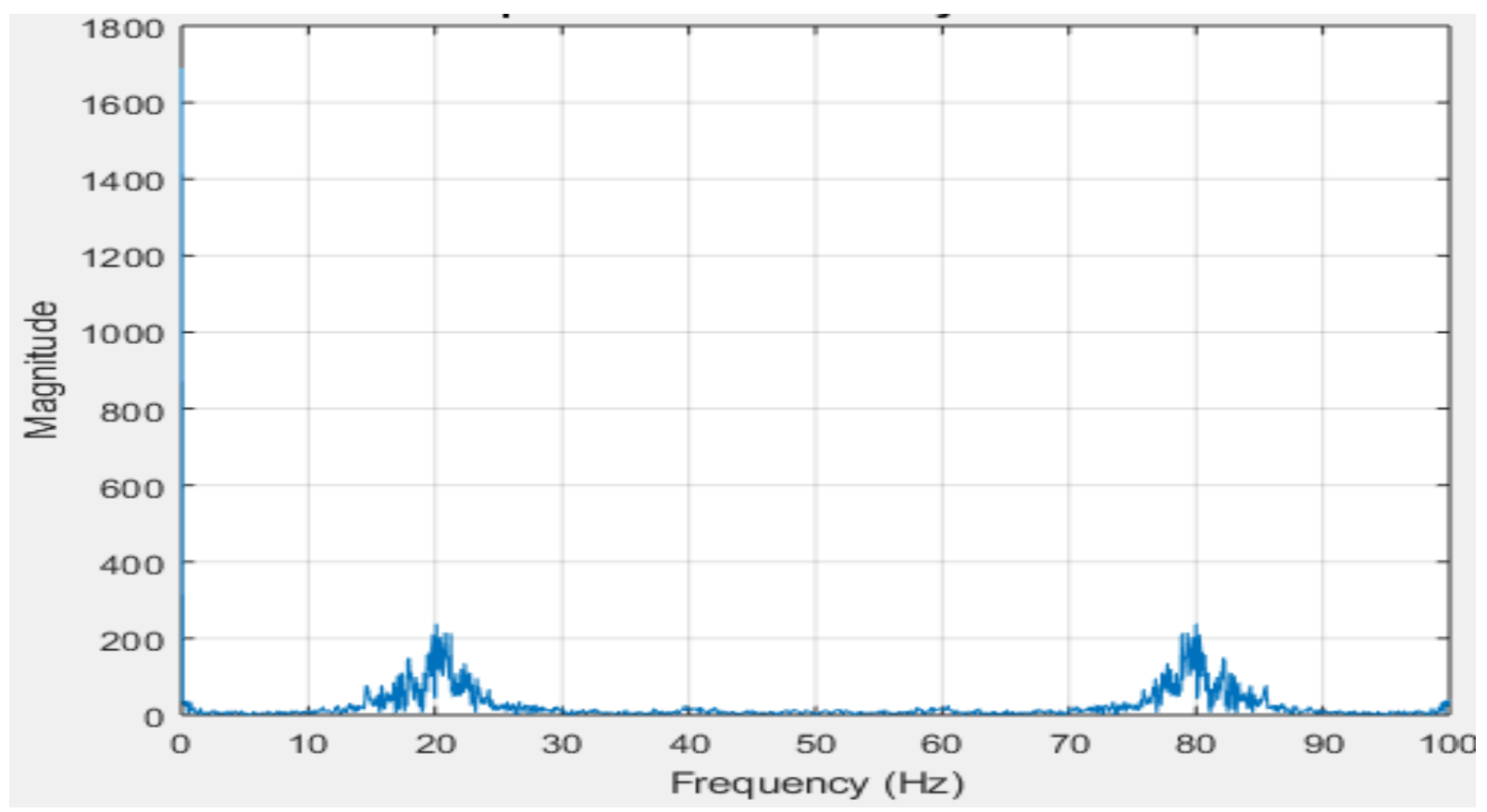

Figure 5.37: FFT analysis at the point near (downstream) the bluff body

\subsection{Coal Carrier $\left(\mathrm{CO}_{2}\right)$ Analysis}

Previous results have shown that an increase in the coal concentration resulted in the onset of the flame asymmetry. Thus, the volumetric flow rate of the $\mathrm{CO}_{2}$ used to convey coal was increased. It was hypothesized that an increase in coal carrier would better convey the coal particles and create a better feeding of coal into the burner region. Hence, the volumetric flow rate of coal carrier was increase from $15 \mathrm{slpm}$ to $75 \mathrm{slpm}$ as shown in the table 4 below, where Case 1 represents the boundary condition for the initial volumetric flow rate of $\mathrm{CO}_{2}$ being 15 slpm, and Case 2 represents the modified initial conditions when the volumetric flow rate is increased to 75 SIpm.

Table 4: Inlet conditions for methane and $\mathrm{CO}_{2}$ at the fuel inlet

\begin{tabular}{|l|l|l|l|l|}
\hline & \multicolumn{2}{|l|}{ Case 1 } & Case 2 \\
\hline & $\begin{array}{l}\text { Volumetric flow } \\
\text { rate }(\text { slpm) }\end{array}$ & $\begin{array}{l}\text { Mass flow } \\
\text { rate }(\mathrm{kg} / \mathrm{s})\end{array}$ & $\begin{array}{l}\text { Volumeric flow } \\
\text { rate }(\text { slpm })\end{array}$ & $\begin{array}{l}\text { Mass flow } \\
\text { rate }(\mathrm{kg} / \mathrm{s})\end{array}$ \\
\hline $\mathrm{CH}_{4}$ & 15.1 & $18 \times 10^{-5}$ & 15.1 & $18.41 \times 10^{-5}$ \\
\hline $\mathrm{CO}_{2}$ & 15 & $49.6 \times 10^{-5}$ & 75 & $24.54 \times 10^{-4}$ \\
\hline Total & 30.1 & $67.7 \times 10^{-5}$ & 90.1 & $26.34 \times 10^{-4}$ \\
\hline
\end{tabular}


The result obtained when $\mathrm{CO}_{2}$ is increased showed a more symmetric flame as seen in Figs. 5.38

-5.39 . Thus, it may be concluded that this flame oscillation is due to a non-uniform injection of the coal as seen in Fig. 5.40. Hence, an increase in the coal carrier promoted the uniformity at which coal is fed into the burner region as one can observe in Fig. 5.41.

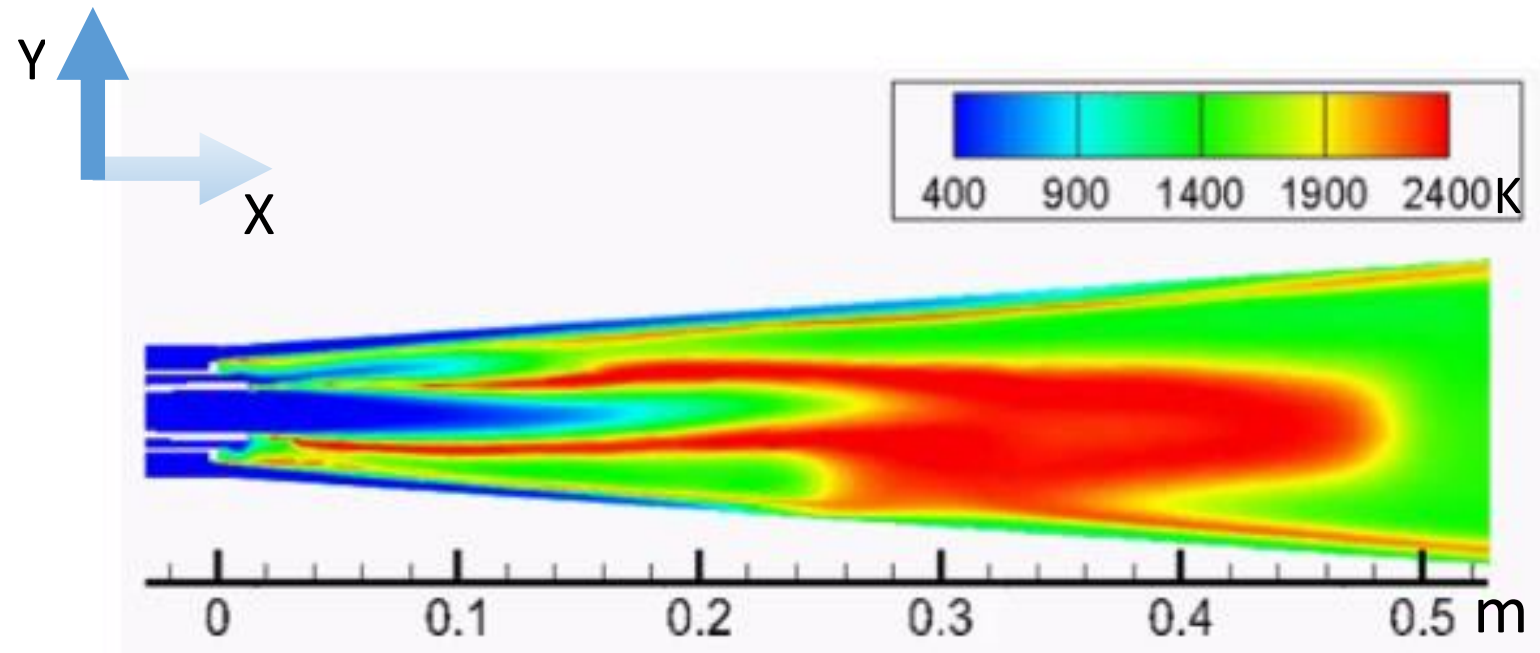

Figure 5.38: An instantaneous temperature plot (Case 1) without an increased $\mathrm{CO}_{2}$ volume flow rate using the time step of $0.01 \mathrm{sec}$

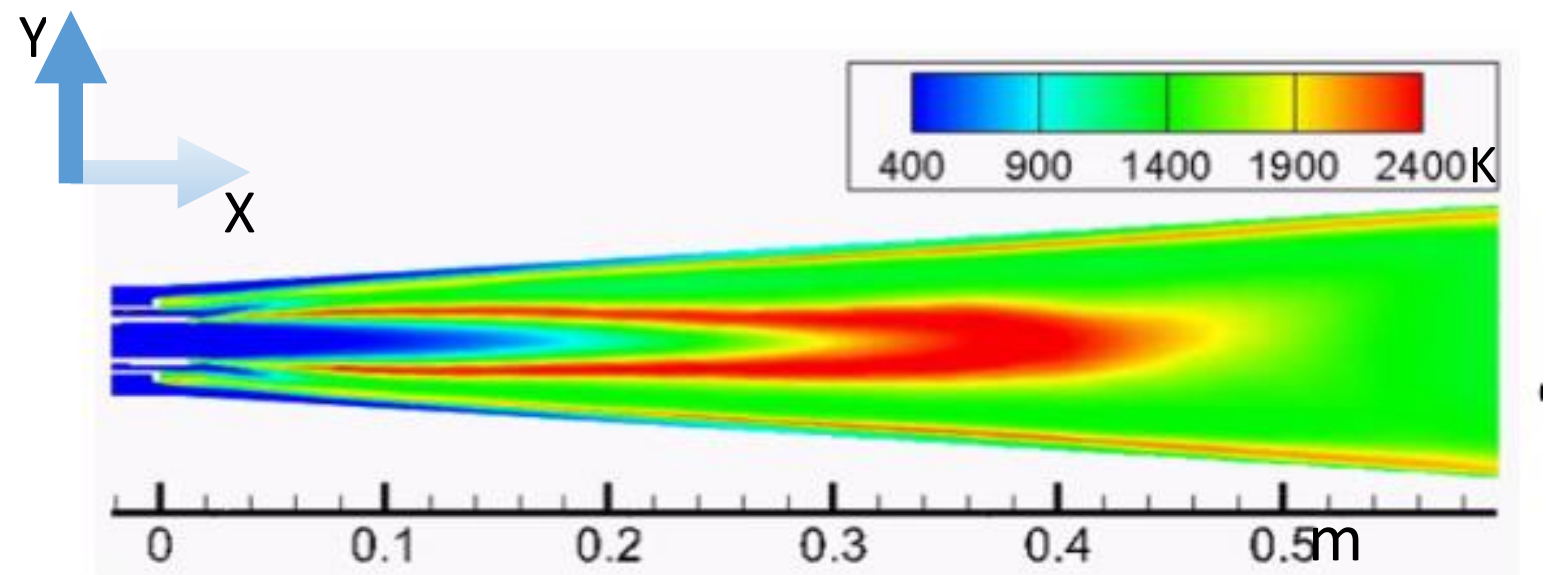

Figure 5.39: An instantaneous temperature plot (Case 2) for increased $\mathrm{CO}_{2}$ volumetric flow rate $(75$ slpm). 


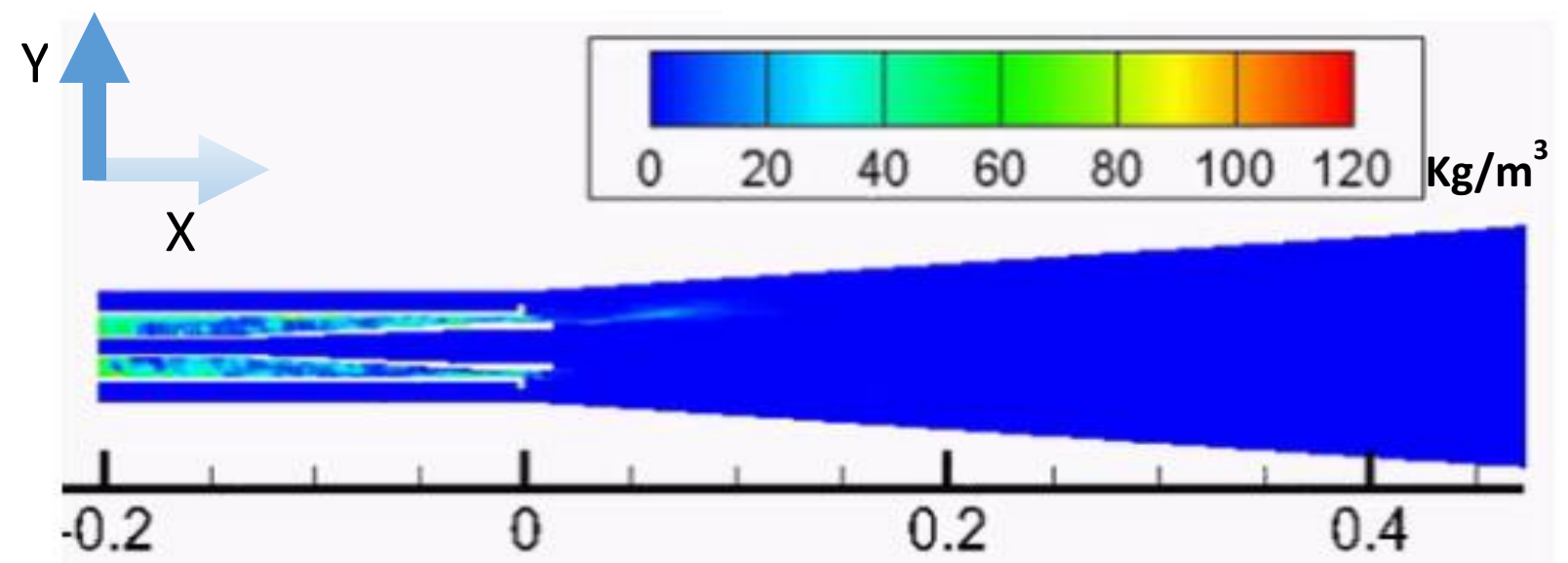

Figure 5.40: Instantaneous Dpm concentration contour (Case 1) without an increased $\mathrm{CO}_{2}$ volumetric flow rate using the time step of $0.01 \mathrm{sec}$.

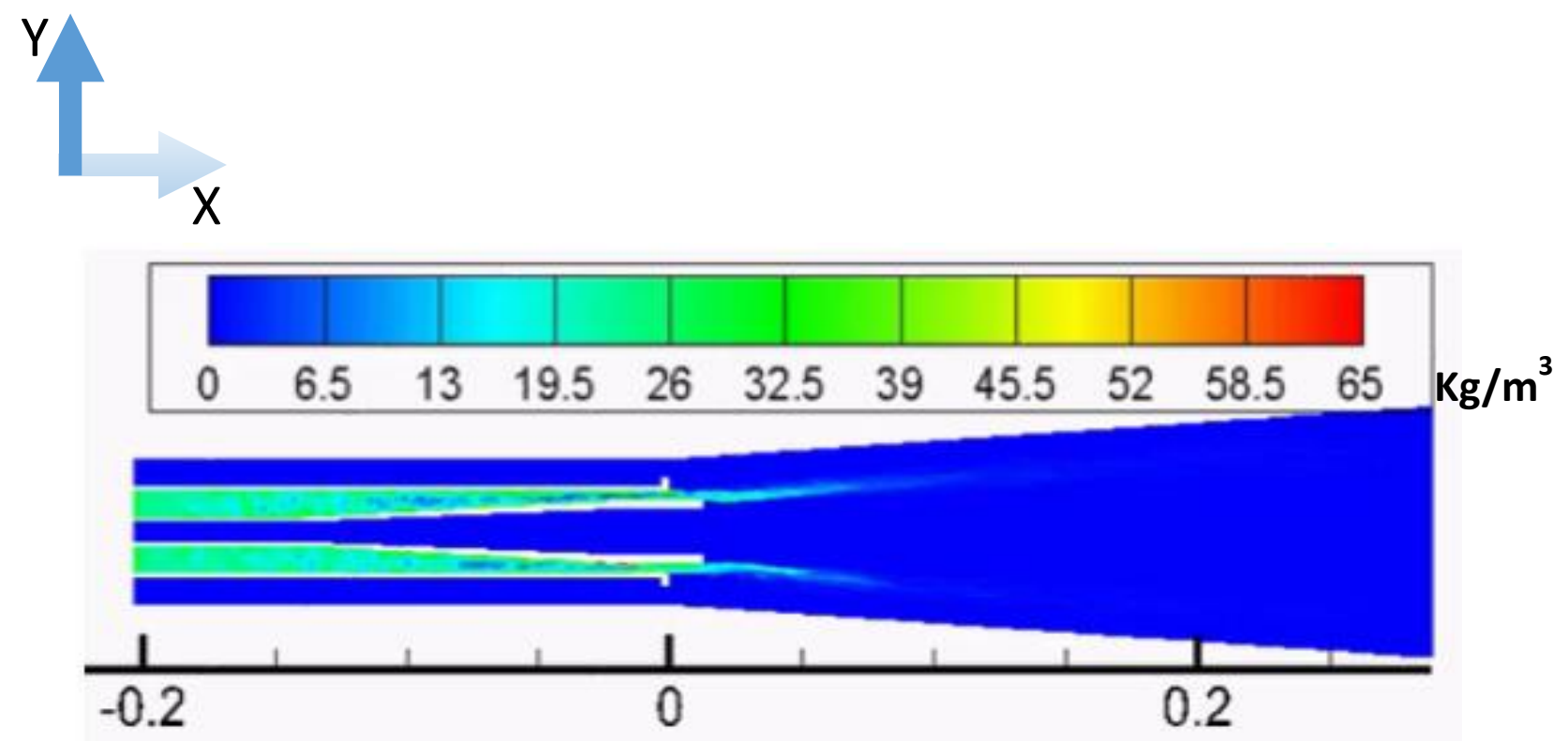

Figure 5.41: Instantaneous Dpm concentration (Case 2) for increased $\mathrm{CO}_{2}$ volume flow rate using the time step of $0.01 \mathrm{sec}$ 


\section{Conclusion}

The objective of this thesis is to compliment the WUSTL SPOC experimental facility with a physicsbased model by means of comprehensive computational simulations. Specifically, numerical simulation of a $100 \mathrm{~kW}$ lab-scale reactor is presented in this thesis, with $90 \mathrm{~kW}$ supplied from coal combustion and $10 \mathrm{~kW}$ from that of methane.

It is pointed out that although bluff body usage is a flame stabilizing technique, the regime of flow past this bluff body should be taking into consideration since an increase in the Reynolds number would result in the onset of vortex shedding. In addition, it has been shown that coal carrier plays a very relevant role in the injection properties of coal. In fact, this thesis showed that an increase in coal without sufficient amount of coal carrier to transport coal into the burner would result in non-uniform distribution of coal, which would leads to non-uniform fuel feed and ultimately flame asymmetry.

Moreover, it is concluded that for the numerical stability of CFD simulations, the time step must be sufficiently small to capture the fluctuations and for reduced numerical errors. 


\section{Work-in-Progress}

Currently, there is an ongoing large eddy simulation for the lab-scale reactor, where the volumetric flow rate of coal carrier is increased using a small time step. This LES simulation is being performed using methane to ignite coal and subsequently shut out, enabling $100 \%$ of the reactor power to be obtained from coal combustion.

This simulation is in progress and the results obtained from this simulation would be for comparison with the experimental data obtained from our partners in WUSTL.
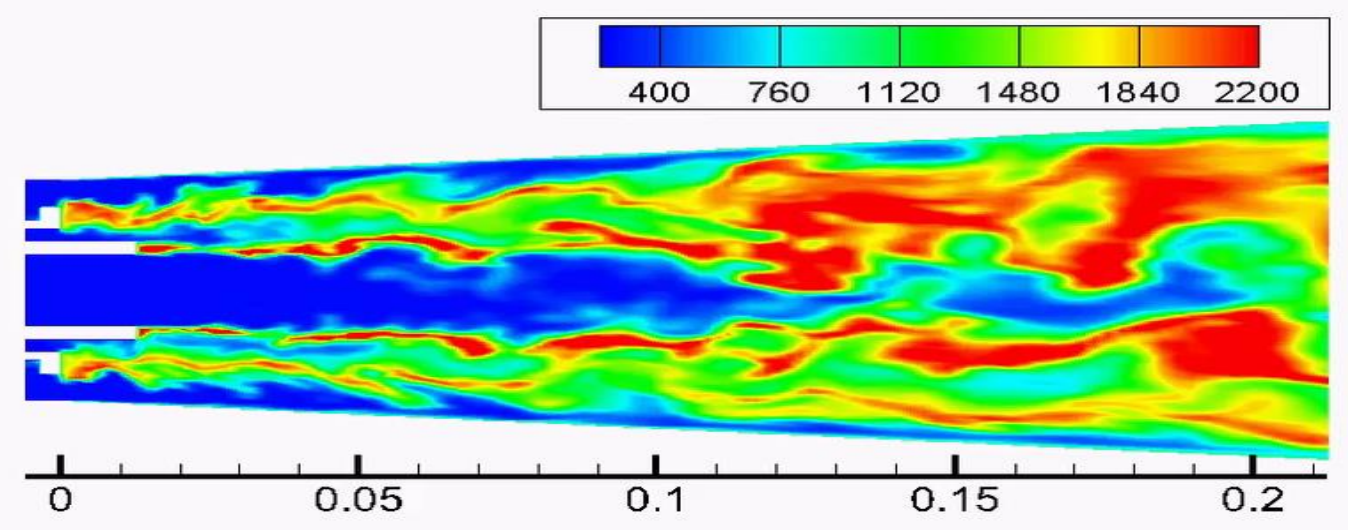


\section{References}

[1] https://en.wikipedia.org/wiki/Fossil fuel

[2] https://www.acs.org/content/acs/en/climatescience/greenhousegases.html

[3] T. Anderson, E. Hawkins, P. Jones. " $\mathrm{CO}_{2}$, the Greenhouse Effect and Global Warming: From the Pioneering Work of Arrhenius and Calendar to Todays Earth System Models." Endeavour 40, no. 3 (2016): 178-87.

[4] T. Koeth, M. Hiebert, "Unprecedented Arctic Warming due to Greenhouse Gases." Physics Today 72, no. 5 (2013): 36.

[5] https://www.epa.gov/ghgemissions/sources-greenhouse-gas-emissions .

[6] M. Kanniche, R. Gross-Bonnivard, P. Jaud, J. Valle-Marcos, J. Amann, C. Bouallou. "Pre-, Post- and OxyCombustion in Thermal Power Plant for $\mathrm{CO}_{2}$ Capture." Applied Thermal Engineering 30, no. 1 (2010): 53-62.

[7] C. Kunze, H. Spliethoff. "Assessment of Oxy-Fuel, Pre- and Post-Combustion-based Carbon Capture for Future IGCC Plants." Applied Energy 94 (2012): 109-16.

[8] L. Vecchione, F. Cossio, L. Longoo. "Comparison of Different Systems for Tar Removal for Renewable Energy Derivation from Biomass Gasification." Contemporary Engineering Sciences 9 (2016): 413-23.

[9] J. Wang, Y. Zhang, N. Altaf, D. O'Hare, Q. Wang, "Layered Double Hydroxides-Derived IntermediateTemperature $\mathrm{CO}_{2}$ Adsorbents", p. 1-60 in "Pre-Combustion Carbon Dioxide Capture Materials" (Ed. Q. Wang), Inorganic Materials Series, The Royal Society of Chemistry, UK, 2018.

[10] http://www.dartmouth.edu/ cushman/courses/engs41/BP-StatisticalReview-2010.pdf

[11] https://www.eia.gov/outlooks/aeo/pdf/0383(2011).pdf

[12] https://www.eia.gov/outlooks/ieo/pdf/0484(2013).pdf

[13] Pulverized coal oxy combustion power plants. Bituminous coal to electricity, rev. 2. Report DOE/NETL2007/1291, vol. 1. US Department of Energy National Energy Technology Laboratory; 2008.

[14] D. McDonald, D. DeVault, R. Varagani. "Oxy-Combustion in Pulverized Coal Power Plants for Carbon Dioxide Concentration." Electric Power Conference, Chicago, IL, May 1-3, 2007.

[15] S. Carpenter, H. Long. "Integration of Carbon Capture in IGCC Systems." Integrated Gasification Combined Cycle (IGCC) Technologies 13 (2017): 445-63.

[16] A. Gopan, B. Kumfer, R. Axelbaum. "Effect of Operating Pressure and Fuel Moisture on Net Plant Efficiency of a Staged, Pressurized Oxy-Coal Combustion Power Plant." International Journal of Greenhouse Gas Control 39 (2015): 390-96. 
[17] J. Hong, G. Chaudhry, J. Brisson, R. Field, M. Gazzino, A. Ghoniem. "Analysis of Oxy-Fuel Combustion Power Cycle Utilizing a Pressurized Coal Combustor." Energy 34 (2009): 1332-40.

[18] H. Hagi, M. Nemer, Y. Moullec, C. Bouallou. "Towards Second Generation Oxy-Pulverized Coal Power Plants: Energy Penalty Reduction Potential of Pressurized Oxy-combustion Systems." Energy Procedia 63 (2014): 431-39.

[19] B. Kumfer, R. Axelbaum. "Staged, High Pressure Oxy-Combustion Technology: Development and Scale-Up" The NETL CO ${ }_{2}$ Capture Technology Meeting (2016).

[20] J. Lasek, K. Głód, M. Janusz, K. Kazalski, J. Zuwała. "Pressurized Oxy-Fuel Combustion: A Study of Selected Parameters." Energy \& Fuels 26, no. 11 (2012): 6492-500.

[21] A. Gopan, B. Kumfer, J. Phillips, D. Thimsen, R. Smith, R. Axelbaum. "Process Design and Performance Analysis of a Staged, Pressurized Oxy-Combustion (SPOC) Power Plant for Carbon Capture." Applied Energy 125 (2014): 179-88.

[22] J. Hong, R. Field, M. Gazzino A. Ghomiem. "Operating Pressure Dependence of the Pressurized 0xyFuel Combustion Power Cycle." Energy 35, no. 12 (2010): 5391-99.

[23] B. Launder, D. Spalding. "The Numerical Computation of Turbulent Flows." Numerical Prediction of Flow, Heat Transfer, Turbulence and Combustion, (1983): 96-116.

[24] D.C. Wilcox. Turbulence Modelling for CFD. DCW Industries Inc., 1993, 460pp.

[25] L. Chen, A. Ghoniem. "Simulation of Oxy-Coal Combustion in a $100 \mathrm{KW}$ Test Facility Using RANS and LES: A Validation Study." Energy \& Fuels 26, no. 8 (2012): 4783-98.

[26] I. Celik, M. Klein, M. Freitag, J. Janicka. "Assessment Measures for URANS/DES/LES: An Overview with Applications." Journal of Turbulence 7 (2006): 48.

[27] I. Celik, M. Klein, J. Janicka. "Assessment Measures for Engineering LES Applications." Journal of Fluids Engineering 131, no. 3 (2009): 031102.

[28] V. Ranade. "9 Flow Modeling for Reactor Engineering." Process Systems Engineering Computational Flow Modeling for Chemical Reactor Engineering 5 (2002): 243-82.

[29] J. Silva, J. Teixeira, S. Teixeira, S. Preziati, J. Cassiano. "CFD Modeling of Combustion in Biomass Furnace." Energy Procedia 120 (2017): 665-72.

[30] P. Stopford. "Recent Applications of CFD Modelling in the Power Generation and Combustion Industries." Applied Mathematical Modelling 26, no. 2 (2002): 351-74.

[31] B. Xia, D. Sun. "Applications of Computational Fluid Dynamics (CFD) in the Food Industry: A Review." Computers and Electronics in Agriculture 34, no. 1-3 (2002): 5-24. 
[32] A. Al-Abbas, J. Naser, D. Dodds. "CFD Modelling of Air-Fired and Oxy-Fuel Combustion of Lignite in a 100KW Furnace." Fuel 90, no. 5 (2011): 1778-95.

[33] S. Hjärtstam, K. Andersson, F. Johnsson, B. Leckner. "Combustion Characteristics of Lignite-Fired OxyFuel Flames." Fuel 88, no. 11 (2009): 2216-24.

[34] A. Al-Abbas, J. Naser, D. Dodds, A. Blicblau. "Numerical Modelling of Oxy-Fuel Combustion in a FullScale Tangentially-Fired Pulverised Coal Boiler." Procedia Engineering 56 (2013): 375-80.

[35] D. Toporov, P. Bocian, P. Heil, A. Kellermann, H. Stadler, S. Tschunko, M. Förster, R. Kneer. "Detailed Investigation of a Pulverized Fuel Swirl Flame in $\mathrm{CO}_{2} / \mathrm{O}_{2}$ Atmosphere." Combustion \& Flame 155, no. 4 (2008): 605-18.

[36] M. Hanna, M. Bardon, V. Rao. "Flame Stabilization behind Bluff Bodies." 25 th Joint Propulsion Conference, Monterrey, CA, July 12-16, 1989.

[37] B. Raushenbakh, S. Belyy, I. Bespalov, V. Borodachev, M. Volynskiy, A. Prudnikov. Physical Principles of the Working Process in Combustion Chambers of Jet Engines, Defense Technical Information Center, 1967.

[38] A. Abdel-Rehim, K. El-Nagar, I. El_Semary "Effect of Bluff Body Geometry on Flame Stabilization with the Assist of Langmuir Probe" Mechanical Engineering Dept. Benha University. Cairo, Egypt, Jan 2013.

[39] L. Chen, S. Yong, A. Ghoniem "Oxy-Fuel Combustion of Pulverized Coal: Characterization, Fundamentals, Stabilization and CFD Modeling." Progress in Energy and Combustion Science 38, no. 2 (2012): 156-214.

[40] J. Howell, R. Sigel, M. Pinar Menguc. Thermal Radiation Heat Transfer. Boca Raton: CRC Press, 2015.

[41] D. Edwards. "Radiation Heat Transfer Notes." Washington D.C. Hemisphere Publishing Corp., 1981.

[42] A. Habibi, B. Merci, G.J. Heynderickx. "Impact of Radiation Models in CFD Simulations of Steam Cracking Furnaces." Computers \& Chemical Engineering 31, no. 11 (2007): 1389-406.

[43] P. Moin. "Large Eddy Simulation of Multi-Phase Turbulent Flows in Realistic Combustors." Progress in Computational Fluid Dynamics 4, no. 3-5 (2004): 237-240.

[44] M. Garcia, Y. Sommerer, T. Schonfeld, T. Poinsot. "Evaluation of Euler-Euler and Euler-Lagrange Strategies for Large-Eddy Simulations of Turbulent Reacting Flows". Toulouse, France, Dec 2004.

[45] F. Menter. "Two-Equation Eddy-Viscosity Turbulence Models for Engineering Applications." AIAA Journal 32, no. 8 (1994): 1598-605.

[46] Ansys Inc., "Shear-Stress Transport (SST) k-w Model." in ANSYS FLUENT 12.0, Theory Guide., 2009, ch. 4, pp. 4-31-4-36. 
[47] Ansys Inc., "Choosing a Turbulence Model." in ANSYS FLUENT 12.0, Theory Guide., 2009, ch. 4,pp. 43-4-4.

[48] J. Hinze. Turbulence. McGraw-Hill Publishing Co., New York, 1975.

[49] J. Smagorinsky. "General Circulation Experiments with the Primitive Equations." Monthly Weather Review 91, no. 3 (1963): 99-164.

[50] M. Germano, U. Piomelli, P. Moin, W. Cabot. "A Dynamic Subgrid-Scale Eddy Viscosity Model." Physics of Fluids A 3, no. 7 (1991): 1760-65.

[51] K. Lilly. "A Proposed Modification of the Germano Subgrid-Scale Closure Method." Physics of Fluids A 4, no. 3 (1992): 633-35.

[52] Ansys Inc., "Species Transport and Finite-Rate Chemistry." in ANSYS FLUENT 12.0, Theory Guide, 2009.

[53] Ansys Inc., "Species Transport and Finite-Rate Chemistry." in ANSYS FLUENT 12.0, Theory Guide, 2009, ch. 7, pp. 7-1 - 7-11.

[54] B. Magnussen, B. Hjertager. "On Mathematical Modeling of Turbulent Combustion with Special Emphasis on Soot Formation and Combustion." Proceedings of the Combustion Institute 16, no. 1 (1977): 719-29.

[55] D. Grant, R. Pugmire, T. Fletcher, A. Kerstein. "Chemical Model of Coal Devolatilization using Percolation Lattice Statistics." Energy \& Fuels 3, no. 2 (1989): 175-86.

[56] T. Fletcher, A. Kerstein, R. Pugmire, D. Grant. "Chemical Percolation Model for Devolatilization. 2. Temperature and Heating Rate Effects on Product Yields." Energy \& Fuels 4, no. 1 (1990): 54-60.

[57] T. Fletcher, A. Kerstein, R. Pugmire, M. Solum, D. Grant. "Chemical Percolation Model for Devolatilization. 3. Direct Use of Carbon-13 NMR Data to Predict Effects of Coal Type." Energy \& Fuels6, no. 4 (1992): 414-31.

[58] S. Morsi, A. Alexander. "An Investigation of Particle Trajectories in Two-Phase Flow Systems." Journal of Fluid Mechanics 55, no. 2 (1972): 193.

[59] Ansys Inc., "Turbulent Dispersion of Particles." in ANSYS FLUENT 12.0, Theory Guide., 2009, ch. 15, pp. $15-6-15-14$.

[60] P. Vesilind. "The Rosin-Rammler Particle Size Distribution." Resource Recovery and Conservation5, no. 3 (1980): 275-77.

[61] Ansys Inc., "Turbulent Dispersion of Particles." in ANSYS FLUENT 12.0, Theory Guide., 2009, ch. 15, pp. $15-6-15-14$.

[62] J. Blazek. "Principles of Solution of the Governing Equations." Computational Fluid Dynamics: Principles and Applications, 2015, pp. 29-72. 
[63] Ansys Inc., "Solver Theory." in ANSYS FLUENT 12.0, Theory Guide., 2009, ch. 18, pp. 18-1 - 18-67.

[64] H. Versteeg, W. Malalasekera. "An Introduction to Computational Fluid Dynamics" The Finite Volume Method, $2^{\text {nd }}$ ed. England: Pearson Education Limited, 2007. 


\section{Appendix A}

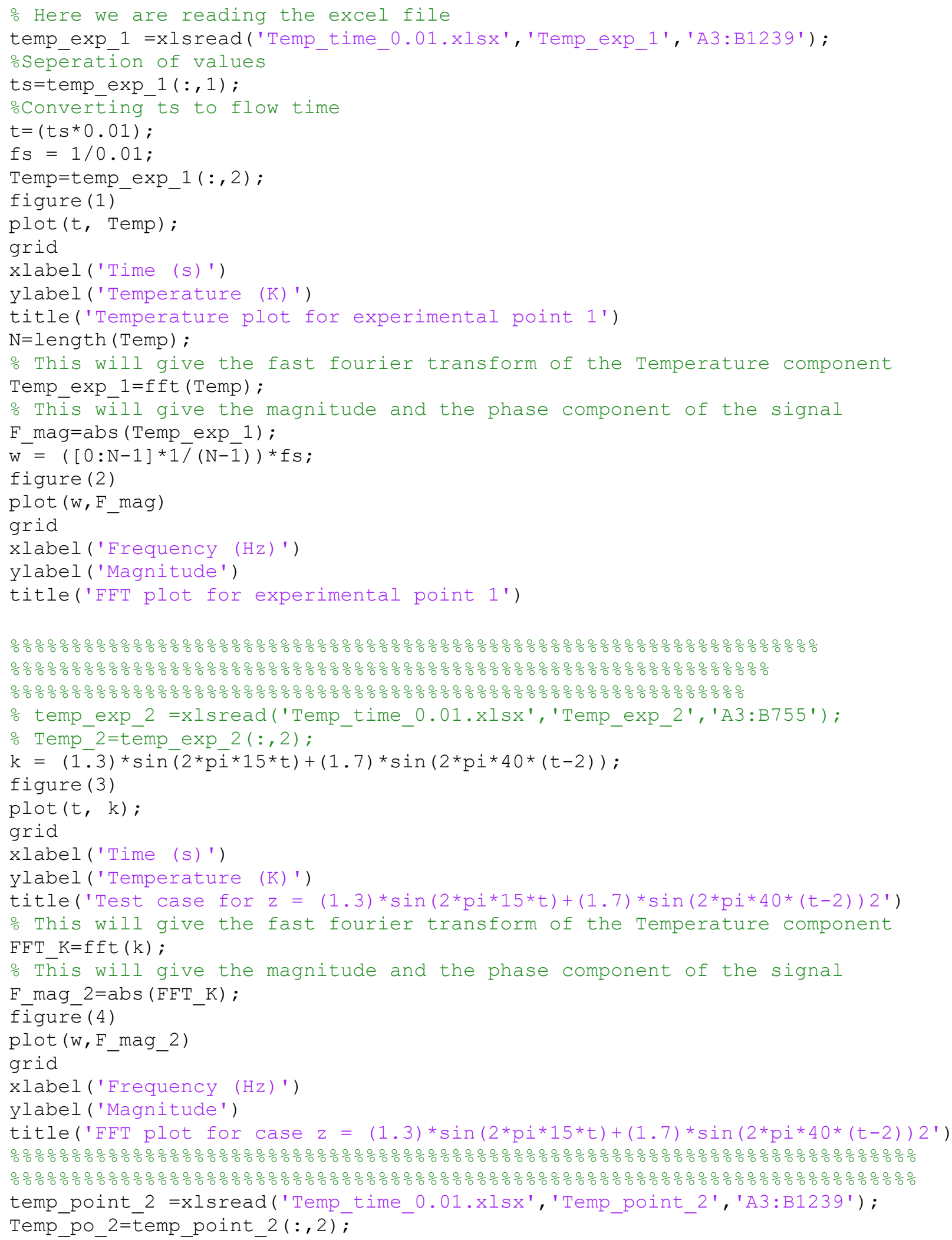




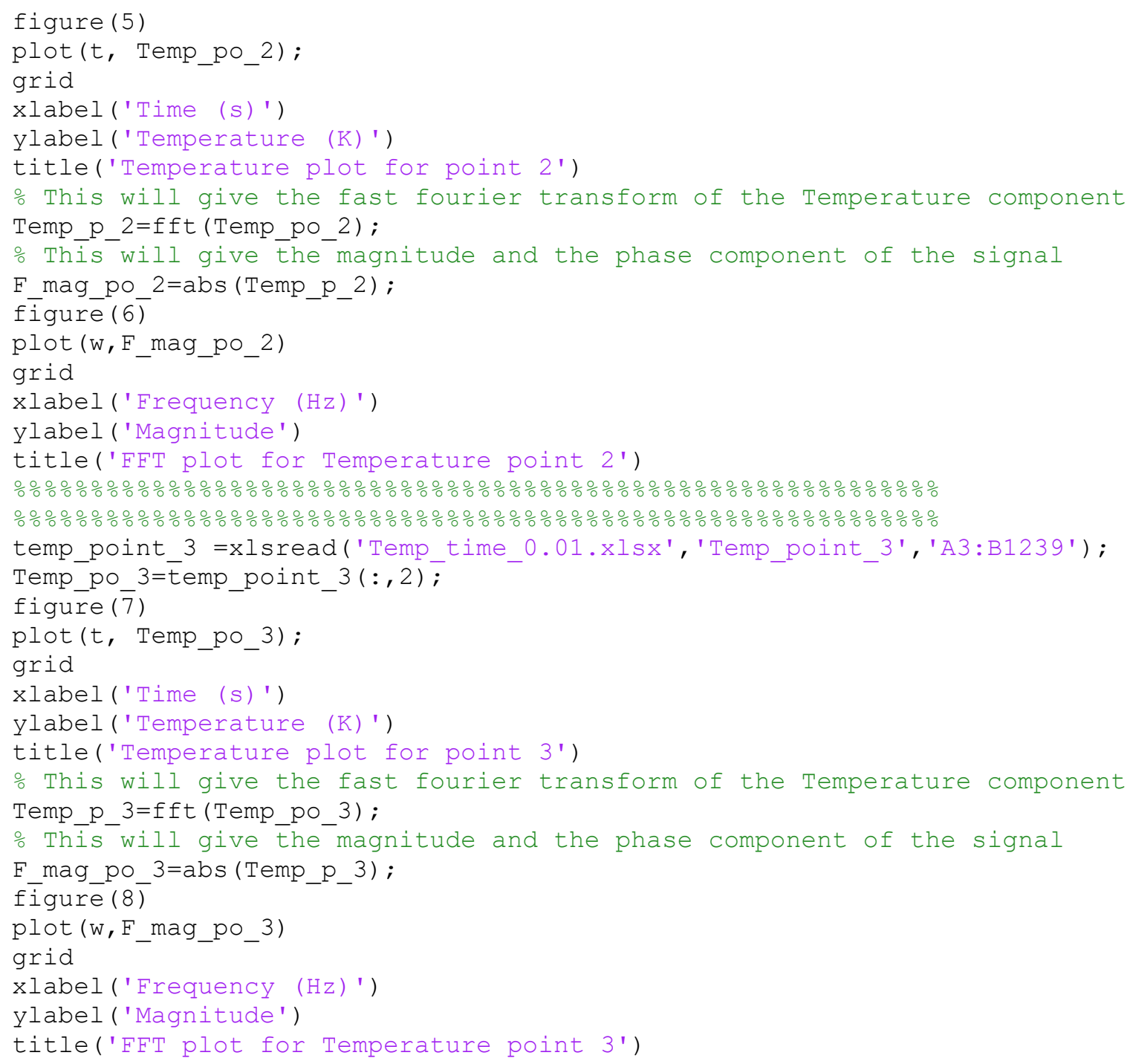

